LUCAS GONÇALVES DIAS MENDONÇA

MICRO-SENSOR CAPACITIVO PARA AVALIAÇÃO DA QUALIDADE DE COMBUSTÍVEIS AUTOMOTIVOS

São Paulo

2008 
LUCAS GONÇALVES DIAS MENDONÇA

\section{MICRO-SENSOR CAPACITIVO PARA AVALIAÇÃO DA QUALIDADE DE COMBUSTÍVEIS AUTOMOTIVOS}

Dissertação apresentada à Escola Politécnica da Universidade de São Paulo para obtenção do título de mestre em Engenharia Mecânica

São Paulo 
LUCAS GONÇALVES DIAS MENDONÇA

\title{
MICRO-SENSOR CAPACITIVO PARA AVALIAÇÃO DA QUALIDADE DE COMBUSTÍVEIS AUTOMOTIVOS
}

\author{
Dissertação apresentada à Escola \\ Politécnica da Universidade de São Paulo \\ para obtenção do título de mestre em \\ Engenharia Mecânica

\section{Área da concentração:} \\ Engenharia de Controle e Automação \\ Mecânica
}

Orientador: Prof. Dr. Ricardo Cury Ibrahim

São Paulo 
Este exemplar foi revisado e alterado em relação à versão original, sob responsabilidade única do autor e com a anuência de seu orientador.

São Paulo, de agosto de 2008.

Assinatura do autor

Assinatura do orientador

FICHA CATALOGRÁFICA

Mendonça, Lucas Gonçalves Dias

Micro-sensor capacitivo para avaliação da qualidade de combustíveis automotivos / L.G.D. Mendonça. -- ed.rev. -- São Paulo, 2008. $139 \mathrm{p}$.

Dissertação (Mestrado) - Escola Politécnica da Universidade de São Paulo. Departamento de Engenharia Mecatrônica e de Sistemas Mecânicos.

1.Sensor 2.Sistemas microeletromecânicos 3.Combustíveis veiculares I.Universidade de São Paulo. Escola Politécnica. Departamento de Engenharia Mecatrônica e de Sistemas Mecânicos II.t. 


\section{DEDICATÓRIA}

Dedico esse trabalho à minha família por sempre ter me incentivado e por me apoiar nos momentos difíceis. 


\section{AGRADECIMENTOS}

Ao CNPq/CT-Petro, processo: 550467/2005-0 pelo apoio financeiro.

Ao LSI-EPUSP (Laboratório de Sistemas Integráveis da Escola Politécnica da USP) pelo uso de instalações e equipamentos

Ao LMF-LNLS - Laboratório de Microfabricação do Laboratório Nacional de Luz Síncrotron/MCT - onde amostras foram fabricadas.

Ao Prof. Dr. Ricardo Cury Ibrahim pela orientação e incentivo.

Ao Prof. Dr. Delson Torikai por discussões que contribuíram muito para este trabalho.

Ao Prof. Dr. Nilton Itiro Morimoto por discussões que contribuíram muito para este trabalho.

Ao Grupo de Sensores e Atuadores do Departamento de Engenharia Mecatrônica e de Sistemas Mecânicos pelo uso das instalações.

A Professores, amigos, colegas e familiares que de alguma forma contribuíram para minha formação e/ou para o desenvolvimento desse trabalho. 


\section{RESUMO}

Neste trabalho é proposto um sensor capacitivo do tipo eletrodos interdigitados para avaliação da qualidade de combustíveis automotivos. Os eletrodos interdigitados apresentam algumas características adequadas ao sensor em questão. Entre elas o fato de elevar significativamente a capacitância por apresentar grande quantidade de capacitores em paralelo e de ser uma estrutura possível de se fabricar por processos convencionais de microfabricação. Além disso, esses eletrodos permitem que o combustível preencha seus espaçamentos funcionando como seu dielétrico. Foram feitas modelagens e simulações do sensor para verificação da influência de diversos parâmetros de projeto. Protótipos foram fabricados em substratos de alumina com eletrodos de níquel eletrodepositado. Os eletrodos têm larguras entre $50 \mu \mathrm{m}$ e $100 \mu \mathrm{m}$, com espaçamento entre eletrodos tendo valores dessa mesma ordem. O comprimento dos eletrodos é de $800 \mu \mathrm{m}$. A altura dos eletrodos varia entre $20 \mu \mathrm{m}$ e $40 \mu \mathrm{m}$. O sensor como um todo tem área em torno de $4 \mathrm{~cm}^{2}$. Foram realizadas medições com misturas álcool e água, gasolina e álcool, gasolina e querosene entre outras. As caracterizações mostraram bons resultados comprovando a validade do princípio proposto. O sensor se mostrou capaz de detectar os tipos de adulteração mais comuns no Brasil, adição de água ao álcool combustível e adição solventes orgânicos ou de álcool além do permitido à gasolina.

Palavras-chave: Sensor de combustível. Adulteração de combustível. Sistemas Microeletromecânicos. MEMS 


\begin{abstract}
This work proposes a capacitive sensor with interdigitated electrodes in order to evaluate the quality of automotive fuel. Interdigitated electrodes have some interesting features for this type of sensor. Among them, they increase the capacitance by having several capacitors in parallel, and by having a structure feasible to be manufactured by conventional microfabrication processes. In addition, automotive fuel, serving as the dielectric material, fills the gaps of the electrodes. Modeling and computational simulations of the sensor were carried out in order to realize the influence of several design parameters. Samples were manufactured using alumina substrates with electroplated nickel electrodes. The width of the electrodes was chosen to be between $50 \mu \mathrm{m}$ and $100 \mu \mathrm{m}$, with gaps of similar size. The paired length of the electrodes was $800 \mu \mathrm{m}$. The height of the electrodes varied between $20 \mu \mathrm{m}$ and $40 \mu \mathrm{m}$. The whole sensor was around $4 \mathrm{~cm}^{2}$ in area. Several measurements were carried out using mixtures of alcohol and water, gasoline and alcohol, gasoline and kerosene, and others. Characterizations showed good results, validating the method. The sensor was capable of detecting the main types of fuel adulteration used in Brazil: addition of water to alcohol, and addition of organic solvents or alcohol to gasoline beyond the acceptable limit.
\end{abstract}

Keywords: Fuel sensor. Fuel adulteration. Microelectromechanical systems. MEMS 


\section{LISTA DE FIGURAS}

Figura 2.1- Esquema do mecanismo Pistão-Biela-Virabrequim. ...........................

Figura 2.2- Diagrama P-V de um Ciclo Otto padrão a ar (ideal) ..............................

Figura 2.3 - Mecanismo Pistão-Biela-Virabrequim com múltiplos pistões. ..............10

Figura 2.4- Câmara de combustão de um motor de quatro tempos com ignição por centelha.

Figura 2.5- Quatro tempos do Ciclo Otto (a) 1ำ tempo- admissão; (b) 2o tempoCompressão; (c) $3^{\circ}$ tempo- Combustão; (d) 4ํtempo- exaustão.

Figura 2.6- Diagrama P-V do Ciclo Otto em um motor de quatro tempos com ignição por centelha.

Figura 2.7- principais componentes de um motor dois tempos. .14

Figura 2.8- ciclo de operação de um motor dois tempos. (a) pistão no PMI permite entrada da mistura no cilindro; (b) subida do pistão comprime a mistura; (c) centelha da vela explode a mistura forçando o pistão para baixo; (d) quando o pistão passa pela janela de exaustão os gases da queima saem do cilindro. ...15

Figura 2.9- Diagrama P-V de um motor de dois tempos. ................................. 15

Figura 3.1 - Estrutura de um comb-drive. .................................................... 34

Figura 3.2- Banda morta de um sensor em uma função de trasferência..................36

Figura 3.3- Erro de calibração em um sensor. ............................................... 37

Figura 3.4- Função de transferência com histerese ............................................38

Figura 3.5- Função de transferência com efeito de não linearidade........................39

Figura 3.6- Erro de repetitividade 39

Figura 3.7- moléculas polares (a) na ausência de um campo elétrico. Os dipolos têm orientação aleatória; (b) com o campo elétrico, os dipolos tendem a se orientar alinhando-se com o campo.

Figura 3.9 (a) Campo elétrico aplicado a um capacitor sem dielétrico, ocorre acúmulo de cargas nas superfícies das placas; (b) Campo elétrico aplicado em um capacitor com dielétrico, além das cargas acumuladas nas placas, há uma resultante de cargas induzidas nas superfícies do dielétrico, o que provoca um campo E' em sentido oposto a $\mathrm{E}_{0}$. 44

Figura 4.1- Configuração dos eletrodos interdigitados do sensor. .49 
Figura 4.2- Modelo 3D de dois pentes interdigitados emparelhados do sensor.

Figura 4.3 Arranjo completo de um sensor típico.

Figura 4.4- Modelo de capacitores considerado para a simulação do comportamento elétrico sensor.....

Figura 4.5- Modelo montado para a simulação do comportamento elétrico do sensor.

Figura 4.6- Discretização no ANSYS para: (a) cálculo da capacitância, (b) determinação do potencial e do campo elétrico.

Figura 5.1 - Perfil das estruturas durante etapas de fabricação; a) lâmina antes do processo; b) após etapas 1 e 2 Deposição das camadas titânio-ouro; c) após a deposição do fotorresiste que faz parte da litografia; d) após a revelação do fotorresiste completando a litografia; e) após processo de eletro-deposição; f) após a remoção do fotorresiste; g) após a remoção das camadas titânio-ouro. 55

Figura 5.2- Aparato utilizado nas medições. 60

Figura 6.1- Modelo para simulação de um sensor a fim de se descobrir as dimensões mais apropriadas.

Figura 6.2- Distribuição do campo elétrico em etanol para diferentes larguras e espaçamentos entre eletrodos.

Figura 6.3- Distribuição do campo elétrico em gasolina para diferentes larguras e espaçamentos entre eletrodos. 66

Figura 6.4- Distribuição do potencial aplicado aos eletrodos para simulação do sensor S1 imerso em querosene. .68

Figura 6.5- Distribuição do campo elétrico entre os eletrodos para simulação do sensor S1 imerso em querosene. .68

Figura 7.1- Fotos de amostras fabricadas e caracterizadas.............................. 70

Figura 7.2- Detalhes da amostra S5 ampliados ao microscópio. ...........................71

Figura 7.3- Gráficos para medições com a mistura álcool-água DI. .74

Figura 7.4- Gráfico da capacitância (sem mostrar curva da água pura) para medições com a mistura álcool-água DI .75

Figura 7.5- Medições para mistura etanol-água com variações pequenas. .76

Figura 7.6- Gráficos para medições com a mistura gasolina-etanol anidro. .78

Figura 7.7- Gráficos para medições com a mistura gasolina-etanol anidro em pequenas concentrações. .80 
Figura 7.8- Gráficos para medições com a mistura gasolina-querosene para o sensor S1

Figura 7.9- Gráficos para medições com a mistura gasolina-querosene para o sensor S2. .83

Figura 7.10- Gráficos para medições com a mistura gasolina-aguarrás para o sensor S1 .85

Figura 7.11- Gráficos para mistura gasolina + querosene + álcool onde $\mathrm{C} 1<\mathrm{C} 2<\mathrm{C} 3$ representam diferentes concentrações de álcool e querosene. .86

Figura 7.12- Gráficos para mistura gasolina álcool hidratado para simulação de misturas que podem ocorrer num carro flex. .88

Figura 7.13- Gráficos para misturas de aguarrás e querosene .89

Figura 7.14- Medições com diferentes tensões de bias CC aplicadas ao sensor S4 mergulhado em etanol anidro.

Figura 7.15- Medições com diferentes tensões CC aplicadas ao sensor mergulhado em água. 92

Figura 7.16- (a) Amostra em que não foi aplicada tensão CC. (b) Amostra em que foi aplicada uma tensão CC de 3V. Um dos eletrodos sofreu oxidação. .93

Figura 7.17- Medições com diferentes tensões CC aplicadas ao sensor mergulhado em querosene. .94

Figura 7.18- Medições com diferentes tensões CC aplicadas ao sensor mergulhado em mistura gasolina-etanol. .95 


\section{LISTA DE ABREVIATURAS E SIGLAS}

AEAC - Álcool Etílico Anidro Combustível

AEHC - Álcool Etílico Hidrata Combustível

ANP - Agência Nacional do Petróleo Gás Natural e Bio-combustíveis

DLP - Processamento Digital de luz (do inglês, Digital Light Processing)

FFVs - Veículos Flexiveis (do inglês, Flexible Fuel Vehicles)

GL- Gay Lussac

INPM- Instituto Nacional de Pesos e Medidas. Grau

MEMS - Sistemas Micro-Eletro-Mecânicos (do inglês, Micro-electro-mecanical systems)

MOEMS - Sistemas Micro-Opto-Eletro-Mecânicos (do inglês, Micro-OptoElectro-Mechanical Systems)

NEMS - Sistemas Micro-Eletro-Mecânicos (do inglês, Nano-Electro-Mechanial Systems)

PMS- Ponto morto superior

PMI- Ponto morto inferior 


\section{LISTA DE SÍMBOLOS}

$\mathrm{K}_{\mathrm{al}}$ - Constante dielétrica da alumina.

$\mathrm{K}_{\mathrm{et}}$ - Constante dielétrica do etanol anidro.

$\mathrm{K}_{\mathrm{g}}$ - Constante dielétrica da gasolina pura (gasolina tipo $\mathrm{A}$ ).

$\mathrm{K}_{\mathrm{gc}}$ - Constante dielétrica da gasolina tipo $\mathrm{C}$ (gasolina com etanol).

$\mathrm{K}_{\mathrm{q}-\text { Constante dielétrica do querosene. }}$

$\mathrm{K}_{\mathrm{ag}}$ - Constante dielétrica da água.

$\varepsilon$ - Permitividade elétrica de um material.

$\varepsilon_{0}$ - Permitividade do vácuo.

${ }^{\circ} G L$ - Grau alcoólico de um álcool medido em ${ }^{\circ}$ Gay Lussac. Onde a porcentagem é medida em volume.

oINPM - Grau alcoólico de um álcool em que a porcentagem é medida em massa.

E10 - Mistura composta por 10\% etanol e 90\% gasolina, utilizada nos EUA.

E85- Mistura compostas por $85 \%$ etanol e $15 \%$ gasolina.

B20 - Mistura por 20\% de biodiesel e $80 \%$ de diesel de petróleo.

d - distância entre os centros de carga negativa e positiva de uma molécula polar.

$\mu$ - Momento de dipolo elétrico de uma molécula de dielétrico.

$E_{L}$ - campo que atua localmente nas moléculas do dielétrico.

$\alpha$ - Polarizabilidade total de um dielétrico.

$\alpha_{E}$ - Polarizabilidade eletrônica das moléculas do dielétrico.

$\alpha_{M}$ - Polarizabilidade molecular das moléculas do dielétrico.

$\alpha_{0}$ - Polarizabilidade de orientação molecular das moléculas do dielétrico.

$E_{0}$ - Campo elétrico aplicado entre os eletrodos de um capacitor.

E' - Campo devido à polarização das moléculas do dielétrico oposto a $E_{0}$.

$E-$ Campo resultante $\left(E^{\prime}+E_{0}\right)$ cujo módulo é menor que $E_{0}$.

$Q$ - Carga na superfície das placas de um capacitor.

$G$ - Espaçamento entre os eletrodos do sensor (gap).

$\mathrm{L}$ - Largura de um eletrodo do sensor.

$\mathrm{LL}$ - Comprimento de emparelhamento entre dois eletrodos que formam um capacitor do sensor. 
B - Nos modelos desenvolvidos para a simulação é o comprimento extra deixado entre a extremidade do modelo e os eletrodos das extremidades.

SS - Espessura considerada para o substrato nos modelos para simulação.

DD - Espessura considerada para o dielétrico nos modelos para simulação.

CC - Sinal de corrente contínua.

CA - Sinal de corrente alternada. 


\section{SUMÁRIO}

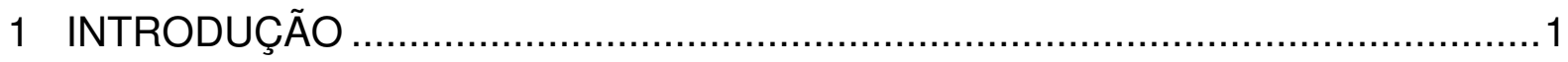

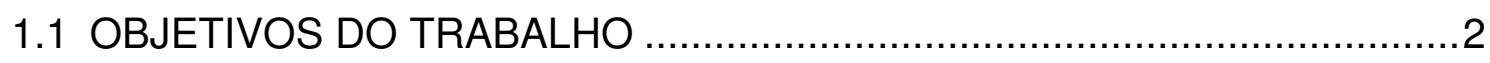

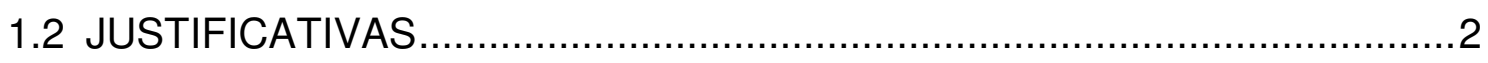

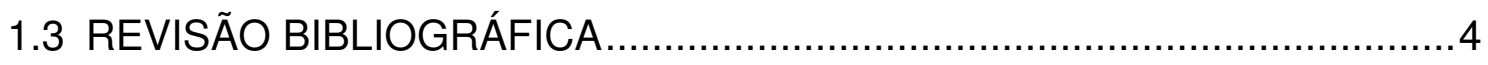

2 CONCEITOS BÁSICOS SOBRE VEÍCULOS LEVES E COMBUSTÍVEIS

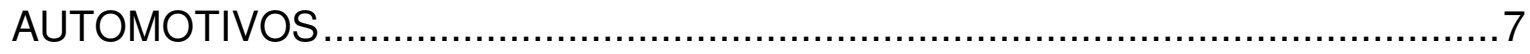

2.1 FUNCIONAMENTO DE MOTORES DE COMBUSTÃO INTERNA ............. 7

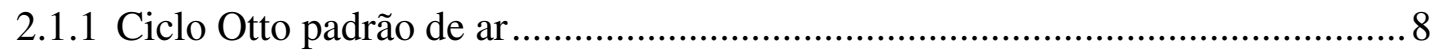

2.1.2 Motor real: modificações do Ciclo Otto padrão de ar ..................................... 9

2.1.3 Motor de quatro tempos com ignição por centelha......................................... 10

2.1.4 Motores de dois tempos com ignição por centelha......................................... 13

2.2 PROBLEMAS QUE PODEM OCORRER DURANTE A COMBUSTÃO ..... 15

2.2.1 Problemas relacionados à propagação da chama................................................ 16

2.3 SISTEMA DE ALIMENTAÇÃO DE COMBUSTÍVEL ..............................18

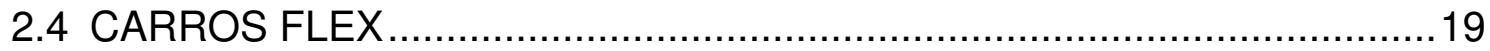

2.5 COMBUSTÍVES AUTOMOTIVOS ..................................................20

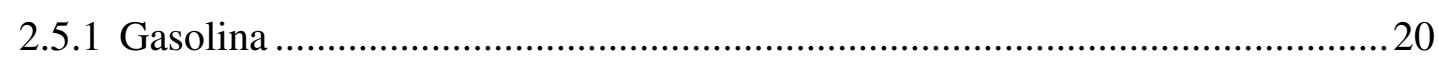

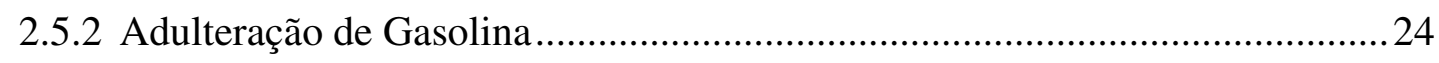

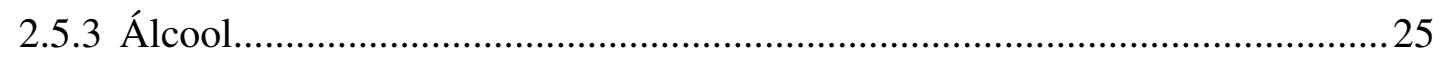

2.5.4 Adulteração do etanol .............................................................................. 31

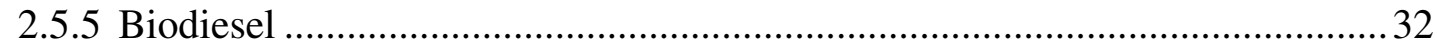

3 SISTEMAS MICRO-ELETRO-MECÂNICOS, SENSORES E MATERIAIS

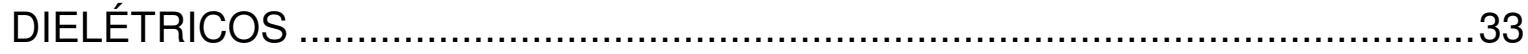

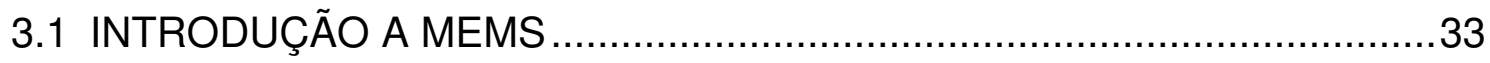

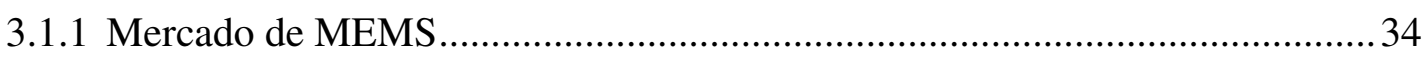

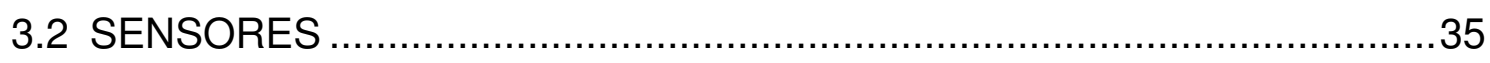

3.2.1 Principais características de um sensor......................................................... 35

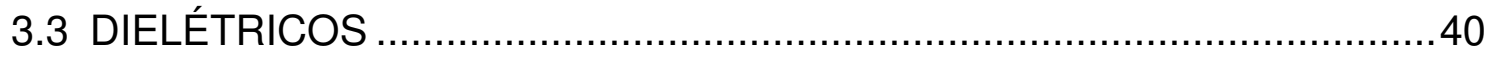


3.3.1 Polarização de moléculas do dielétrico.

3.3.2 Dependência da permitividade com a frequência ........................................... 45

3.3.3 Condução em dielétricos líquidos .............................................................46

4 PRINCÍPIO DE FUNCIONAMENTO E MODELAGEM DO SENSOR ................48

4.1 PRINCÍPIO DE FUNCIONAMENTO DO SENSOR .............................48

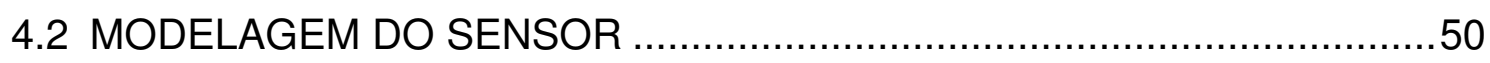

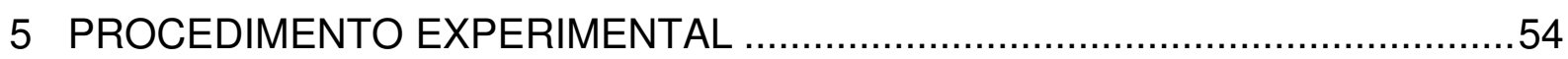

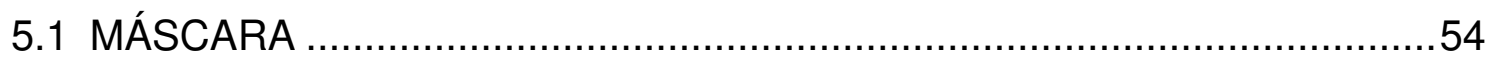

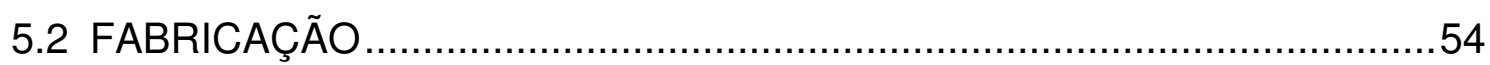

5.2.1 Deposição de camadas de adesão de Titânio e de ouro ....................................55

5.2.2 Litografia com radiação ultra-violeta ..........................................................55

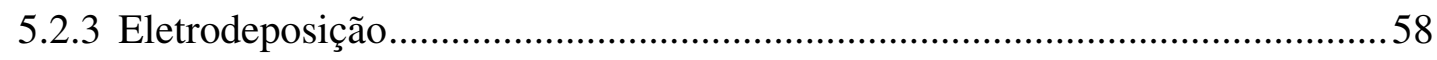

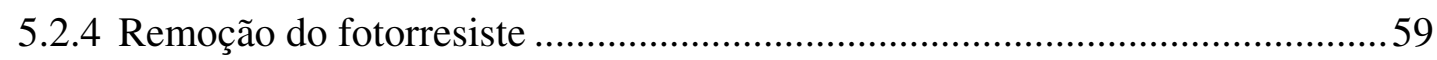

5.2.5 Remoção das camadas Titânio-ouro ............................................................60

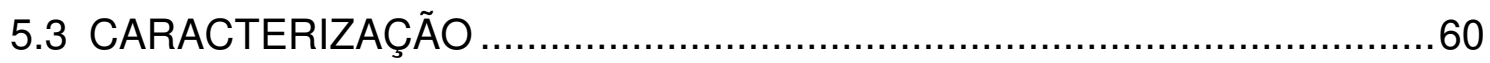

6 RESULTADOS DE SIMULAÇÕES.......................................................... 62

6.1 SIMULAÇÕES DE CAPACITÂNCIA DO MODELO DO SENSOR ..............62

6.2 SIMULAÇÕES DE CAMPO ELÉTRICO ...........................................64

6.3 SIMULAÇÕES DE AMOSTRAS FABRICADAS E CARACTERIZADAS ....67

6.3.1 Simulação para sensor imerso em querosene ...............................................67

6.3.2 Simulação para sensor imerso em etanol ...................................................69

7 RESULTADOS EXPERIMENTAIS E DISCUSSÕES ................................. 70

7.1 MEDIÇÕES COM ÁLCOOL COMBUSTÍVEL ..................................... 72

7.1.1 Comparação de álcool de posto com misturas de referência ............................72

7.1.2 Medições com etanol para variações pequenas .............................................75

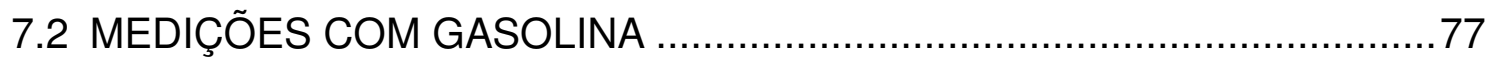

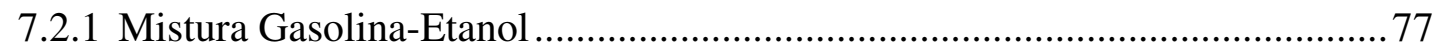

7.2.2 Misturas de Gasolina com solventes orgânicos apolares................................ 81

7.2.3 Mistura de gasolina com compostos polares e apolares simultaneamente ......84

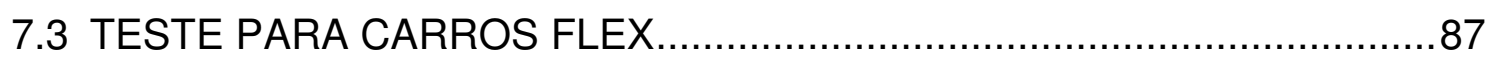

7.4 MEDIÇÕES COM COMPOSTOS APOLARES ..................................88 
7.5 RESULTADOS COM APLICAÇÃO DE TENSÃO DE BIAS CC .90

7.5.1 Efeito da tensão de Bias CC no Etanol Anidro . .90

7.5.2 Efeito da tensão de bias $\mathrm{CC}$ na água. . .91

7.5.3 Efeito da tensão de bias $\mathrm{CC}$ em compostos apolares . .93

7.5.4 Efeito da tensão de bias CC na mistura gasolina-álcool .94

7.6 COMPARAÇÃO DE RESULTADOS SIMULADOS E EXPERIMENTAIS...96

8 CONCLUSÕES .97

9 SUGESTÕES DE TRABALHOS FUTUROS .99

10 REFERÊNCIAS BIBLIOGRÁFICAS 101

APÊNDICE A- EXEMPLO DE ROTINA UTILIZADA NA AQUISIÇÃO DE DADOS. 106 APÊNDICE B: EXEMPLO DE ROTINA UTILIZADA EM SIMULAÇÃO DE CAPACITÂNCIA. 109

APÊNDICE C: LISTA DE ARTIGOS PUBLICADOS DEVIDO A ESTE ESTUDO ...112 ANEXO A- TABELA DE ESPECIFICAÇÕES DA GASOLINA ESTABELECIAS PELA ANP 113

ANEXO B- TABELAS DE ESPECIFICAÇÕES DO AEAC E AEHC ESTABELECIAS PELA ANP. 115 


\section{INTRODUÇÃO}

Um sensor pode ser definido como um sistema que recebe um estímulo físico e o converte em um sinal, geralmente elétrico, que será analisado por outro sistema. O estímulo pode ser dos mais variados tipos como calor, luz, pressão, movimento ou som, por exemplo. Existem inúmeros tipos de sensores com as mais variadas aplicações possíveis.

A industria automobilística é uma grande consumidora de sensores e representa um mercado crescente, (BANNATYNE, 2000; EDDY; SPARKS, 1998; FLEMING, 2001; VENKATESH, 2007). Alguns exemplos são os sensores das bolsas infláveis (air-bags), sensor de oxigênio do escapamento, sensores de pressão e sensores de temperatura, etc. Num automóvel, os sensores podem estar trabalhando em conjunto com atuadores, ambos ligados a uma unidade de controle composta por hardware e software. Esses elementos formam um sistema responsável por um amplo conjunto de operações do automóvel, como o sistema ABS de freio, por exemplo. Alguns dos benefícios do uso desses sistemas com sensores, atuadores e unidades de controle microprocessadas em automóveis são maior segurança, melhor desempenho, maior economia de combustível e o conforto. O uso de hardware e software reduz o tempo e o custo de desenvolvimento desses sistemas.

O avanço dos sistemas de controle eletrônicos exige um número cada vez mais elevado de sensores e novas abordagens quanto ao desenvolvimento dos mesmos. Assim, o desenvolvimento de sensores depende cada vez mais da tecnologia de Sistemas Micro-eletro-mecânicos (microelectromechanical systems, MEMS). A tecnologia MEMS permite que sensores e atuadores sejam microfabricados de maneira a combinar processamento de sinal e comunicação em um único chip ou encapsulamento (EDDY; SPARKS, 1998).

O presente trabalho se encaixa na área de microtecnologia propondo um sensor do tipo capacitivo, fabricado por processos comumente utilizados na microeletrônica. Suas dimensões reduzidas seguem a tendência do mercado que é de miniaturizar os sensores. Com a miniaturização, há menor consumo de energia, 
melhores possibilidades de elevar o número de sensores no automóvel, custos de produção mais baixos, menor consumo de matéria prima entre outras vantagens.

\subsection{OBJETIVOS DO TRABALHO}

Esse trabalho tem como meta apresentar uma metodologia de desenvolvimento de um sensor capacitivo que analise a qualidade de combustíveis automotivos. Essa metodologia deve incluir a técnica de projeto envolvendo modelagem e simulação computacional; a fabricação de protótipos com técnicas usuais de microfabricação utilizando materiais e instalações disponíveis no Brasil; e caracterizações do desempenho do sensor para diferentes tipos de misturas combustíveis e adulterantes.

O sensor deverá apresentar as seguintes características: boa sensibilidade para distinguir os principais adulterantes de combustíveis; baixo custo de produção; dimensões reduzidas, e bom tempo de resposta. O processo de fabricação deve ser tal que permita fácil industrialização. É desejável, ainda, que o sensor possa ser facilmente instalado em automóveis, bombas de combustíveis, e em sistemas portáteis de medição.

\subsection{JUSTIFICATIVAS}

No Brasil são utilizados diferentes tipos de combustíveis automotivos. Entre eles, os principais são a gasolina tipo $C$ e o álcool hidratado para veículos leves. A abertura de mercado de combustíveis, a redução do subsídio ao álcool e a liberação da importação de solventes são medidas que levaram a um grande crescimento da prática de adulteração de combustíveis. Atualmente a adulteração é cada vez mais freqüente em todo o país. Na grande São Paulo, em 2007, algumas fiscalizações chegaram a encontrar amostras com até $70 \%$ de álcool em sua composição. Em se tratando da gasolina, uma das principais fraudes praticadas é a adição de álcool anidro além da quantidade estabelecida pela ANP (Agência Nacional do Petróleo, Gás Natural e Biocombustíveis). Também são utilizados, com menor freqüência, solventes orgânicos tais como querosene e aguarrás. Além dos fatores já citados, a elevada incidência de impostos que recaem sobre a gasolina também contribui para 
que seu preço seja muito superior ao de seus adulterantes, o que contribui para o aumento da ocorrência de fraudes.

Quanto ao álcool combustível, a principal forma de adulteração é a adição de água. Seja pela adição desta ao álcool anidro para vendê-lo como álcool hidratado (mistura falsa conhecida como álcool molhado), seja pela adição ao próprio álcool hidratado, ficando este com teor de água acima do permitido pela ANP.

A utilização destes combustíveis adulterados pode causar perda de rendimento e diversos danos ao motor e todo o sistema de alimentação de combustível. Os danos causados ao automóvel devido ao uso de combustíveis adulterados resultam em grandes incômodos ao consumidor. Além de grandes prejuízos financeiros, há o inconveniente de não poder utilizar o veículo enquanto o mesmo estiver sendo reparado. O prejuízo financeiro é transferido às montadoras caso o veículo se encontre no período de garantia. O estado também sofre prejuízos com arrecadação de tributos. Os danos ao meio ambiente também são maiores, pois ocorre aumento da poluição devido à queima incompleta do combustível adulterado, que lança gases tóxicos à atmosfera.

Diante do presente cenário de adulteração de combustíveis no Brasil, se faz necessário o uso de sensores que monitorem a qualidade do combustível utilizado no automóvel. Sensores que acusem a utilização de uma mistura irregular de combustível no veículo, alertando o motorista, evitariam diversos transtornos.

O tipo de sensor proposto neste trabalho (capacitivo), não se baseia em reações químicas, não envolve análise de espectros, apresenta bom tempo de resposta, permite a utilização de sistemas micro-eletro-mecânicos (MEMS) e pode ser facilmente automatizado. Por essas razões optou-se por essa configuração procurando-se explorar todas as possibilidades de se utilizar a dieletrometria para a detecção de adulterantes em combustíveis automotivos.

A característica do sensor de analisar uma mistura gasolina-etanol permite que este seja também utilizado em carros flex para determinar a proporção da mistura. O sensor poderia identificar a proporção de álcool tanto na gasolina que estiver sendo colocada no carro no momento do abastecimento quanto em toda a mistura presente no tanque. As informações da qualidade do combustível e do conteúdo de álcool poderiam ser enviadas tanto ao motorista (para conhecimento) quanto aos sistemas de injeção e ignição (para controle dos parâmetros do motor). 


\subsection{REVISÃO BIBLIOGRÁFICA}

Para ser utilizado em um automóvel, um sensor de combustível deve possuir algumas características importantes. Entre elas, baixo custo, tamanho reduzido, baixo consumo de energia e deve ser robusto o suficiente para poder trabalhar imerso no combustível, que é um meio bastante agressivo. O sensor deve ainda apresentar a viabilidade de ser acoplado a um microprocessador que o controle e grave as informações em um banco de dados. O banco de dados deve criar um histórico da qualidade do combustível utilizado no automóvel por um determinado período de tempo.

Muitos pesquisadores vêm trabalhando no desenvolvimento de sensores para combustíveis automotivos. Parte deles também utiliza a capacitância como princípio de medição. Capacitância é realmente uma grandeza muito utilizada em sensores como acelerômetros e sensores de pressão. Há também outros princípios que vêm sendo usados em sensores para combustíveis, entre eles propriedades ópticas.

Santos (2003) desenvolveu um sensor para determinar a concentração de álcool (etanol) na gasolina brasileira através da medição de propriedades elétricas. As amostras passam por uma análise com esse sensor e somente aquelas que não forem aprovadas por ele passam por análises mais complexas. Assim esse sensor poupa tempo evitando a necessidade de se fazer análises complexas em um número muito grande de amostras quando a demanda for muito grande. Trata-se de um sensor tipo linha de transmissão coaxial.

Rocha e Simões-Moreira (2005) desenvolveram um sensor do tipo coaxial que utiliza um par de eletrodos de aço inoxidável. Esse sensor utiliza a impedância para determinar o teor de misturas etanol-gasolina.

Hoffmann et al (1996) desenvolveram um sensor do tipo eletrodos interdigitados para líquidos. Protótipos foram fabricados em substrato cerâmico e também em silício. Foram realizadas medições em água, gasolina, etanol e metanol. Também foram analisadas misturas de gasolina e metanol. O sensor utiliza medição de capacitância e resistência como princípio de funcionamento. Esses pesquisadores também descobriram que havia melhores resultados para sensores fabricados em silício que sensores fabricados em cerâmica. O mesmo grupo continuou estudando o método e melhorando o sensor (HOLFMANN et al, 1997). 
Roy (1999) propôs um sensor para determinar a adulteração de gasolina e óleo diesel por querosene. O sensor utiliza uma fibra ótica que mergulhada no combustível, tem seu índice de refração alterado em presença de querosene.

Lima et al. (2004) propuseram um método foto-térmico para detecção de adulterantes em gasolina. O combustível é analisado na fase de vapor. A análise baseia-se na mudança da difusividade térmica com o tempo, que é resultado da mudança na concentração do vapor. A calibração é feita com base em amostras já analisadas por métodos convencionais que foram divididas em amostras conformes e não conformes.

Falate et al. $(2003,2004)$ Propuseram um sensor baseado em fibra óptica do tipo "Long period gratings" (LPG). As LPG são sensíveis quando há uma mudança no índice de refração do meio externo. Esses pesquisadores analisaram misturas de gasolina com alguns solventes utilizando esse método. Os diferentes solventes causam diferentes mudanças nos picos do espectro de comprimentos de onda da saída da fibra.

Tomita et al (2003) desenvolveram uma técnica para medir a concentração de hidrocarbonetos do combustível dentro do cilindro do motor. O sensor é colocado na vela de ignição e usa método de absorção de laser infravermelho.

Paixão, Cardoso e Bertotti (2007) propuseram um sensor para medir a concentração de etanol em gasolina. O sensor utiliza uma célula eletroquímica com um micro-eletrodo de cobre. É utilizada solução aquosa de $\mathrm{NaOH}$ para remover o etanol da gasolina e fazer a análise.

O sensor proposto nesse trabalho é fabricado sobre um substrato apresentando dimensões reduzidas. O que o faz ser leve, ocupar pouco espaço e consumir pouca energia. Isso representa vantagens em relação a sensores maiores como sensores coaxiais e foto-térmicos. O sensor capacitivo proposto também apresenta montagem simples e não exige prévio preparo de amostras. Assim apresenta também algumas vantagens sobre outros sensores como os baseados em fibra ótica e os que utilizam células eletroquímicas. As vantagens citadas dizem respeito à praticidade, portabilidade e facilidade de automação da análise para que 0 sensor possa ser utilizado em um automóvel.

Este micro-sensor capacitivo com eletrodos em configuração interdigitada se diferencia do sensor de HOFFMAN et al. $(1996,1997)$ por não ser fabricado em 
silício, e por apresentar eletrodos com espessuras maiores, crescidos por eletrodeposição, com o objetivo de aumentar o valor de capacitância a ser medido. Além disso, Hoffman e seu grupo apenas utilizaram o sensor para determinar composições de misturas de combustíveis certificados para carros flex, enquanto que 0 presente trabalho também visa detectar eventuais adulterações em combustíveis comercializados. 


\section{CONCEITOS BÁSICOS SOBRE VEÍCULOS LEVES E COMBUSTÍVEIS AUTOMOTIVOS}

Esse capítulo trata de alguns conceitos importantes sobre veículos leves motorizados, tais como o funcionamento do motor e sistemas de injeção e ignição. Também serão abordados os combustíveis álcool e gasolina que fazem parte do escopo principal desse trabalho.

\subsection{FUNCIONAMENTO DE MOTORES DE COMBUSTÃO INTERNA}

A grande maioria dos veículos automotivos utiliza motores de combustão interna, os quais também são utilizados em diversos tipos de máquinas e ferramentas. O motor de combustão converte a energia química de combustíveis em energia mecânica adequada a impulsionar os veículos automotivos. Essa conversão de energia é baseada em um ciclo termodinâmico, sendo que os mais utilizados atualmente são os motores baseados no Ciclo Otto ou no Ciclo Diesel.

Neste trabalho os sensores foram analisados apenas para uso em veículos leves, movidos a álcool ou gasolina. Normalmente, esses veículos leves utilizam motores baseados no Ciclo Otto. A utilização desses sensores em veículos baseados no Ciclo Diesel, que usam o óleo diesel como combustível, deverá ser feita em outro trabalho específico. Assim, o presente trabalho se concentra em motores de combustão interna baseados no Ciclo Otto, que utilizam álcool, gasolina, ou uma mistura de ambos combustíveis.

O Ciclo Otto consiste numa seqüência de processos termodinâmicos executados com algumas adaptações de forma a converter a energia química de um combustível automotivo em energia mecânica de movimento controlado do veículo.

Em seguida, será feita uma breve exposição do Ciclo Otto aplicado a um sistema mecânico Pistão-Biela-Virabrequim. Nesse mecanismo, esquematizado na figura 2.1, a parte inferior do pistão é conectada por um pino a uma barra chamada de biela. A outra extremidade da biela, por sua vez, é conectada por um mancal a um eixo não retilíneo chamado de virabrequim ou árvore de manivelas. $O$ virabrequim possui segmentos com eixos deslocados em relação à linha de eixo 
principal. Essa excentricidade promove o efeito de uma manivela. Assim, com esse mecanismo, é possível converter um movimento linear alternado do pistão em movimento rotativo do eixo virabrequim (utilizado em automóveis). Também é possível utilizar o mesmo mecanismo de forma inversa, em que a rotação de um motor elétrico pode ser convertida em um movimento linear alternado (utilizado em compressores).

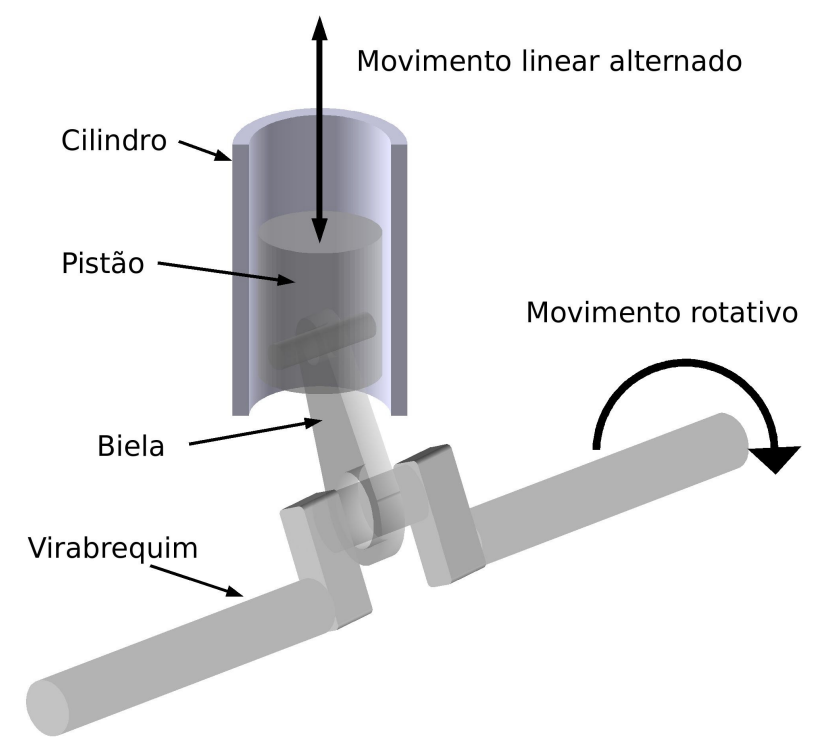

Figura 2.1- Esquema do mecanismo Pistão-Biela-Virabrequim.

\subsubsection{Ciclo Otto padrão de ar}

O ciclo Otto padrão a ar consiste num sistema fechado contendo ar que sofre quatro processos em seqüência. Trata-se de um ciclo idealizado para simplificar certos cálculos de motores de combustão. Considere um pistão dentro de um cilindro fechado. Esse pistão executa movimento alternado (linear) seguindo as etapas descritas abaixo e ilustrado no diagrama pressão-volume $(\mathrm{P}-\mathrm{V})$ da figura 2.2 (GALLO; WALTER, 1986; KEATING, 2007; MILTON, 1995). 


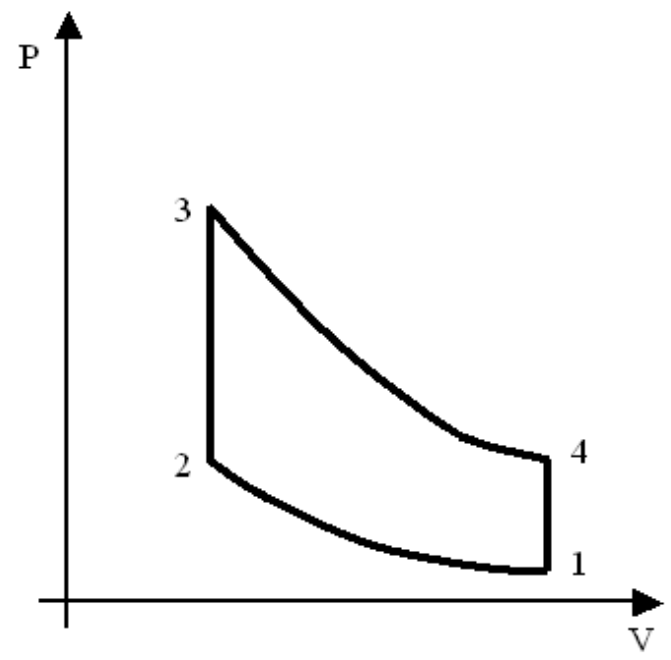

Figura 2.2- Diagrama P-V de um Ciclo Otto padrão a ar (ideal).

1)Etapa de compressão isentrópica (curva 1-2), onde o pistão se move do ponto morto inferior até o ponto morto superior comprimindo o ar interior. Este é um trabalho negativo (consumido).

2)Etapa de adição de calor a volume constante (curva 2-3). Aumenta a energia do sistema cilindro-pistão-ar.

3)Etapa de expansão isentrópica (curva 3-4), onde o pistão se move do ponto morto superior até o ponto morto inferior, descomprimindo o ar interior. Este é um trabalho positivo (liberado para o pistão).

4)Etapa de rejeição de calor a volume constante (curva 4-1). Diminui a energia de forma a completar o ciclo.

\subsubsection{Motor real: modificações do Ciclo Otto padrão de ar}

O Ciclo Otto padrão de ar é um ciclo termodinâmico ideal, que não leva em consideração alguns processos que ocorrem num motor de combustão interna real. Esta seção aborda essas variações.

Os motores de combustão interna utilizados atualmente nos veículos automotivos, normalmente, possuem vários pistões (figura 2.3), sendo dois o número mínimo utilizado em algumas motocicletas mais simples. A potência e eficiência, geralmente, aumentam com o número de pistões utilizados. O mecanismo é análogo ao descrito anteriormente. Entretanto, é importante notar que os motores reais 
utilizam uma mistura combustível-ar ao invés de apenas ar usado no Ciclo Otto padrão.

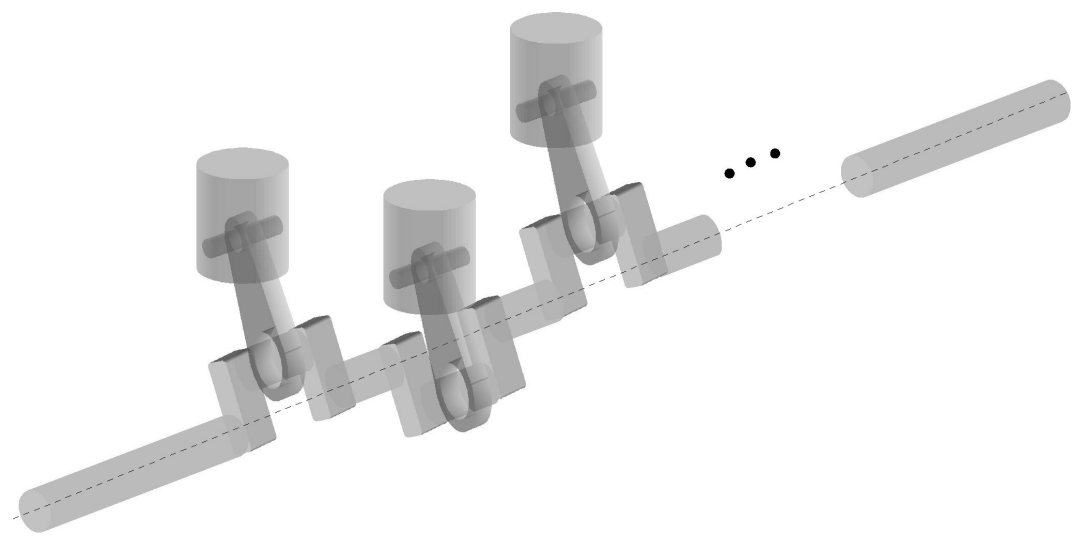

Figura 2.3 - Mecanismo Pistão-Biela-Virabrequim com múltiplos pistões.

A combustão da mistura ar-combustível dentro da câmara superior do cilindro aumenta a pressão forçando o pistão para baixo (para um motor com pistões na posição vertical). Esse trabalho mecânico (movimento linear dos pistões) é passado ao virabrequim (movimento rotativo). Assim, há conversão de um movimento linear alternado do pistão em um movimento rotativo do virabrequim que será utilizado para impulsionar as rodas e outros sistemas do automóvel. A posição mais alta do pistão é chamada de ponto morto superior (PMS) a mais baixa, de ponto morto inferior (PMI).

\subsubsection{Motor de quatro tempos com ignição por centelha}

O motor de quatro tempos com ignição por centelha é utilizado em veículos movidos à gasolina, álcool, gás natural e misturas gasolina-álcool. Esse tipo de motor é baseado no ciclo Otto padrão a ar (por isso também chamado motor de Ciclo Otto) com algumas diferenças.

Num motor automotivo de ignição por centelha a câmara de combustão tem válvulas de admissão e de escape. Os principais componentes da câmara de combustão de um motor desse tipo podem ser vistos na figura 2.4. Os quatro tempos do motor podem ser vistos na figura 2.5 e são os seguintes (GALLO; WALTER, 1986; LOGAN, 1999; KEATING, 2007): 
1ำ tempo: admissão- $O$ pistão desce e a válvula de admissão se abre injetando a mistura ar-combustível na câmara de combustão.

$2^{\circ}$ tempo: compressão- $\mathrm{O}$ pistão sobe impulsionado pelo sistema de manivelas comprimindo a mistura com as válvulas de admissão e de escape fechadas.

3ำ tempo: combustão- Quando o pistão se aproxima do PMS, a vela produz uma faísca provocando a combustão da mistura. Com isso, o pistão é forçado para baixo descendo até o PMI.

4ำ tempo: exaustão- o pistão sobe novamente impulsionado pelo sistema de manivelas, desta vez a válvula de escape se abre descartando os gases resultantes da queima.

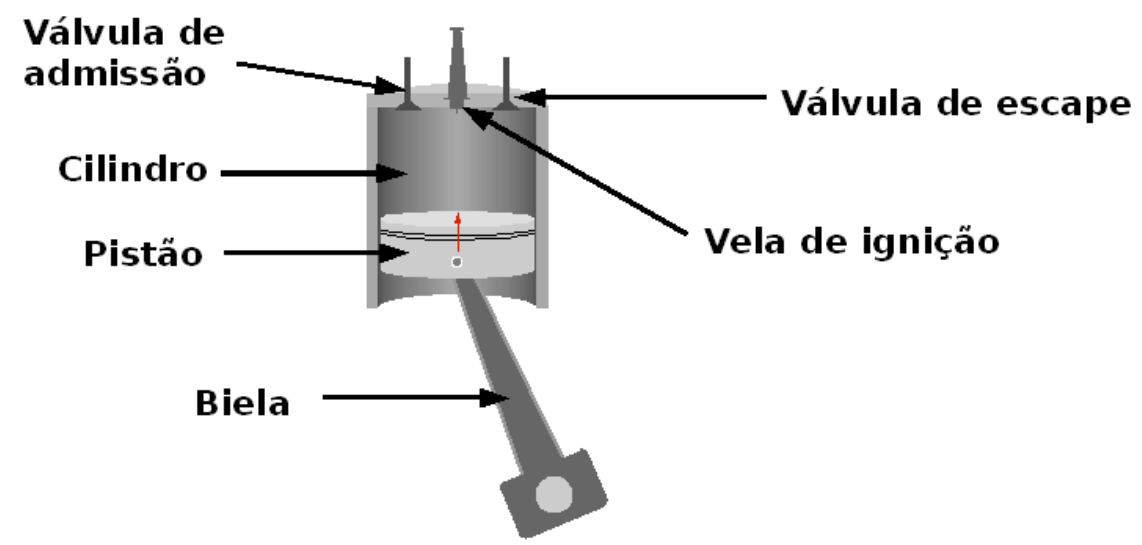

Figura 2.4- Câmara de combustão de um motor de quatro tempos com ignição por centelha.

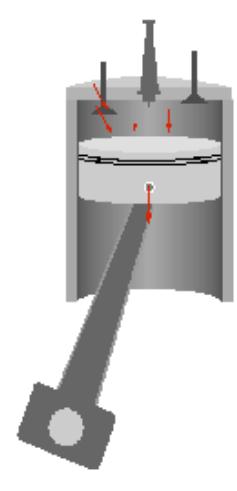

(a)

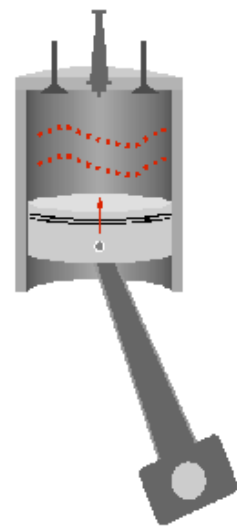

(b)

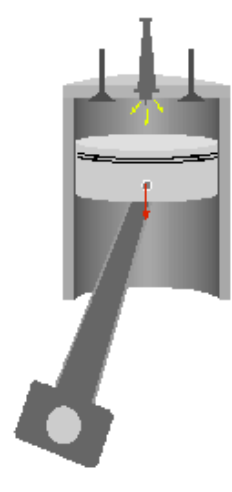

(c)

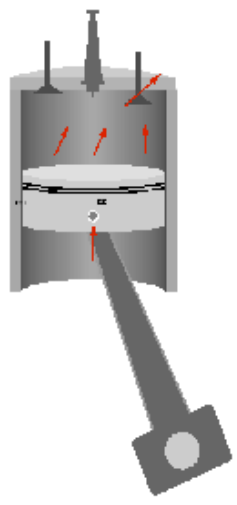

(d)

Figura 2.5- Quatro tempos do Ciclo Otto (a) $1^{\circ}$ tempo- admissão; (b) $2^{\circ}$ tempoCompressão; (c) $3^{\circ}$ tempo- Combustão; (d) $4^{\circ}$ tempo- exaustão. 
A seguir são descritas as similaridades e diferenças entre Ciclo Otto padrão de ar e ciclo de motor de combustão interna com ignição por centelha (faísca) (MILTON, 1995).

1)O diagrama para motor real possui etapas de admissão e exaustão, não existentes no Ciclo Otto padrão de ar. Na admissão a pressão interna é menor que a atmosférica, possibilitando a entrada da mistura ar + combustível. Na exaustão a pressão interna é maior que a atmosférica, possibilitando a saída dos gases. $O$ diagrama pode ser visto na figura 2.6.

2)A etapa isentrópica de compressão no ciclo real é bem semelhante à do ciclo Otto, com pequenas diferenças devido à troca de calor através das paredes e devido ao início da combustão na parte final desta etapa.

3)A etapa de combustão no ciclo real é bem diferente de sua etapa correspondente no ciclo Otto (adição de calor num processo a volume constante). Há variação interna de volume. Além disso, a pressão atinge valores menores pelo fato da combustão ser incompleta devido à dissociação dos produtos da combustão.

4) Na etapa seguinte, de expansão, também ocorre diferença do ciclo real em relação ao ciclo ideal isentrópico. A diferença se deve à transferência de calor através das paredes, à turbulência dos gases, e à energia calorífica liberada com as reações químicas de recombinação dos produtos da combustão no ciclo real.

5)Na última etapa, a válvula de escape é aberta no motor real para o escape dos gases. Esse processo de descompressão não ocorre a volume constante como no ciclo ideal. Nenhum motor real de combustão realiza um ciclo termodinâmico completo (fechado), pois há constante renovação da substância (GALLO; WALTER, 1986). 


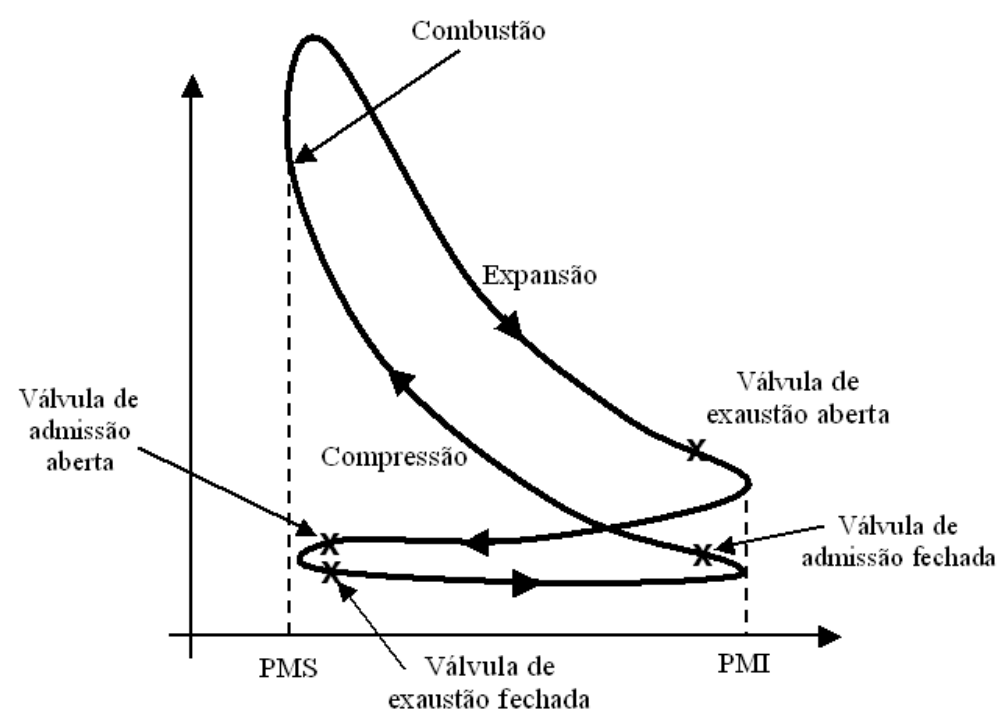

Figura 2.6- Diagrama P-V do Ciclo Otto em um motor de quatro tempos com ignição por centelha.

\subsubsection{Motores de dois tempos com ignição por centelha}

Uma variante do motor de ignição por centelha é o motor de dois tempos. Motores de dois tempos são utilizados em veículos mais simples como algumas motocicletas, barcos, jet skis; ferramentas como cortadores de grama e motorserras; aeromodelos etc. Apresentam menos peças móveis que um motor quatro tempos por isso são bastante leves em relação à potencia que produzem. Nesse tipo de motor não há válvulas de admissão nem de escape. Há duas janelas com as mesmas funções, mas que são abertas e fechadas pelo pistão durante seu movimento. A mistura ar combustível é injetada no Carter do motor, por isso a gasolina utilizada nesse tipo de motor recebe adição de um óleo lubrificante. As etapas são bem semelhantes às do motor 4 tempos (compressão isentrópica, combustão, expansão, exaustão). Entretanto, há algumas diferenças importantes (KEATING, 2007):

1)Não há etapas adicionais de admissão e exaustão existentes no motor de 4 tempos.

2)A etapa de exaustão deve ocorrer antes do pistão chegar ao PMI, iniciandose a uma pressão maior e a um volume menor do que o motor de 4 tempos.

3)Como consequência dessas diferenças, a taxa de compressão de um motor de 2 tempos é menor do que a de um motor de 4 tempos equivalente, resultando numa eficiência menor da combustão. 
A figura 2.7 mostra as principais partes de um motor desse tipo. Os dois tempos do motor são os seguintes (ver figura 2.8) (GALLO; WALTER, 1986; KEATING, 2007):

1ํ tempo: compressão

Durante o tempo de compressão, ocorre também a admissão. Quando o pistão chega ao PMI abre a janela de admissão e a mistura ar-combustível-óleo comprimida no carter durante a descida entra na câmara de combustão. O pistão sobe, forçado pelo sistema de manivela comprimindo a mistura até chegar ao PMS. A subida do pistão faz vácuo no Carter, com isso se abre a válvula de palheta e o Carter é novamente preenchido com ar combustível e óleo.

2o tempo: combustão

Durante o tempo de combustão ocorre também a exaustão. Quanto o pistão chega ao PMS, a vela de ignição é acionada e ocorre a combustão (expansão). O pistão é forçado para baixo realizando trabalho e ao passar pela janela de exaustão, os gases da queima são liberados. Durante a descida do pistão a mistura arcombustível-óleo no cárter é comprimida, o que a forçará a entrar na câmara no próximo ciclo. Logo abaixo da janela de exaustão está a janela de admissão, quando o pistão a alcança, começa um novo ciclo.

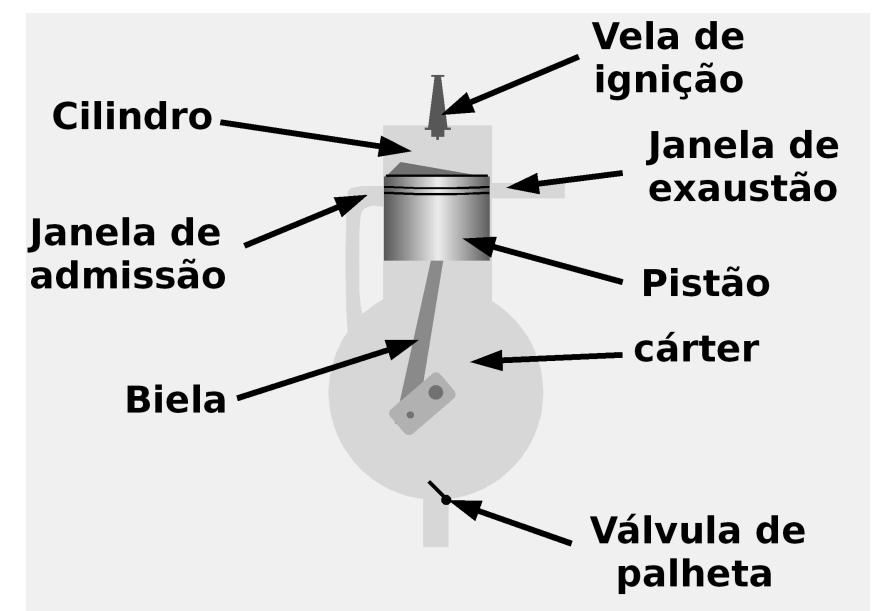

Figura 2.7- principais componentes de um motor dois tempos. 


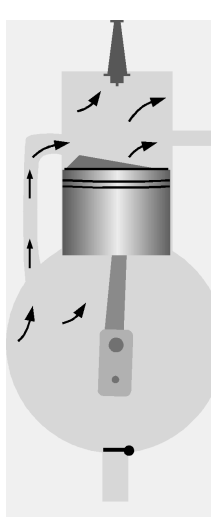

(a)

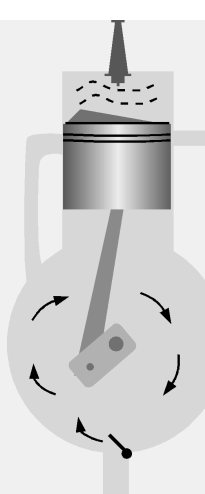

(b)

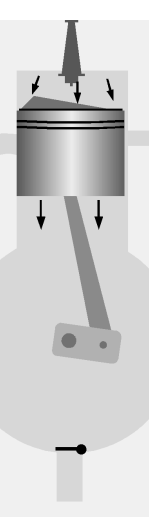

(c)

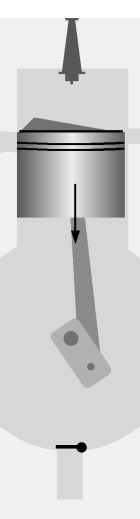

(d)

Figura 2.8- ciclo de operação de um motor dois tempos. (a) pistão no PMI permite entrada da mistura no cilindro; (b) subida do pistão comprime a mistura; (c) centelha da vela explode a mistura forçando o pistão para baixo; (d) quando o pistão passa pela janela de exaustão os gases da queima saem do cilindro.

O diagrama $\mathrm{P}-\mathrm{V}$ de um motor dois tempos pode ser visto na figura 2.9.

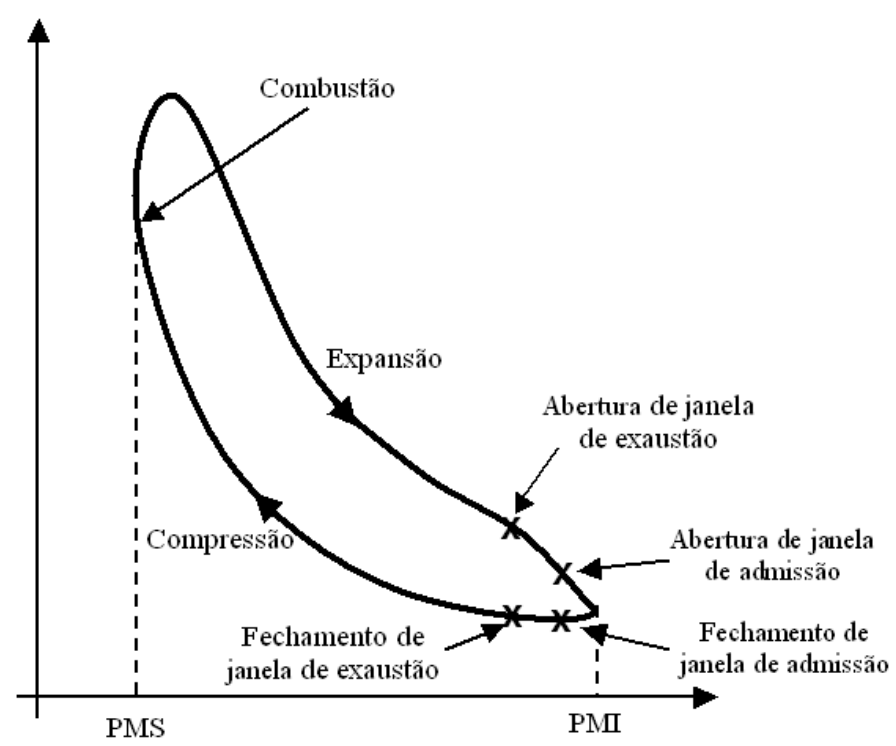

Figura 2.9- Diagrama P-V de um motor de dois tempos.

\subsection{PROBLEMAS QUE PODEM OCORRER DURANTE A COMBUSTÃO}

Um bom aproveitamento da combustão da mistura ar-combustível dentro do cilindro é essencial para o controle de emissões, bom rendimento do motor, economia de combustível e para manter a integridade do motor. A combustão é uma reação de oxidação do tipo Combustível + Oxidante $\rightarrow$ Produtos. O oxigênio proveniente do ar é o oxidante mais utilizado. Em cálculos teóricos do processo de 
combustão é considerado o "ar seco", constituído de $21 \% \mathrm{O}_{2}$ e $79 \% \mathrm{~N}_{2}$ em volume. Esse ar tem um peso molecular de aproximadamente 28,96 e a proporção molar é de $1 \mathrm{~mol}$ de $\mathrm{O}_{2}$ para 3,76 moles de $\mathrm{N}_{2}$.

A reação estequiométrica de combustão completa de um hidrocarboneto $\mathrm{C}_{\mathrm{x}} \mathrm{H}_{\mathrm{y}}$ é dada por:

$$
C_{x} H_{Y}+\left(x+\frac{y}{4}\right)\left(O_{2}+3,76 N_{2}\right) \rightarrow x C O_{2}+\frac{y}{2} H_{2} O+\left(x+\frac{y}{4}\right) 3,76 N_{2}
$$

Como pode ser visto na equação 2.1, considerando o "ar seco" para cálculos teóricos, os produtos da combustão teoricamente seriam $\mathrm{CO}_{2}, \mathrm{H}_{2} \mathrm{O}$ e $\mathrm{N}_{2}$. Uma deficiência na quantidade de oxigênio presente na mistura (mistura rica em combustível) resulta em uma combustão incompleta. Com isso somam-se aos produtos da combustão gases como $\mathrm{H}_{2}, \mathrm{CO}, \mathrm{C}$, e $\mathrm{C}_{x} \mathrm{H}_{\mathrm{y}}$ (hidrocarbonetos não queimados). Isso eleva o nível de poluição do veículo e desperdiça combustível devido aos hidrocarbonetos não queimados. Se houver excesso de oxigênio, a fração não utilizada deste gás fará parte dos produtos além de $\mathrm{CO}_{2}, \mathrm{H}_{2} \mathrm{O}$ e $\mathrm{N}_{2}$. Para garantir a combustão deve haver um certo excesso de $\mathrm{O}_{2}$. (GALLO; WALTER, 1986; MILTON, 1995).

Além desses desvios de estequiometria, outros efeitos podem ocorrer, dependendo das condições internas da câmara de combustão e da qualidade do combustível utilizado. O nível de poluição do veículo pode ser elevado devido a condições de alta temperatura e alta pressão no interior da câmara de combustão. $O$ que resulta em pequena quantidade de óxidos de nitrogênio $\left(\mathrm{NO}_{\mathrm{x}}\right)$, causadores de chuva ácida nos produtos da queima (MILTON, 1995; KEATING, 2007).

\subsubsection{Problemas relacionados à propagação da chama}

Dentro da câmara de combustão, mesmo na fase de compressão, a mistura ainda está a uma temperatura abaixo da chamada temperatura de ignição. No momento em que a vela de ignição dispara a centelha, fornece a energia de ativação para que a combustão se inicie. Então uma frente de chama começa a se propagar partindo desse ponto para o final da câmara. Esse é o comportamento esperado para um motor cujos sistemas de injeção e ignição estejam bem regulados e que esteja usando um combustível de boa qualidade. 
Entretanto, podem ocorrer alguns problemas durante a combustão como será visto a seguir (GALLO; WALTER, 1986; MILTON, 1995).

\subsubsection{Auto-ignição}

Define-se por auto-ignição a combustão espontânea de parte da mistura durante a propagação da frente de chama.

Acontece que, enquanto a frente de chama se propaga na câmara, os gases em combustão se expandem. A expansão desses gases comprime a parte da mistura que ainda não foi queimada. Com a compressão a parte não queimada sofre uma elevação de temperatura. Caso seja atingida a temperatura de ignição daquela mistura, inicia-se a fase de pré-chama. Se a frente de chama demora a chegar àquele ponto, ocorre então a combustão espontânea da mistura, que origina uma nova frente de chama.

\subsubsection{Detonação}

A detonação é consequência da auto-ignição e acontece de duas maneiras. Um tipo de detonação ocorre quando há um rápido aumento de pressão causando auto-ignição de grande parte da mistura simultaneamente. O impacto da pressão causa uma pancada surda no motor. Outro tipo ocorre quando o processo de autoignição cria várias frentes de chama e se realimenta, pode ocorrer com velocidades explosivas. Há criação de uma onda de choque com grandes gradientes de pressão localizados. Ao atravessar os gases no interior da câmara essa onda de choque causa-Ihes vibração que é transferida ao motor. Essa vibração causa o ruído conhecido como batida de pino.

A detonação causa impacto sobre os componentes do motor, prejudica a lubrificação causando maior desgaste e erosão da superfície do pistão. Contribui ainda na criação de pontos quentes, que causam a pré-ignição, que será vista a seguir.

Alguns dos fatores que influenciam a detonação são a octanagem do combustível, a temperatura da mistura, a rotação do motor, a taxa de compressão do motor, distância que a chama percorre (tamanho da câmara), faísca adiantada, deficiência na refrigeração do gás final etc. 


\subsubsection{Pré-ignição}

Pré-ignição é a combustão da mistura antes da centelha da vela de ignição. Ocorre devido a pontos quentes presentes na câmara. Ou seja, pontos específicos onde a temperatura atinge valores muito elevados provocando a combustão da mistura antes do momento apropriado. Alguns exemplos de possíveis pontos quentes são, a vela de ignição, válvulas de escape e carbono incandescente nas paredes da câmara.

A pré-ignição aumenta o trabalho de compressão da mistura aumentando mais ainda a pressão e a temperatura que tendem a acelerar o processo. Esse aumento acelerado do trabalho de compressão pode causar danos ao motor principalmente se apenas um cilindro estiver trabalhando em pré-ignição.

\subsection{SISTEMA DE ALIMENTAÇÃO DE COMBUSTíVEL}

Em essência, o sistema de alimentação de combustível de um automóvel é composto pela bomba de combustível, que pode ser interna ou externa ao tanque, filtro de combustível, distribuidor, regulador de pressão e válvulas injetoras. A bomba impulsiona o combustível, que passa pelo filtro e através da tubulação chega ao distribuidor. Do distribuidor o combustível é injetado nos cilindros pelas válvulas injetoras (há também sistemas compostos por uma única válvula que injeta o combustível em todos os cilindros). Junto ao distribuidor existe um regulador de pressão que devolve ao tanque o combustível não utilizado (Bosch, 2008).

Sistemas eletrônicos de gerenciamento controlam a injeção de combustível e a ignição. Os sistemas de injeção eletrônica substituíram o carburador que não é mais utilizado nos automóveis produzidos atualmente. Existem sistemas que incorporam injeção e ignição no mesmo módulo de controle.

Um sensor de oxigênio (sonda lambda, por exemplo) analisa os gases da queima e envia um sinal para a unidade de controle que é controlada por software. Através do sinal recebido o sistema determina por estequiometria a proporção da mistura ar-combustível que deve ser injetada no motor. Esses recursos eletrônicos permitem, entre outros benefícios, melhor rendimento do motor, economia de combustível e redução da poluição do ar (Bosch, 2008). 


\subsection{CARROS FLEX}

Os automóveis flexíveis surgiram nesta década de 2000 como solução para os problemas do uso do álcool como combustível alternativo no Brasil. Esses automóveis permitem o uso da gasolina, álcool ou uma mistura do dois combustíveis em qualquer proporção. Assim o consumidor pode escolher que combustível vai utilizar no momento do abastecimento e não mais na ocasião da compra do veículo. Essa possibilidade afastou o medo de se adquirir um automóvel movido a álcool e enfrentar problemas com a falta do combustível e aumento de preço.

Para utilizar álcool, um automóvel deve apresentar algumas modificações em relação a um automóvel que só utiliza gasolina. $O$ álcool é mais corrosivo para os metais que a gasolina devido à presença e absorção de água (KEATING, 2007). Isso exige o uso de materiais resistentes à corrosão para peças metálicas internas do motor e de todo o sistema de distribuição de combustível. Também há modificações no ajuste dos sistemas de ignição e injeção de combustível e na taxa de compressão. As velas de ignição também são diferentes, pois necessitam apresentar grau térmico diferente.

Em carros Flex, os controles da injeção de combustível e da ignição também são feitos baseando-se no sinal do sensor de oxigênio. Porém há uma grande diferença na unidade de controle, que tem software e hardware mais sofisticados. A mesma é programada para os dois tipos de combustíveis e suas misturas. Assim, através do sinal do sensor de oxigênio, a unidade de controle é capaz de reconhecer o álcool presente no combustível e adaptar todos os parâmetros do motor como injeção e ignição para qualquer proporção dos dois combustíveis (Bosch, 2008). As velas de ignição de um carro flex têm grau térmico intermediário entre álcool e gasolina. Tanto veículos a álcool quanto veículos flex necessitam ainda de um sistema de partida à frio, que geralmente utiliza um reservatório de gasolina.

Embora esse sistema funcione e dispense 0 uso de sensores mais sofisticados, o ajuste sempre é feito após a queima da mistura, baseado na análise da sonda lambda. Com isso sempre que há uma mudança brusca no combustível após um abastecimento, o motor funciona por algum tempo com o ajuste errado (mistura anterior). Isso pode causar alguns problemas de desempenho logo após o abastecimento até que o sistema se adapte às novas condições do combustível. 
Com o uso de um sensor que analisasse a mistura antes da queima, o sistema de ajuste dos parâmetros do motor seria otimizado evitando tal problema. Esse é o caso do sensor estudado neste trabalho.

\subsection{COMBUSTÍVES AUTOMOTIVOS}

\subsubsection{Gasolina}

A gasolina é um combustível de origem fóssil constituída basicamente por hidrocarbonetos selecionados de acordo com as características de ignição e escoamento adequadas ao funcionamento dos motores do ciclo Otto (ANP, 2007). São diferentes hidrocarbonetos contendo de 4 a 12 átomos de carbono em sua estrutura molecular (SPEIGHT, 1999), são mais leves que os que compõem o óleo diesel (PETROBRAS DISTRIBUIDORA, 2007). Seus pontos de ebulição estão entre $180^{\circ} \mathrm{C}$ e $200^{\circ} \mathrm{C}$. Estes hidrocarbonetos são de três tipos gerais: parafinas (alcanos), oleofinas (alquenos) e aromáticos (SPEIGHT, 1999). A composição exata da gasolina pode variar de acordo com a matéria prima utilizada e o processo de fabricação (ANP, 2007). A gasolina também possui, em baixas concentrações, compostos de enxofre, nitrogênio e compostos metálicos. A gasolina se tornou o combustível preferido para automóveis por apresentar alta energia de combustão e pela capacidade de mistura com o ar em um carburador (SPEIGHT, 1999), que eram utilizados nos veículos até alguns anos atrás.

No Brasil, a gasolina vendida ao consumidor final recebe adição de etanol anidro em sua composição. A mistura é obrigatória para toda a gasolina automotiva comercializada no país. Essa mistura aumenta a octanagem, reduz o consumo de petróleo e realiza uma queima mais limpa (ANP, 2007; MINTEER, 2006). A quantidade de etanol varia entre $20 \%$ e $25 \%$ (em volume) dependendo de fatores como a oferta do álcool no mercado, o preço do mesmo e o preço do açúcar e do petróleo no mercado internacional. As especificações determinadas pela ANP para a gasolina podem ser vistas na tabela do ANEXO A.

Uma propriedade muito importante da gasolina é a octanagem. Octanagem é uma medida da capacidade que um combustível tem de resistir à pressão dentro do cilindro sem entrar em auto-ignição. Um combustível de maior octanagem apresenta melhor poder de combustão, pois resiste a altas pressões sem sofrer auto-ignição. 
Os métodos que avaliam a octanagem são o Motor Octane Number (MON), o Research Octane Number (RON) e O Índice Anti-detonate (IAD). O método MON avalia a resistência à detonação em alta rotação como em ultrapassagens e em subidas com marcha reduzida. O método $\mathrm{RON}$ avalia a resistência à detonação sob condições mais suaves de trabalho e a baixas rotações como numa arrancada. $O$ método IAD é uma média dos métodos $M O N$ e $R O N$. $I A D=(M O N+R O N) / 2$ (PETROBRAS DISTRIBUIDORA, 2007).

\subsubsection{Processo de fabricação da gasolina}

A gasolina é fabricada através de uma série de processos de refinamento do petróleo que serão descritos a seguir. Maiores detalhes podem ser encontrados na obra de Speight (1999), referência utilizada nesta seção. O petróleo contém os hidrocarbonetos cujo tamanho das cadeias estão na faixa da gasolina (entre 4 e 12 átomos de carbono). No entanto, se só estes hidrocarbonetos fossem aproveitados para produzir gasolina, o processo apresentaria baixo rendimento e a gasolina apresentaria péssima octanagem.

Então moléculas mais pesadas do petróleo são quebradas em moléculas menores na faixa da gasolina. Esse processo é chamado de craqueamento.

$\mathrm{O}$ craqueamento térmico foi descoberto na primeira década do século 20. Era realizado em reatores pressurizados. Eram usadas temperaturas acima de $350^{\circ} \mathrm{C}$. Esse processo, além de aumentar o rendimento da produção, produzia gasolina de maior octanagem.

Ocorre que a octanagem da gasolina está diretamente ligada à estrutura do hidrocarboneto. Os hidrocarbonetos alifáticos de cadeias ramificadas e os aromáticos são os que conferem maior octanagem ao combustível. Portanto, quanto maior a fração destes hidrocarbonetos na gasolina, maior a octanagem.

Por isso o craqueamento térmico foi substituído pelo craqueamento catalítico descoberto na década de 1930. O craqueamento catalítico é semelhante ao térmico. A grande diferença está no uso de um catalisador que direciona o curso das reações. Com isso, são favorecidas as reações que produzem isoparafinas e aromáticos. Esses compostos possuem maior octanagem e melhor estabilidade química que as mono-oleofinas e dioleofinas presentes em grande quantidade nas gasolinas produzidas pelos métodos mais antigos. São utilizadas ainda diversas 
técnicas de refinamento para aumento de produtividade e melhora de qualidade da gasolina. Estas técnicas permitem que materiais não obtidos pelo craqueamento sejam adicionados à gasolina. Algumas destas técnicas são polimerização, alquilação, isomerização e reforma catalítica. Essas técnicas basicamente transformam moléculas de gás ou de gasolina de baixa octanagem em gasolina de boa qualidade. Também são baseadas em reações químicas e utilizam técnicas como destilação, alta pressão e uso de catalisadores.

Destes processos resulta a gasolina tipo A (isenta de compostos oxigenados). A gasolina tipo $\mathrm{C}$ recebe álcool anidro nas distribuidoras como será visto a seguir.

\subsubsection{Tipos de gasolina comercializados no Brasil}

\subsection{Gasolina A}

Por estabelecimento da portaria 309 de 27 de dezembro de 2001, a gasolina tipo A é aquela produzida no Brasil ou importada pelos agentes econômicos autorizados para cada caso, isenta de compostos oxigenados como o álcool anidro e comercializada com o distribuidor de combustíveis líquidos derivados do petróleo, álcool combustível e outros combustíveis automotivos. A Petrobrás produz e oferece essa gasolina às companhias distribuidoras.

\subsection{Gasolina $C$}

A gasolina $C$ é aquela vendida ao consumidor final, utilizada nos automóveis de motor à gasolina ou flex. Esta gasolina recebe adição de 20\% a 25\% (em volume) de álcool etílico anidro combustível (AEAC) em sua composição. A mistura é realizada nas distribuidoras, antes de chegar aos postos de combustíveis. Essa gasolina possui algumas variantes quanto à composição. Trata-se basicamente da presença ou ausência de aditivos do tipo detergente dispersante. Por isso as gasolinas são diferenciadas em comum e aditivadas (ANP, 2007).

\subsubsection{Tipos de gasolina $\mathrm{C}$ vendidos ao consumidor final no Brasil}

\subsection{Gasolina comum}

A gasolina comum é a gasolina $\mathrm{C}$ sem aditivos do tipo detergente dispersante e sem corante. Possui a cor natural das gasolinas (incolor a amarelada) (PETROBRAS DISTRIBUIDORA, 2007). Deve estar de acordo com as 
especificações da portaria ANP № 309 de 27 de dezembro de 2001. Esse tipo de gasolina apresenta IAD (Índice Antidetonante) igual a 87 e o teor de enxofre é de 1000ppm (ANP, 2007).

\subsection{Gasolina aditivada}

A gasolina aditivada deve apresentar as mesmas especificações que a gasolina comum. Portanto também apresenta IAD igual a 87 e teor de enxofre de 1000 ppm. Mas, recebem aditivos que apresentam uma característica detergente dispersante. Esses aditivos têm a função de manter limpo todo o sistema de alimentação de combustível (tanque, bomba de combustível, tubulações, bicos injetores e válvulas do motor). Esses aditivos evitam a formação de uma goma resultante do acúmulo de precipitados devido ao processo natural de oxidação da gasolina. Essa goma pode causar entupimentos no sistema de alimentação citado. A Petrobrás produz e comercializa esse tipo de gasolina com o nome de Gasolina Supra Aditivada. Normalmente essa gasolina recebe um corante que the confere uma cor esverdeada para ser diferenciada da gasolina comum (ANP, 2007; PETROBRAS DISTRIBUIDORA, 2007).

\subsection{Gasolinas de alta octanagem}

São comercializas no Brasil gasolinas de alta octanagem (IAD=91 ou superior) chamadas de Gasolinas Premium. Essas gasolinas também possuem aditivos (detergentes/dispersantes) que mantêm limpo o sistema de combustão. Possuem o mesmo teor de álcool que as gasolinas comum e aditivada, o que as difere de gasolinas similares comercializadas em outros países. São recomendadas para veículos com motores de alto desempenho que apresentem taxas de compressão a partir de 10:1 ou que requeiram combustível de alta octanagem. Esses veículos podem sofrem problemas de detonação caso seja utilizada uma gasolina de baixa octanagem. Gasolinas tipo Premium também podem ser utilizadas em qualquer veículo à gasolina, no entanto não trazem nenhum benefício a veículos com baixa taxa de compressão. 


\subsubsection{Adulteração de Gasolina}

Uma das principais fraudes praticadas contra a gasolina é a adição de álcool anidro além da quantidade estabelecida pela ANP. Também é utilizada uma série de solventes orgânicos como o óleo diesel, querosene, aguarrás, solvente de borracha, rafinados petroquímicos etc. (TAKESHITA, 2006). Rafinados são produtos inacabados ou resíduos de processos petroquímicos como a produção de óleos lubrificantes. Esses produtos contêm parafinas lineares ou pouco ramificadas que prejudicam a octanagem da gasolina (ALONSO, 2001). A adulteração é lucrativa aos fraudadores devido ao fato de todos esses adulterantes serem mais baratos que a gasolina (TAKESHITA, 2006).

No ano de 2007, na grande São Paulo, diversas operações de fiscalização flagraram uma enorme quantidade de postos vendendo gasolina adulterada. A principal irregularidade encontrada foi a adição de álcool anidro acima do permitido. Foram encontradas amostras com teor acima de 50\% de álcool quando o permitido era $23 \% \pm 1 \%$ (ANP). Inúmeros postos foram lacrados (GLOBO.COM, 2007; O ESTADO ONLINE, 2007).

Certos postos utilizavam-se de avançados sistemas para burlar a fiscalização utilizando tanques com gasolina boa e outros com gasolina adulterada. Válvulas permitiam a saída de uma ou de outra para camuflar a fraude em caso de fiscalização.

Com a fiscalização intensificada e a ampla divulgação dos meios de comunicação, alguns postos passaram a vender o que veio a ser chamado de gasolina de fim de semana. Vendiam gasolina legalizada com preços normais durante a semana e gasolina adulterada a preços baixos nos fins de semana, quando não há fiscalização (O GLOBO ONLINE, 2007).

A curto prazo veículos que rodam com gasolina adulterada consomem mais combustível, sofrem perdas de rendimento, apresentam dificuldade em dar partida pela manhã, o motor morre em pequenas paradas e podem ocorrer irregularidades na combustão (auto-ignição e/ou pré-ignição) . A longo prazo ocorrem danos em diversas peças do motor e do sistema de alimentação de combustível. Peças não tratadas para uso de álcool em grandes concentrações (peças para veículos à gasolina) sofrem oxidação devido ao álcool em excesso. As mangueiras também sofrem corrosão quando utilizados solventes de borracha. 
A adulteração favorece ainda a carbonização, que é a formação de fuligem durante a combustão. Com isso há depósito de fuligem nos sensores e no catalisador, carbonização de válvulas e da cabeça do pistão e contaminação do óleo. O deposito de fuligem na sonda lambda, prejudica o sistema de controle de injeção, pois a sonda lambda irá sistematicamente, indicar mistura rica fazendo com o módulo reduza a quantidade de combustível na mistura (AUTOPLAST MOTORES, 2008).

O óleo pode se decompor formando uma goma, resultado de sua contaminação somado a um aquecimento do cabeçote devido à carbonização. Goma semelhante a esta pode se formar devido à queima incompleta de alguns adulterantes como tolueno e rafinados que formam produtos que também contaminam o óleo e não se dissolvem (A CIDADE, 2007; AUTOPLAT MOTORES, 2008).

A goma se acumula causando entupimentos que impedem a circulação do óleo prejudicando a lubrificação, o que pode causar o travamento do motor (A CIDADE, 2007).

Problemas causados ao automóvel causam prejuízo ao consumidor. Prejuízo esse que é transferido às montadoras no caso do veículo se encontrar no prazo de garantia. O governo também sofre perdas com arrecadação de tributos.

Além das perdas financeiras sofridas pelo consumidor e pelo estado há ainda um aumento na poluição do ar. A adulteração do combustível favorece a queima incompleta lançando à atmosfera gases como $\mathrm{H}_{2}, \mathrm{CO}, \mathrm{C}$ e $\mathrm{C}_{x} \mathrm{H}_{\mathrm{y}}$ como mencionado na seção 2.2. Também pode haver elevação na emissão gases tipo de $\mathrm{SO}_{\mathrm{x}}$, que assim como os $\mathrm{NO}_{x}$, são causadores de chuva ácida. (BOSCH, 2005; TAKESHITA, 2006).

\subsection{3 Álcool}

A palavra álcool deriva do árabe al-kuhul e era utilizada para designar o pó de antimônio ou chumbo utilizado pra colorir as pálpebras. Nas línguas européias a palavra alcohol passou a designar pós obtidos por sublimação e por analogia, produtos de destilações. 


\subsubsection{1 Álcoois}

A família dos álcoois está entre os compostos orgânicos que apresentam o grupo hidroxila $(\mathrm{OH})$. No caso dos álcoois, o grupo hidroxila está ligado a um carbono saturado da cadeia. Os compostos que também apresentam o grupo $\mathrm{OH}$ porém ligado a um carbono insaturado recebem o nome de enóis. $O$ átomo de carbono saturado pode ser de um grupo alquila simples como no caso do metanol e do etanol. Mas esse átomo de carbono também pode ser de um grupo alquenila ou alquinila ou pode ainda estar ligado a um anel de benzeno. Os compostos cujo grupo hidroxila está ligado diretamente a um anel de benzeno são chamados de fenóis. Dois exemplos de álcoois bem conhecidos são o etanol ou álcool etílico $\left(\mathrm{CH}_{3} \mathrm{CH}_{2} \mathrm{OH}\right)$, e o metanol $\left(\mathrm{CH}_{3} \mathrm{OH}\right)$ (BROWN, 2005; SOLOMONS, 1990).

Os álcoois são classificados em primários, secundários e terciários. Esta classificação está relacionada com o carbono que contém o grupo hidroxila. Se este carbono estiver ligado a apenas um outro carbono, diz-se que ele é um carbono primário e o álcool é um álcool primário, se o carbono do grupo hidroxila estiver ligado a dois outros átomos de carbono, o álcool é secundário e se o carbono que contém a hidroxila estiver ligado a três outros átomos de carbono, o álcool é terciário. O etanol entra nesta classificação como álcool primário (BROWN, 2005).

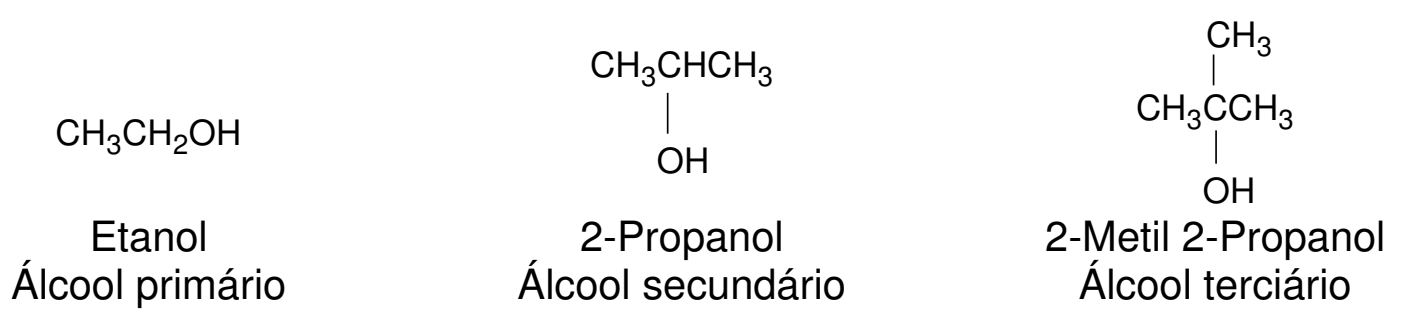

Uma importante característica dos álcoois é que eles podem ser convertidos em diversos tipos de compostos como alcanos, haloalcanos, aldeídos, cetonas, ácidos carboxílicos e ésteres. O processo inverso também é possível. Ou seja, estes compostos também podem ser convertidos em álcool (BROWN, 2005).

\subsubsection{Etanol}

O etanol ou álcool etílico é muito utilizado em diversas aplicações como bebidas, perfumaria, produto de limpeza, solvente industrial e em alguns países como o Brasil e Estados Unidos, como combustível automotivo (BROWN, 2005; MINTEER, 2006; SOLOMONS, 1990). 


\subsubsection{3 Álcool Combustível}

No Brasil, desde a década de 1970, o etanol vem sendo usado como combustível automotivo. Foi o primeiro bio-combustível brasileiro e foi criado com o objetivo de reduzir o consumo de gasolina durante a crise do petróleo (DIAS, 2007; FERNANDES; COELHO, 1996; OMETTO, 1998). Existem no mercado brasileiro dois tipos de álcool combustível, o Álcool Etílico Hidratado Combustível (AEHC) e o Álcool Etílico Anidro Combustível (AEAC). O AEHC deve apresentar grau alcoólico entre 92,6 e 93,8ํㅣㄱ. Esse álcool é utilizado como combustível em automóveis com motor adaptado para recebê-lo. O AEAC é desidratado ao máximo e deve apresentar teor alcoólico mínimo de 99,3 INPM. Essas e outras especificações para ○ AEAC e o AEHC são determinadas pela resolução ANP № 36 de 6.12.2005. Essa alta pureza do $A E A C$ é necessária porque esse álcool é adicionado à gasolina.

A percentagem de álcool numa solução alcoólico-aquosa recebe o nome de grau alcoólico. O grau alcoólico medido em ${ }^{\circ} \mathrm{GL}$ ( ${ }^{\circ} \mathrm{Gay}$ Lussac) é a porcentagem de álcool em volume que a mistura apresenta. É definido como a quantidade de álcool em mililitros contida em 100ml da solução. Medido em ㅇNPM (Instituto Nacional de Pesos e Medidas) é a porcentagem de álcool em massa que a mistura tem, definido como a quantidade de álcool em gramas contida em 100 gramas da solução. O grau alcoólico é determinado de acordo com a norma NBR 5992.

$O$ etanol adicionado à gasolina age como oxidante tornando a queima do combustível mais limpa com baixa emissão de monóxido de carbono e hidrocarbonetos não queimados. A melhora na queima se dá devido à presença do oxigênio na molécula do etanol, que também eleva a octanagem da gasolina, pois a alta octanagem é uma característica do álcool. (LEE; SPEIGHT; LOYALKA, 2007).

Fora do Brasil, um dos principais agentes oxidantes utilizados na gasolina é o MTBE (metil-terc-butil-eter). Esse oxidante, no entanto é muito tóxico e lança mais enxofre e oleofinas na atmosfera que o etanol além de contaminar a água de lençóis freáticos. O etanol em contra-partida, lança mais $\mathrm{NO}_{x}$ que o MTBE (MINTEER, 2006). As vantagens e desvantagens dos dois oxidantes vêm sendo estudadas por pesquisadores. Entre elas os efeitos ambientais (SONG, 2006; WILLIAMS; CUSHING; SHEEHAN, 2003). 
Até o momento o etanol parece ser a melhor solução. O MTBE já foi banido no Brasil no início da década de 1990, sendo substituído pelo etanol. A substituição também vem ocorrendo nos EUA (FIGUEIRA, 2005).

O Brasil é o único país a usar, em larga escala, o etanol sem adição de gasolina como combustível automotivo. O AEHC substitui totalmente a gasolina, necessitando de um sistema de partida a frio, adaptações no motor e diferentes ajustes nos sistemas de injeção e ignição. Desde que começou a ser utilizado no Brasil, O AEHC passou por altos e baixos havendo períodos em que os consumidores deixavam de comprar veículos movidos a álcool por receio de falta do combustível no mercado (DIAS, 2007; FERNANDES; COELHO, 1996). O problema parece ter sido definitivamente resolvido com a chegada ao mercado dos automóveis flexíveis (DIAS, 2007). Assim mesmo que falte álcool no mercado, o consumidor pode abastecer com gasolina.

\subsubsection{Obtenção do Álcool Combustível}

O processo mais utilizado para fabricação de álcool combustível é a fermentação de açúcares de vegetais seguida de destilações. Podem ser utilizados vegetais como a cana-de-açúcar, milho e beterraba (MINTEER, 2006; KEATING, 2007).

O Brasil, atualmente, produz cerca de 16 bilhões de litros de álcool combustível por ano (GLOBO.COM-BOM DIA BRASIL, 2008). No processo brasileiro é utilizada a cana-de-açúcar. Atualmente é o processo mais barato do mundo.

Após a colheita e a moagem, o caldo de cana passa por processos de prétratamento e pasteurização (aquecimento e resfriamento rápido). Então o material passa por um processo de fermentação anaeróbica. Neste processo, é adicionado ao melaço, o fermento contendo as enzimas diastase (ou maltase) e zimaze responsáveis pela catalisação da reação. Reação esta que ocorre em duas fases, primeiro ocorre a hidrólise do amido catalisada pela maltase. Depois o produto dessa reação (açúcar) é fermentado pela ação da zimase. Os produtos da reação são o etanol e dióxido de carbono. O tempo de fermentação varia entre 4 e 12 horas. Após a fermentação, o material passa por um processo de centrifugação para recuperação do fermento (CALLE; BAJAY; HOTHMAN, 2000). 


$$
\begin{aligned}
& \mathrm{C}_{12} \mathrm{H}_{22} \mathrm{O}_{11}+\mathrm{H}_{2} \mathrm{O} \stackrel{\text { invertase }}{\longrightarrow} 2 \mathrm{C}_{6} \mathrm{H}_{12} \mathrm{O}_{6} \\
& \mathrm{C}_{6} \mathrm{H}_{12} \mathrm{O}_{6} \stackrel{\text { zimase }}{\longrightarrow} 2 \mathrm{C}_{2} \mathrm{H}_{5} \mathrm{OH}+2 \mathrm{CO}_{2}
\end{aligned}
$$

Através da fermentação obtém-se uma mistura com teor alcoólico entre 7\% e $10 \%$. Esse teor de álcool é baixo para o etanol combustível. Por isso, essa mistura deve passar por um processo de destilação para reduzir a concentração de água. $O$ processo de destilação permite a obtenção do etanol de $96^{\circ} \mathrm{GL}$ ou $93,2^{\circ}$ INPM. Este teor corresponde a $96 \%$ de etanol e $4 \%$ de água, em volume. Esse processo não permite obtenção de pureza maior. Isso ocorre porque a mistura $95 \%$ álcool - 5\% água é um azeótropo com ponto de ebulição inferior ao da água e também ao do álcool. (MINTEER, 2006) Esse álcool pode ser utilizado como combustível nos motores a álcool e motores flex. Não é utilizado na mistura com a gasolina para evitar separação de fases nos tanques de armazenagem devido ao teor de água.

Para obtenção do AEAC é necessário um processo de desidratação. À mistura é adicionado ciclohexano que forma um novo azeótropo (CALLE; BAJAY; HOTHMAN, 2000). Este azeótropo tem ponto de ebulição inferior ao álcool. O processo permite a remoção de quase toda a água. $O$ etanol obtido no final deste processo tem $99,7^{\circ} \mathrm{GL}$. Esse álcool é misturado à gasolina $A$ para formar a gasolina C comercializada no país.

O processo de fabricação do etanol deixa um resíduo chamado de vinhoto (CALLE; BAJAY; HOTHMAN, 2000). Se lançado em rios esse resíduo é altamente poluente. Existem métodos adequados para descarte do vinhoto. O mais utilizado no Brasil é reaproveitá-lo como fertilizante. $O$ bagaço da cana também é reaproveitado para produzir energia.

\subsubsection{5 Álcool combustível em outros países}

Os EUA são o outro grande produtor de etanol. Está começando a ultrapassar - Brasil em volume de produção com cerca 18 bilhões de litros anuais (GLOBO.COM, 2008a). Os dois países juntos são responsáveis por cerca de 70\% da produção mundial.

Nos EUA, a principal matéria-prima utilizada é o milho. No processo de fabricação, o amido deve ser transformando em açucares. Esse processo é 
realizado em solução aquosa em presença de ácido e enzimas. Os processos subseqüentes são a fermentação e destilação, como no processo brasileiro (LEE; SPEIGHT; LOYALKA).

Para quebrar o azeótropo $95 \%$ etanol $5 \%$ água podem ser utilizadas duas técnicas. Uma delas, a destilação azeotrópica, consiste em adicionar um terceiro líquido, normalmente benzeno e fazer uma nova destilação. Através da formação de novo azeótropo é possível separar o etanol com pureza muito superior. A outra técnica consiste em utilizar as chamadas peneiras moleculares (MINTEER, 2006). Peneiras moleculares são materiais contendo pequenos poros de tamanho preciso e uniforme como zeólitas sintéticas. Esse material absorve seletivamente a água da mistura por diferença de tamanho de moléculas.

Os EUA utilizam etanol em misturas com a gasolina. A mistura mais usada é o E10, em que são adicionados até 10\% de etanol à gasolina (MINTEER, 2006).

O E85 é um combustível alternativo composto de $85 \%$ de etanol e $15 \%$ de gasolina usado nos veículos Flexíveis, os FFVs (Flexible Fuel Vehicles). Esse combustível ainda é pouco usado mas está em ascensão (MINTEER, 2006).

Alguns países europeus produzem etanol a partir da beterraba (GLOBO.COM, 2008b). Estes países demonstram interesse em substituir parte do petróleo consumido por combustíveis renováveis. Não produzem grandes quantidades como Brasil e EUA, mas estão investindo no etanol. Outros países demonstram interesse em utilizar etanol misturado à gasolina como o Japão que já aprovou a mistura e deve importar etanol do Brasil. A China faz testes para decidir se aprova ou não a mistura.

\subsubsection{Etanol Celulósico}

Uma nova forma de produção de etanol em massa vem sendo estudada no Brasil e nos Estados Unidos. É a produção de etanol a partir de celulose. A matéria prima seria restos de cana não aproveitados no processo atual, restos de plantas de outros segmentos da agricultura, restos de madeira ou mesmo vegetais cultivados para esse próprio fim (CALLE; BAJAY; HOTHMAN, 2000). Os processos de obtenção de etanol da celulose envolvem hidrólise da mesma. Isso produz glicose que depois é fermentada para produção do etanol. Os processos de hidrólise podem ser realizados utilizando-se ácidos ou enzimas celulase. Os EUA apostam no etanol 
celulósico para aumentar seu consumo atual de 20 bilhões de litros anuais para 132 bilhões até 2017 (AGENCIA BRASIL, 2007). A matéria prima (celulose) seria retirada de resíduos agrícolas. No Brasil as pesquisas visam baixar o custo de produção que atualmente é inviável se comparado ao do processo usando cana ou amido.

\subsubsection{Adulteração do etanol}

A ANP (Agência Nacional do Petróleo, Gás Natural e Biocombustíveis) determina que o AEAC tenha teor alcoólico de 99,3INPM e o AEHC teor alcoólico entre 92,6 e 93,8 INPM.

Uma das principais fraudes praticadas contra o etanol é a adição de água bruta ao álcool anidro para vendê-lo como se fosse álcool hidratado. Essa mistura é conhecida como álcool molhado. Tal fraude é praticada com a finalidade de sonegar tributos. Isso ocorre porque o álcool anidro não sofre tributação direta quando adquirido para ser adicionado à gasolina. Só recebe influência de tributos depois de misturado à gasolina. Já o álcool hidratado é tributado normalmente. Então é mais lucrativo para o fraudador comprar o AEAC sem pagar tributo e adicionar água do que comprar AEHC verdadeiro pagado tributos (DIAS, 2007).

Esse tipo de adulteração está sendo combatido através da adição de um corante laranja ao álcool anidro definida na resolução ANP oㅜ36. Assim o consumidor poderia identificar a fraude pela cor, pois o AEHC deve ser incolor. Caso fosse adicionada água ao AEAC, a mistura teria um tom alaranjado. Essa cor laranja do AEAC não interfere na mistura com a gasolina, pois os dois combustíveis apresentam o mesmo tom de cor.

Uma maneira de detectar esta adulteração mesmo sem o corante é a medição da condutividade. A condutividade tanto do AEAC quanto do AEHC deve ser $500 \mu \mathrm{S} / \mathrm{m}$. Como nesta fraude normalmente é utilizada água de torneira, a condutividade deve ser muito maior que a especificada para o $A E H C$ verdadeiro. $O$ álcool molhado pode atingir valores de condutividade de até $2000 \mu \mathrm{S}$. A medição de condutividade é feita através de um condutivímetro.

A adição criminosa de água também é feita no próprio álcool hidratado. Assim a concentração de água fica acima do permitido pela ANP (valor entre 6,2\% e 7,4\%). Essa fraude também pode ser constatada através da medição de condutividade. 
Um condutivímetro, entretanto não seria capaz de detectar um processo de destilação incompleto que deixasse o álcool hidratado com mais água que 0 permitido. Neste caso o álcool estaria fora da especificação, porém a água excedente é água destilada. Esta água não é condutora por isso não seria detectada por esse método.

\subsubsection{Biodiesel}

O Biodiesel pela definição da lei o 11.097 de 13 de janeiro de 2005 é um "Bio-combustível derivado de biomassa renovável para uso em motores a combustão interna com ignição por compressão ou conforme regulamento, para geração de outro tipo de energia, que possa substituir parcial ou totalmente combustíveis de origem fóssil". É um combustível renovável, biodegradável e menos poluente que o diesel de petróleo. Geralmente misturas de até $20 \%$ de biodiesel em diesel de petróleo (B20) podem ser utilizadas em motores sem modificações. Misturas acima de B20 até B100 (biodiesel puro) podem ser utilizadas em diversos tipos de motores desde que estes passem por algumas modificações. O combustível pode ser produzido a partir de óleos vegetais, gordura animal e até mesmo de óleo de cozinha reciclado. O processo mais utilizado na fabricação é transesterificação. Nesse processo, o óleo é misturado com um álcool de cadeia curta (etanol ou metanol, por exemplo) e um catalisador. Então as moléculas do óleo (triglicerídeos) são quebradas em metil ésteres (biodiesel) e glicerina por reações químicas. Esses produtos são separados por decantação. Depois os produtos são purificados e o álcool utilizado é recuperado por centrifugação (PORTAL DO BIODIESEL, 2008; LIMA, 2007).

No Brasil, é produzido a partir do óleo vegetal de diversos vegetais como a soja, o dendê, o girassol e a mamona. Também é utilizado sebo bovino (REDE BAIANA DE BIOCOMBUSTÍVEIS, 2007).

O combustível vem sendo usado como mistura com o diesel de petróleo (2\% de biodiesel). Essa mistura é chamada de B2. Também na Europa o biodiesel vem sendo usado em vários países. 


\section{SISTEMAS MICRO-ELETRO-MECÂNICOS, SENSORES E MATERIAIS DIELÉTRICOS}

\subsection{INTRODUÇÃO A MEMS}

MEMS (Micro-electro-mechanical system) é hoje o termo mais utilizado para designar sistemas constituídos de dispositivos mecânicos e elétricos em dimensões micrométricas. Também podem incorporar elementos ópticos. Neste caso é comum o uso do termo MOEMS (Micro-Opto-Electro-Mechanical Systems). O termo NEMS (Nano-Electro-Mechanial Systems) é utilizado para sistemas com dimensões menores ainda e se insere na área de nanotecnologia.

Essa tecnologia surgiu devido aos avanços da microeletrônica na década de 1980. A evolução dos processos de fabricação permitiu aumentar a capacidade de integração reduzindo dimensões, melhorar o desempenho e a confiabilidade e reduzir os custos de fabricação. Atualmente, as técnicas de fabricação permitem a construção de diversas configurações de microestruturas mecânicas num substrato. As microestruturas mais utilizadas podem ter elementos fixos ao substrato, ou suspensos, ou uma combinação dos dois tipos, sendo normalmente fabricadas em silício. Essas estruturas podem servir como sensores ou atuadores.

A figura 3.1 mostra um tipo clássico de estrutura utilizada em MEMS, um comb-drive constituído de dois conjuntos de eletrodos interdigitados cujo principio de funcionamento é capacitivo. Usualmente, um conjunto de eletrodos é fixo, enquanto o outro é móvel por ser uma estrutura suspensa. O conjunto pode trabalhar como um sensor, normalmente sensor de aceleração. Quando sofre uma aceleração, estando num automóvel que sofre um impacto, por exemplo, a parte suspensa do sensor se movimenta causando variação na capacitância que é percebida por um circuito de controle. A estrutura, por outro lado também pode ser utilizada como um atuador. Neste caso a estrutura é excitada por uma diferença de potencial entre os eletrodos. Ocorre então, atração e repulsão eletrostática entre os eletrodos conforme o sinal aplicado e a parte móvel se movimenta realizando trabalho. 


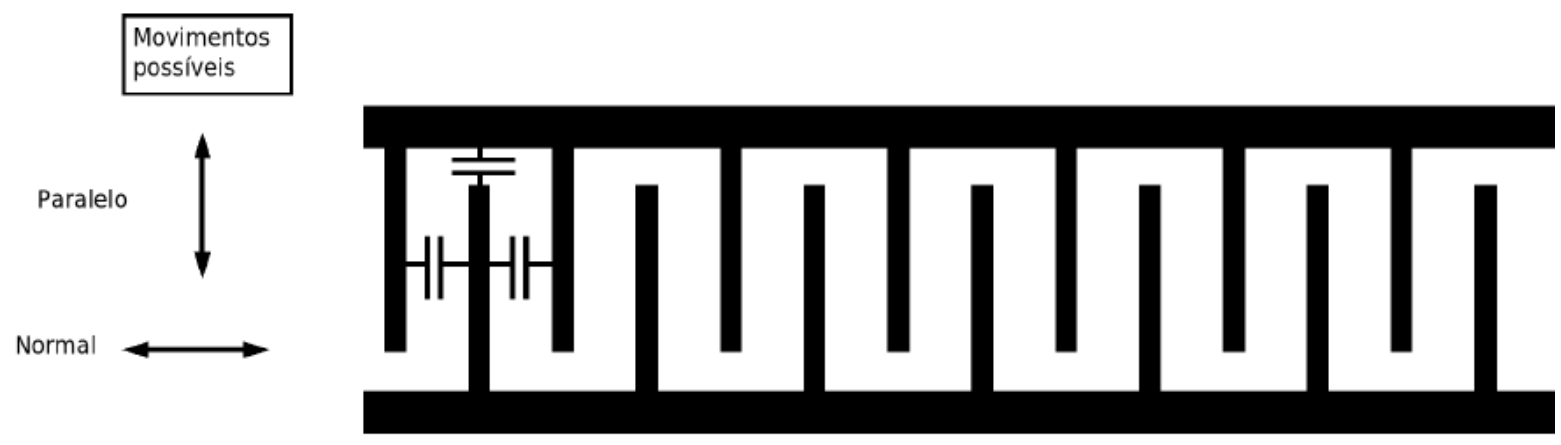

Figura 3.1- Estrutura de um comb-drive.

Esse, no entanto é apenas um exemplo de estrutura MEMS. Existem diversos tipos de estruturas que formam diversos tipos de micro-sistemas não somente eletromecânicos. Também são utilizadas propriedades ópticas, magnéticas, térmicas e de piezoeletricidade. É uma tecnologia de grande interesse, envolvendo diversas áreas do conhecimento.

\subsubsection{Mercado de MEMS}

A Yole Développement, com sede na França e a WTC (Wicht Technologie Consulting), com sede na Alemanha, são duas empresas de consultoria muito respeitadas que trabalham com MEMS.

Estimativas da Yole apontam para um mercado de quase US\$6bi em 2006 e uma projeção de quase US $\$ 11$ bi para 2011. Esses dados não incluem MEMS para cabeças de leitura/gravação que, se inclusos, praticamente dobrariam os valores. $O$ maior consumidor de MEMS é mercado de Tecnologia da Informação (TI). Os produtos com maior tendência de crescimento no mercado são: microfones para celulares e equipamentos multimedia, sensores inerciais (acelerômetros e giroscópios), micro-espelhos para DLP (do inglês- Digital Light Processing) e RFMEMS. 


\subsection{SENSORES}

Esta seção destina-se a introduzir alguns conceitos, definições e características de sensores em geral. Um sensor pode ser definido como um sistema que ao receber um sinal ou estímulo físico responde com um sinal, geralmente elétrico, e o transmite a um controlador (FRADEN, 1996). O estímulo pode ser calor, luz, pressão, som, movimento etc. Sensores fazem parte, por exemplo, de um sistema automatizado de manufatura. Juntamente com os sensores, um sistema sensor apresenta controladores e atuadores.

Os sensores podem ser divididos em Sensores Ativos e Sensores Passivos. Os sensores ativos não geram uma tensão. Precisam de uma alimentação externa para então variar uma propriedade física dando a resposta correspondente. Um exemplo de sensor ativo é o termistor. Sensores passivos geram um sinal elétrico em resposta a um estímulo. Um exemplo é o termopar.

\subsubsection{Principais características de um sensor}

Esta seção aborda os conceitos básicos associados às medições feitas com um sensor. As referências utilizadas foram: (FRADEN, 1996; ABNT; INMETRO; SBM, 1998).

\subsubsection{Função de transferência}

É a relação entre o estímulo recebido por um sensor (entrada) e seu sinal de saída. Essa relação pode se dar em forma de tabela de valores, gráficos ou de uma equação matemática.

Tipicamente, a função de transferência de um sensor pode ser linear, logarítmica, exponencial ou polinomial.

\subsubsection{Sensibilidade}

Sensibilidade é a razão entre a variação no sinal de saída pela variação no sinal de entrada. Assim, a sensibilidade do sensor será tão maior quanto menor a variação no sinal de entrada e maior a variação no sinal de saída. 


\subsubsection{Faixa de utilização}

Todo sensor tem uma faixa de valores em que pode operar corretamente. $O$ fundo de escala da entrada representa o menor e o maior valor que podem ser aplicados ao sensor. Ou seja, o menor o maior valor da grandeza que se está medindo que o sensor é capaz de medir. O fundo de escala da saída é função do sinal mínimo e do sinal máximo aplicados na entrada.

\subsubsection{Saturação}

Saturação é o limite de operação de um sensor. A partir do ponto em que o sinal de entrada atinge a saturação, os resultados da saída não são mais corretos. Quase todo sensor tem seus limites de operação.

\subsubsection{Banda morta}

Banda morta é uma região específica de insensibilidade do sensor. Nessa região o sensor recebe o sinal de entrada, mas responde com valores errados no sinal de saída.

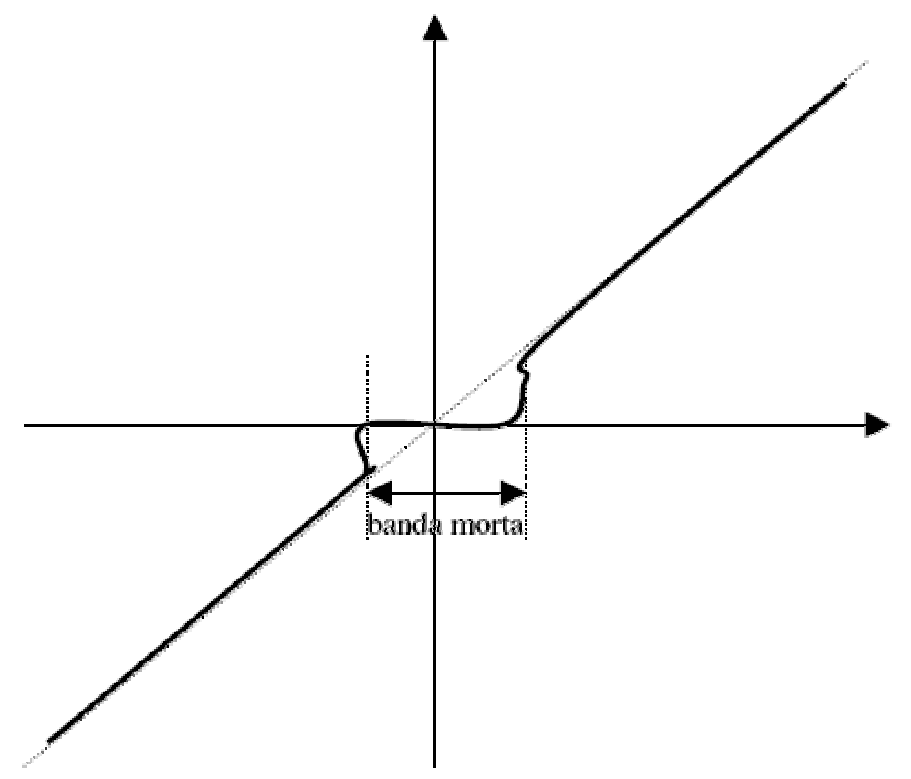

Figura 3.2- Banda morta de um sensor em uma função de trasferência.

\subsubsection{Erros em Medições}

Todo processo de medição tem imperfeições que dão origem a um erro no resultado da medição. Normalmente, um erro é considerado como tendo dois componentes: um componente aleatório, e um componente sistemático. 
O erro aleatório se origina de variações temporais ou espaciais, estocásticas ou imprevisíveis, de grandezas de influência na medição. Em geral, ele pode ser reduzido aumentando-se o número de observações.

O erro sistemático se origina de um efeito reconhecido de uma grandeza de influência em um resultado de medição. Se esse efeito puder ser quantificado, será possível estabelecer um "fator de correção" a ser aplicado para compensar o efeito.

\subsubsection{Erro de calibração}

Erro de calibração é uma imperfeição que pode ocorrer durante o processo de calibração do sensor. Trata-se de um erro de natureza sistemática, ou seja, o erro soma-se a todas as medições. Pode não ser uniforme na faixa de utilização do sensor, o que depende do tipo de erro na calibração. Considere a figura 3.3, o ponto referente a $e_{1}$ foi corretamente calibrado. $O$ mesmo, porém não ocorreu com $e_{2}$. Assim, as medições realizadas com esse sensor apresentarão um erro de acordo com a equação.

$$
\delta_{S}=s_{C}-S=\frac{-\Delta}{e_{2}-e_{1}}
$$

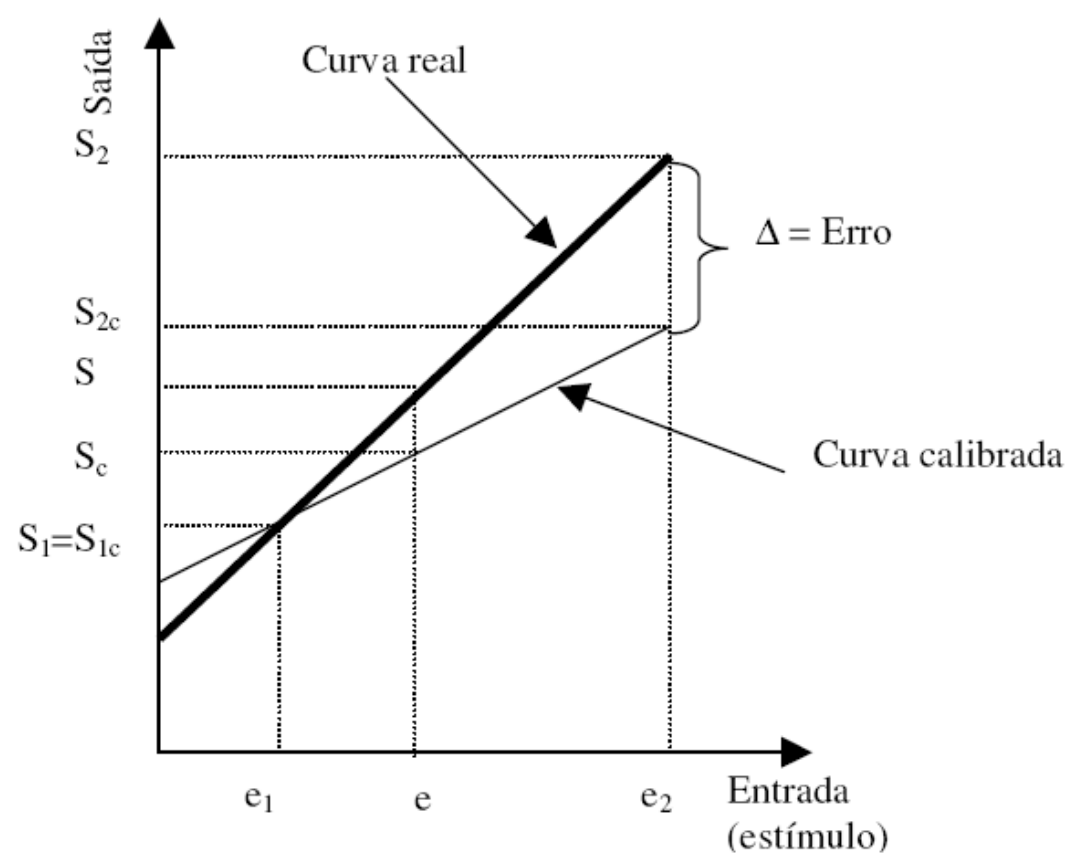

Figura 3.3- Erro de calibração em um sensor. 


\subsubsection{Erro de histerese}

É uma característica que certos sensores têm de não retornar a um valor inicial de saída quando o estímulo retorna a um valor inicial. Observe a figura 3.4, considere o ponto $P_{0}$. Ocorre acréscimo do estímulo levando o sensor de $P_{0}$ para $P_{1}$. Em seguida o estímulo retorna a seu valor inicial. Os valores da saída quando o estímulo aumenta são diferentes de quando o estímulo retorna a posição inicial. A histerese normalmente é causada por atrito e/ou mudanças estruturais nos materiais.

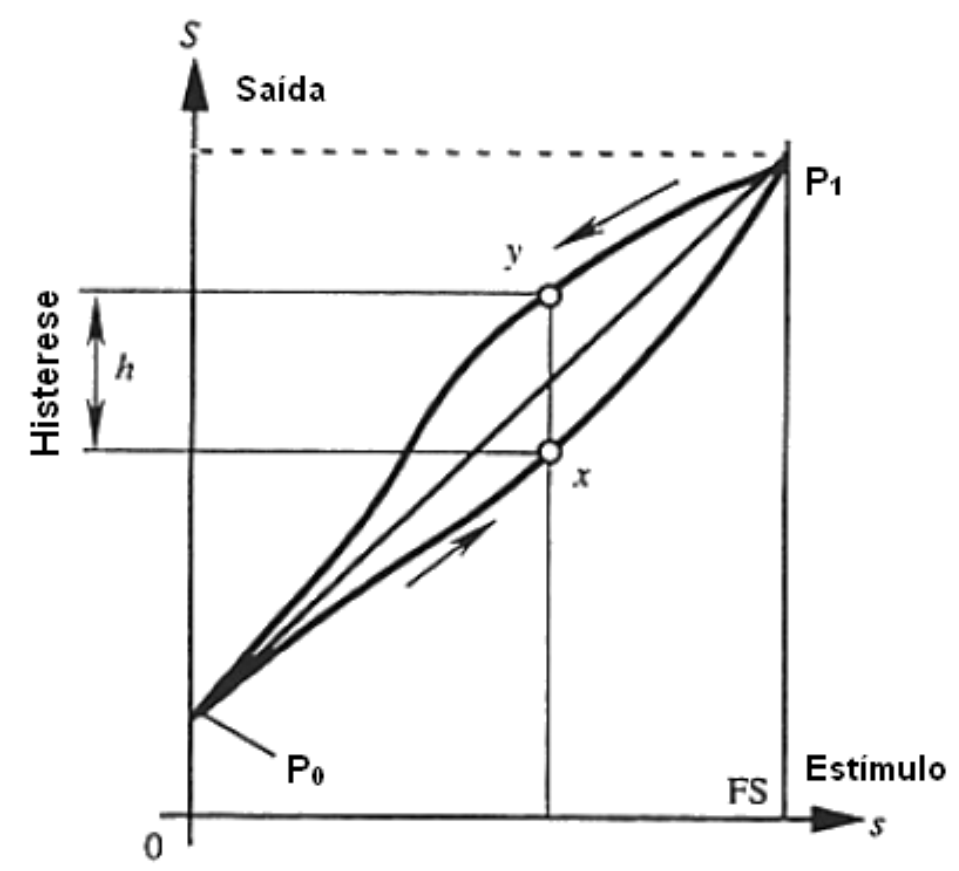

Figura 3.4- Função de transferência com histerese

\subsubsection{Não linearidade}

Não linearidade é o desvio máximo de uma função de transferência real em relação á reta de aproximação. Métodos estatísticos podem ser utilizados para determinar a reta que melhor se aproxima um conjunto de pontos medidos. 


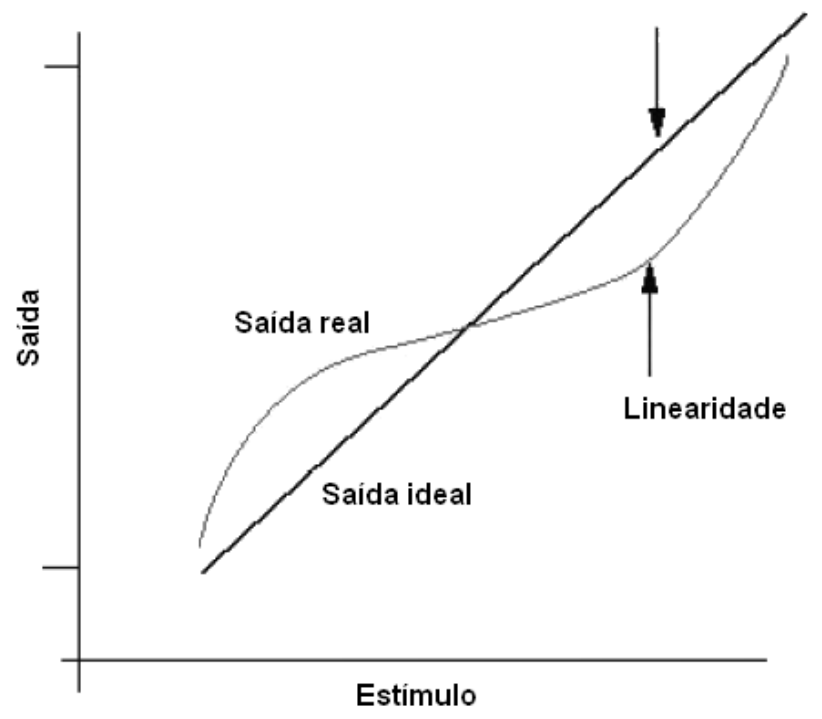

Figura 3.5- Função de transferência com efeito de não linearidade.

\subsubsection{Erro de repetitividade}

É a incapacidade de um sensor apresentar o mesmo valor em duas medições realizadas sob as mesmas condições. É expresso pela maior diferença de leitura em dois ciclos de calibração.

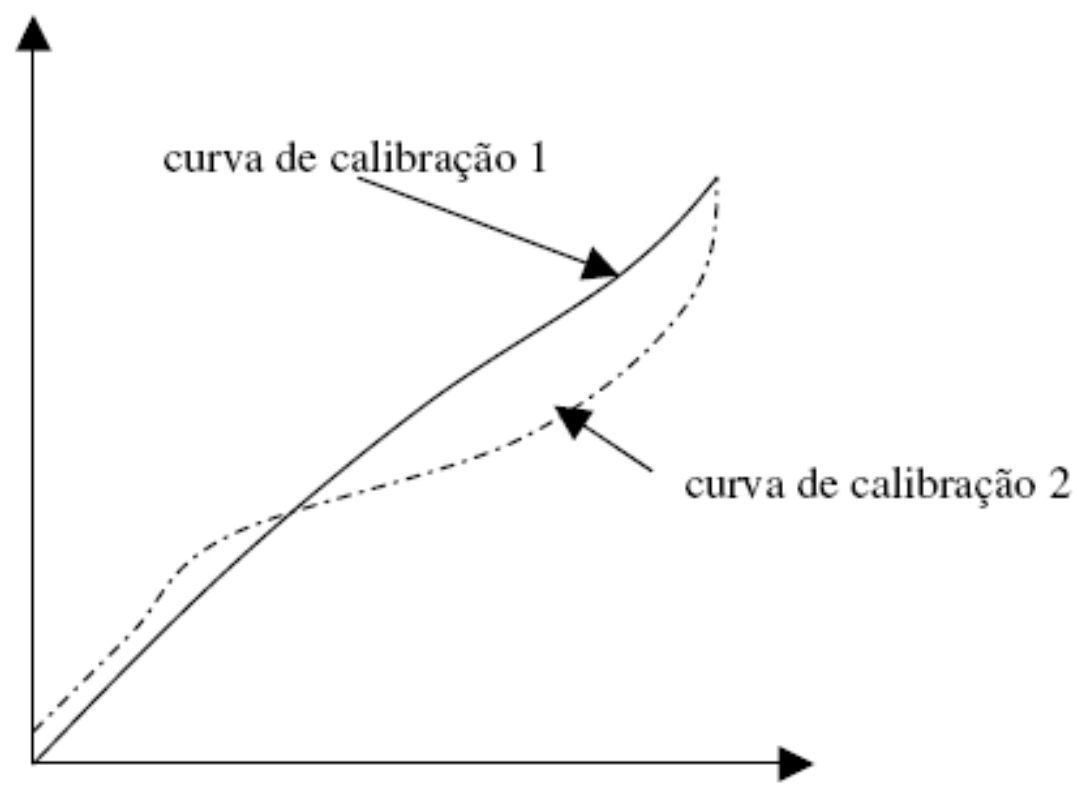

Figura 3.6- Erro de repetitividade 


\subsubsection{Reprodutibilidade}

É o grau de concordância entre os resultados das medições de um mesmo mensurando, efetuadas sob condições variadas de medição. As condições alteradas podem incluir: método de medição; observador; instrumento de medição; padrão de referência; local; condições de utilização; tempo.

\subsubsection{Resolução}

A resolução de um sensor é definida como o menor incremento do estímulo que o sensor é capaz de detectar. Em um sensor, quando o sinal de entrada (estímulo) varia continuamente, o sinal de saída varia em pequenos passos. A continuidade do sinal de entrada depende da resolução do sensor. Quando menor a resolução, mais descontínua será a curva de saída. A resolução pode ser expressa em bits quando se a saída for do tipo digital.

\subsubsection{Exatidão}

É o maior erro (ou desvio) esperado entre o valor medido com o sensor em questão e o valor verdadeiro. Em geral, o resultado de uma medição é somente uma aproximação ou estimativa do valor do mensurando. Assim, o resultado de uma medição só é completo quando acompanhado pela incerteza dessa estimativa.

\subsubsection{Incerteza de medição}

É um parâmetro associado ao resultado de uma medição que caracteriza a dispersão dos valores que podem ser razoavelmente atribuídos ao mensurando.

\subsection{DIELÉTRICOS}

Um dielétrico é um material no qual um campo elétrico não nulo pode existir. O dielétrico possui a capacidade de poder ser polarizado (TAREEV, 1979). As propriedades elétricas de um material dielétrico são normalmente descritas em termos da constante dielétrica (FRÖHLICH, 1968). Para a maioria dos materiais, a constante dielétrica independe da força do campo elétrico para uma ampla faixa de valores. Entretanto, se o campo é alternado, a grandeza dependerá da freqüência. Também há dependência com relação à temperatura (FRÖHLICH, 1968). 
Os efeitos de um dielétrico em um capacitor foram estudados por Faraday. Ele descobriu que quando o espaço entre as placas de um capacitor era preenchido por um dielétrico, a capacitância aumentava de um fator $\mathrm{K}$, que era característico de cada material (Tipler, 1990). Esse fator $\mathrm{K}$ ficou conhecido como constante dielétrica ou permitividade relativa. A permitividade de cada material $(\varepsilon)$ é determinada em relação à permitividade do vácuo $\varepsilon_{0}$ de maneira que $\varepsilon=\mathrm{K} \times \varepsilon_{0}$. (HALLIDAY; RESNICK, 1984). Daí o nome, permitividade relativa.

Tabela 3.1- Constantes dielétricas de dielétricos utilizados na caracterização do sensor

\begin{tabular}{|c|c|}
\hline Dielétrico & Constante dielétrica \\
\hline Água pura & 78,85 \\
\hline Etanol anidro & 24,3 \\
\hline Gasolina tipo A & 2 \\
\hline Querosene & 2 \\
\hline
\end{tabular}

\subsubsection{Polarização de moléculas do dielétrico}

Os materiais dielétricos podem ser polares ou apolares. Ambos têm a somatória de cargas nula, pois o total de cargas positivas é igual ao de negativas. Porém, nas moléculas polares, a distribuição de cargas positivas e negativas é diferente. $O$ centro de cargas positivas está separado do centro de cargas negativas por uma distância molecular d formando um dipolo elétrico permanente (HILL, 1969).

As moléculas do dielétrico de um capacitor sofrem efeito do campo elétrico. $\mathrm{Na}$ figura 3.7a são observadas moléculas polares na ausência de um campo elétrico. Neste caso, os dipolos das moléculas se orientam ao acaso (Hill, 1969). Já na figura 3.7b, o dielétrico está sob a ação de um campo elétrico. Neste caso, os dipolos tendem a se alinhar com o campo elétrico externo. A orientação, não é perfeita, pois as moléculas sempre estão sob agitação térmica. Isso indica que, no caso de moléculas polares, a orientação sob ação do campo elétrico depende da temperatura: quanto maior a temperatura, menor o alinhamento dos dipolos. No caso de moléculas apolares, a dependência com a temperatura não é tão pronunciada.

Ainda que o capacitor seja preenchido por um dielétrico apolar, suas moléculas sofrem polarização sob ação de um campo elétrico externo. Este é o chamado dipolo induzido resultando no deslocamento entre os centros de cargas 
negativas e positivas. O dipolo induzido sob ação de um campo elétrico externo também ocorre em dielétricos polares.

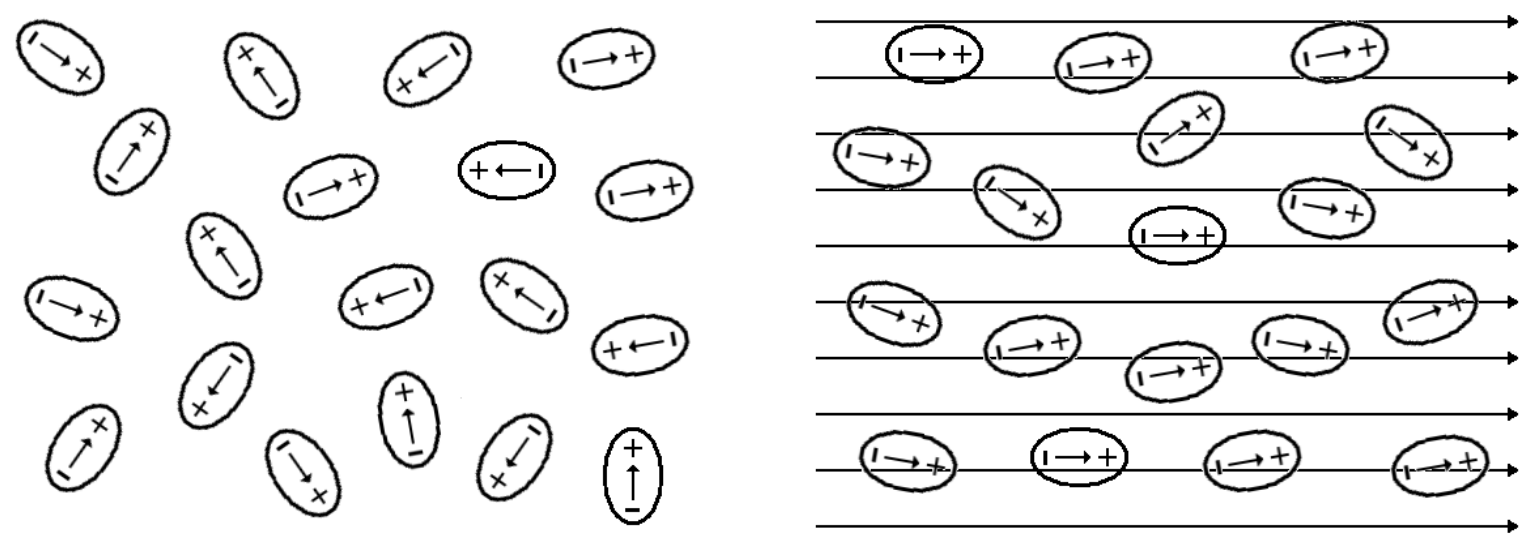

Figura 3.7- moléculas polares (a) na ausência de um campo elétrico. Os dipolos têm orientação aleatória; (b) com o campo elétrico, os dipolos tendem a se orientar alinhando-se com o campo.

Esse efeito microscópico de polarização induzida que afeta as moléculas de um material dielétrico pode ser expresso por uma grandeza vetorial chamada de "momento de dipolo elétrico", $\mu$, expressa como o produto da carga $q$ pelo deslocamento $\boldsymbol{d}$ entre os centros de cargas:

$$
\vec{\mu}=q \vec{d}
$$

Gallagher (1975) classifica os campos elétricos que podem ser aplicados aos dielétricos em três categorias: campos de baixa intensidade (até $100 \mathrm{kV} / \mathrm{m}$ ), campos de intensidade intermediária (até $2 \mathrm{MV} / \mathrm{m}$ ), e campos de alta intensidade (maior que $2 \mathrm{MV} / \mathrm{m}$ ). Nesta dissertação, todos os campos considerados estão na categoria de baixa intensidade.

Para campos de baixa intensidade, pode ser adotado o modelo que considera o momento de dipolo elétrico como sendo proporcional ao campo elétrico local $E_{L}$ (campo que atua localmente nas moléculas do dielétrico). Assim, o momento de dipolo pode ser expresso como (Solymar and Walsh, 1993):

$$
\vec{\mu}=\alpha \vec{E}_{L}
$$


onde $\alpha$ é a polarizabilidade. Há três tipos básicos de polarizabilidade que podem ocorrer nos dielétricos: polarizabilidade eletrônica $\alpha_{E}$, polarizabilidade molecular $\alpha_{M}$, e polarizabilidade de orientação $\alpha_{O}$.

A polarização eletrônica ocorre em todos os materiais, e consiste no acompanhamento da variação de campo elétrico pelos elétrons. Como os elétrons são muito leves, o tempo de resposta é muito curto, e esse efeito ocorre mesmo em altas freqüências.

A polarização molecular consiste em deformações nos espaçamentos das ligações químicas entre átomos com a aplicação do campo elétrico. Como a massa dos átomos ou íons envolvidos é considerável, esse efeito só pode ser observado em baixas freqüências.

A polarização de orientação ocorre em dielétricos polares (com dipolo permanente) ou em dielétricos apolares com dipolo induzido, e consiste no movimento de moléculas inteiras em líquidos ou gases de forma a acompanhar o campo elétrico. Só pode ser observado em freqüências muito baixas.

Assim a polarizabilidade total pode ser expressa com a seguinte soma:

$$
\alpha=\alpha_{E}+\alpha_{M}+\alpha_{o}
$$

Ao variar o campo elétrico a polarização do dielétrico também varia, mas não instantaneamente. A figura 3.8 mostra a dependência da polarização no tempo para um campo elétrico constante aplicado ao dielétrico a partir de um instante $t$.

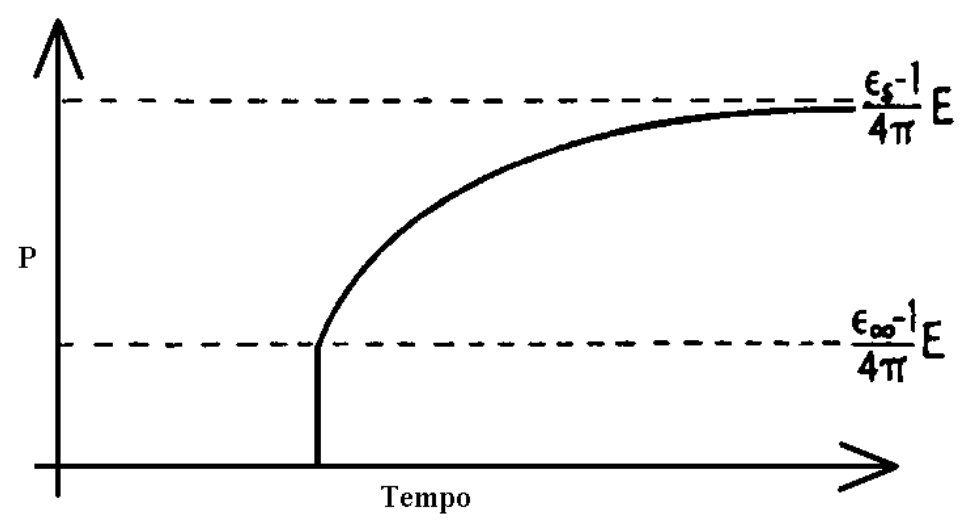

Figura 3.8- Dependência da polarização com o tempo quando o dielétrico está sob ação de um campo elétrico constante. 
Como resultante dos processos de polarização do dielétrico, há a um acúmulo de cargas nas superfícies do material dielétrico. Essas cargas são positivas na superfície voltada para a placa negativa do capacitor e negativas na superfície voltada para a placa positiva como mostra a figura 3.9.

Com isso, há formação de um campo E' oposto a $\mathbf{E}_{0}$. Portanto, o campo resultante $\mathbf{E}$ é igual à soma vetorial $\mathbf{E}_{0}+\mathbf{E}^{\prime}$ e seu módulo é menor que $\mathbf{E}_{0}$ de modo que $\mathrm{o}$ quociente entre $\mathbf{E}_{0}$ e $\mathbf{E}$ é igual à constante dielétrica do material como expresso na equação 3.5 .

$$
\frac{E_{0}}{E}=K
$$

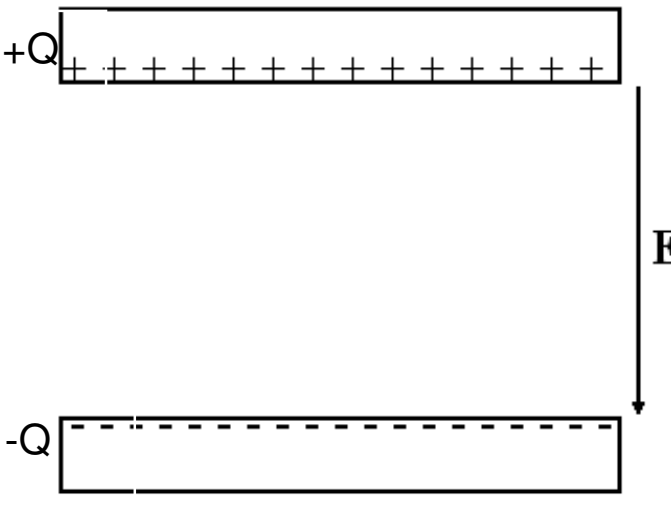

(a)

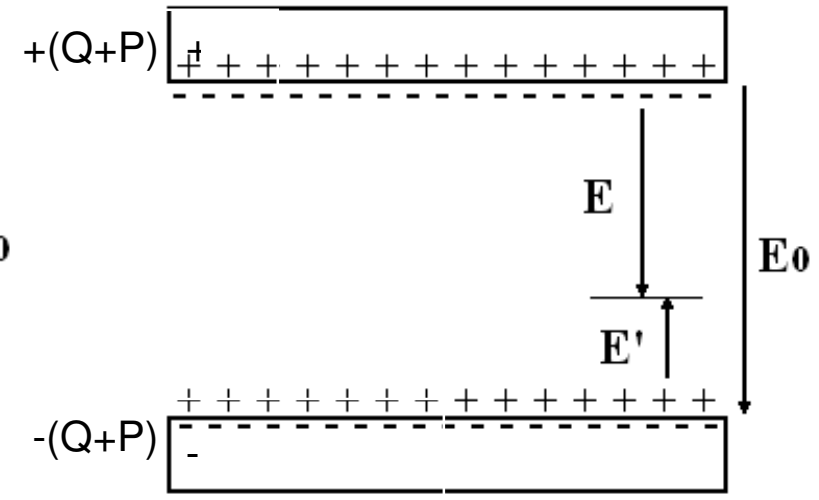

(b)

Figura 3.9 (a) Campo elétrico aplicado a um capacitor sem dielétrico, ocorre acúmulo de cargas nas superfícies das placas; (b) Campo elétrico aplicado em um capacitor com dielétrico, além das cargas acumuladas nas placas, há uma resultante de cargas induzidas nas superfícies do dielétrico, o que provoca um campo E' em sentido oposto a $\mathrm{E}_{0}$.

Assim, se for aplicada uma tensão elétrica $V$ aos eletrodos da figura 3.9(a), haverá a formação de cargas $+Q$ e $-Q$ nas superfícies internas dos eletrodos metálicos. Da definição de capacitância, um capacitor sem dielétrico (vácuo) apresentará uma capacitância $\mathrm{C}_{0}$ dada pela equação 3.6:

$$
C_{0}=\frac{Q}{V}
$$

Por outro lado, um capacitor que apresenta um dielétrico (polar ou apolar) entre suas placas terá carga $(Q+P)$, figura 3.9(b), com uma diferença de potencial $V$, onde $\mathrm{P}$ pode ser considerado como a quantidade de carga induzida na superfície do 
dielétrico devido a todos os efeitos de polarização. A capacitância será dada pela equação 3.7:

$$
C=\frac{Q+P}{V}
$$

Assim, a constante dielétrica $\mathrm{K}$ se relaciona com as capacitâncias de acordo com a equação 3.8:

$$
K=\frac{C}{C_{0}}=\frac{Q+P}{Q}
$$

Para um capacitor de placas planas que no vácuo têm sua capacitância dada pela equação 3.9, o novo valor de capacitância será dado pela equação 3.10:

$$
\begin{gathered}
C_{0}=\varepsilon_{0} \frac{A}{D} \\
C=K \varepsilon_{0} \frac{A}{D}
\end{gathered}
$$

onde $K \varepsilon_{0}$ é a permitividade do dielétrico.

Como um dielétrico polar possui os dois tipos de dipolos (induzido e permanente), sua constante dielétrica e, consequentemente, sua permitividade é mais alta comparada a dielétricos apolares (Hill, 1969).

\subsubsection{Dependência da permitividade com a frequência}

A orientação dos dipolos em um dielétrico não ocorre instantaneamente. Há um atraso tanto na formação dos dipolos induzidos de materiais apolares quanto no alinhamento dos dipolos permanentes de materiais polares, mostrado na figura 3.8, pois o deslocamento de cargas no dielétrico possui uma certa inércia (Fröhlich, 1968).

Se o campo aplicado é alternado, a polarização do dielétrico será dependente da freqüência. Se a freqüência for baixa, os três tipos de polarização (eletrônica, molecular, e de orientação) poderão acompanhar o campo. Por outro lado, em freqüências muito altas (banda ótica), apenas a polarização eletrônica consegue acompanhar o campo. Assim, a polarização e, conseqüentemente, a constante dielétrica diminui com o aumento da freqüência. 
Quanto mais baixa a freqüência, maior a polarização e mais alto será o valor da permitividade. Conseqüentemente maior será a capacitância do capacitor preenchido por esse dielétrico.

A permitividade de dielétricos também é dependente da temperatura, pois a temperatura interfere na agitação térmica de líquidos e gases.

Em dielétricos líquidos, a posição de cada molécula é correlacionada com outras em suas proximidades (Frohlich, 1968). Analises de raio-X mostram que nas vizinhança de uma molécula no estado líquido, há um arranjo ordenado semelhante a uma estrutura cristalina. Entretanto essa rede cristalina tende a desaparecer para moléculas mais distantes (Frohlich, 1968). Além disso, nos líquidos os dipolos têm maior liberdade para se reorientar (Hill, 1969). Esse fenômeno também interfere na polarização dos dipolos fazendo com que dielétricos líquidos tenham um comportamento relativamente diferenciado em relação aos sólidos no que diz respeito à variação da permitividade com a freqüência e a temperatura.

\subsubsection{Condução em dielétricos líquidos}

Esta seção trata da condução elétrica em materiais dielétricos líquidos sob a ação de um campo elétrico de baixa intensidade (até $100 \mathrm{kV} / \mathrm{m}$ ). De acordo com Gallagher (1975), as impurezas encontradas nesses dielétricos líquidos é que são as maiores responsáveis por eventuais processos de condução. Essas impurezas podem ser substâncias iônicas dissociadas (especialmente em dielétricos polares) ou partículas sólidas.

Em dielétricos apolares, como óleos, o oxigênio gasoso e partículas sólidas são os contaminantes principais que podem contribuir para a condução elétrica. Entretanto, essa condução é de intensidade muito baixa para os valores de campo elétrico aplicados neste trabalho. Assim, não há problema de ruptura de dielétrico, e esses líquidos apolares podem ser considerados bons isolantes elétricos.

Em dielétricos polares, os contaminantes principais são compostos iônicos e partículas sólidas. Os compostos iônicos podem se dissociar facilmente em dielétricos polares líquidos tais como água e álcoois. Na água o problema é mais pronunciado devido à grande quantidade de ligações intermoleculares por pontes de hidrogênio e por seu momento de dipolo permanente ser bem mais intenso que o 
álcool. Assim, apesar da água ter alta constante dielétrica, não é um isolante muito bom. 


\section{PRINCÍPIO DE FUNCIONAMENTO E MODELAGEM DO SENSOR}

\subsection{PRINCÍPIO DE FUNCIONAMENTO DO SENSOR}

Neste trabalho é proposto um sensor do tipo capacitivo, com eletrodos interdigitados, para analisar uma mistura de combustíveis. O objetivo é desenvolver um sensor capacitivo que utilize o combustível a ser analisado como seu dielétrico. Desta forma, variações na mistura do combustível resultam em variações na capacitância do sensor.

Optou-se por preparar o sensor por técnicas de microfabricação sobre um substrato de alumina. Uma das formas mais convenientes de se formar os eletrodos do capacitor para serem preenchidos pelo combustível (dielétrico) é usando a configuração de eletrodos interdigitados. Nessa configuração os eletrodos são formados por deposição de filmes ou por eletrodeposição. Assim, optou-se por construir o sensor com essa configuração, que permite que o combustível preencha o espaçamento ("gap") entre os eletrodos. Dessa maneira, mudanças na composição do combustível resultam em mudanças na capacitância medida pelo sensor. O sensor deve ter dimensões relativamente pequenas de forma resultar num dispositivo miniaturizado. Nos protótipos fabricados para testes, a altura dos eletrodos corresponde à espessura do filme do metal eletrodepositado, e varia entre $25 \mu \mathrm{m}$ e $40 \mu \mathrm{m}$; o espaçamento ("gap") entre os eletrodos varia entre $50 \mu \mathrm{m}$ e $150 \mu \mathrm{m}$; a largura dos eletrodos varia entre $50 \mu \mathrm{m}$ e $100 \mu \mathrm{m}$; e o comprimento de emparelhamento dos eletrodos é de $800 \mu \mathrm{m}$. A escolha dessas dimensões está relacionada com os resultados obtidos na etapa de projeto (modelagem e simulação), com limitações de recurso para os processos de fabricação, e com a instrumentação para caracterização dos protótipos.

A altura dos eletrodos é limitada pelo processo de fabricação, que utiliza fotorresistes especiais para camadas espessas e para fotolitografia com expositora de luz ultravioleta. O espaçamento entre as placas não pode ser muito reduzido para que não impeça a penetração do combustível por entre as placas.

A figura 4.1 mostra uma vista de topo da estrutura, onde $\mathbf{G}$ é o espaçamento entre eletrodos, L a largura de um eletrodo e LL é o comprimento de 
emparelhamento entre dois eletrodos que formam um capacitor. Em todos os protótipos, o espaçamento entre a ponta de um eletrodo e a base do pente emparelhado é de $200 \mu \mathrm{m}$. A figura 4.2 mostra uma visão 3D de dois pentes interdigitados emparelhados. Sua estrutura é semelhante à de um "comb-drive", porém é fixa. Com esta configuração e aplicando uma diferença de potencial entre os eletrodos, há a formação de um campo elétrico nas regiões onde há emparelhamento entre os dedos. Desta maneira em cada par de pentes interdigitados, formam-se dezenas de capacitores em paralelo. Uma camada de pentes emparelhados, como a que é esquematizada nas figuras 4.1 e 4.2, apresenta inúmeros capacitores (de 100 a 200). Além disso um sensor apresenta várias camadas desses pentes ligados por trilhas como pode ser visto na figura 4.3. O uso do formato de eletrodos interdigitados permitiu aumentar significativamente a capacitância chegando a centenas de pico faraday.

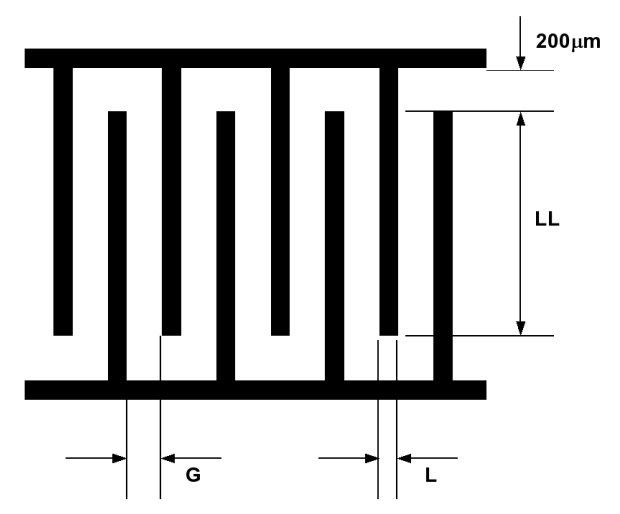

Figura 4.1- Configuração dos eletrodos interdigitados do sensor.

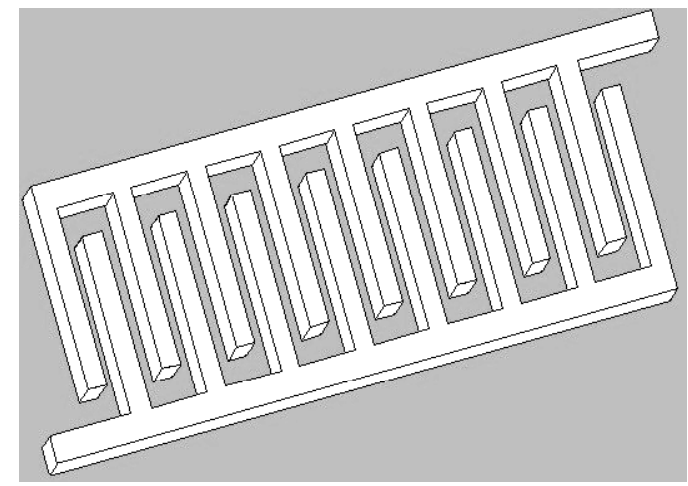

Figura 4.2- Modelo 3D de dois pentes interdigitados emparelhados do sensor. 


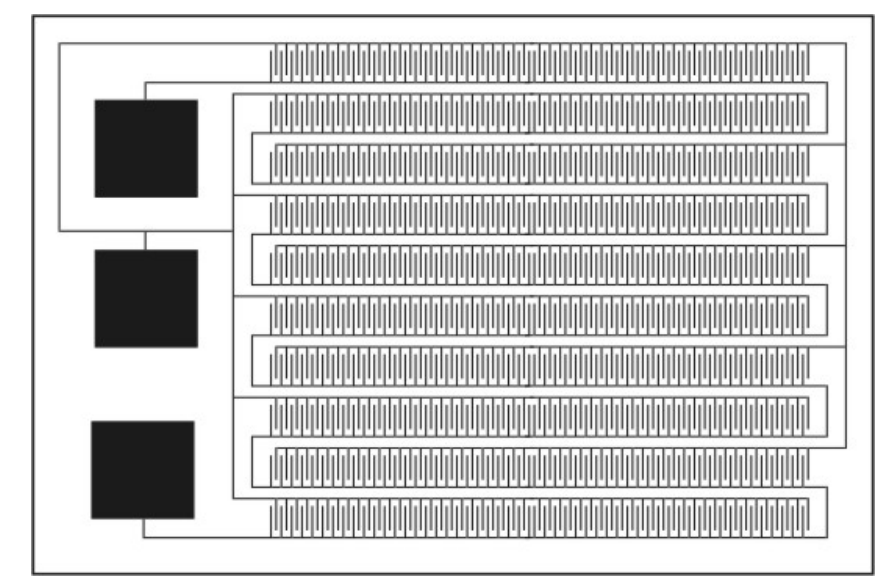

Figura 4.3 Arranjo completo de um sensor típico.

Ao ser imerso na amostra de combustível, o interdigitado tem os "gaps" (espaços entre os dedos) preenchidos pelo mesmo. Desta maneira, o combustível agirá como o dielétrico dos capacitores. Uma mistura adequada do combustível terá um valor característico de capacitância. De modo que um combustível adulterado apresentará valores de capacitância e outros parâmetros de impedância diversos daqueles apresentados pelo combustível certificado. Um bom exemplo é a mistura álcool-gasolina utilizada no Brasil. É muito comum a adulteração da gasolina com a adição indiscriminada de álcool além da quantidade permitida pala ANP, que varia entre $20 \%$ e $25 \%$ em volume. A constante dielétrica da gasolina tem valor $\mathrm{K}_{\mathrm{g}}=2$ e a do álcool $\mathrm{K}_{\mathrm{et}}=24,3$ (WEAST, 1985; MATWEB, 2007). Uma mistura das duas substâncias apresentará uma constante dielétrica intermediária a estes dois valores (BECKMANN, 1997). Gasolina com a quantidade correta de etanol apresentará seu valor característico de constante dielétrica. Uma quantidade de etanol acima da permitida elevará esse valor de constante dielétrica que será percebida pela medição da capacitância.

\subsection{MODELAGEM DO SENSOR}

Foi elaborado um modelo básico deste sensor proposto com o objetivo de realizar algumas simulações computacionais para verificação de desempenho. Para elaboração do modelo foram feitas algumas considerações. Observando-se a estrutura do sensor, mostrada nas figuras 4.1 e 4.2, pode-se perceber a formação de 
capacitores nas regiões onde há emparelhamento dos eletrodos, como mostra a figura 4.4 (capacitância principal).

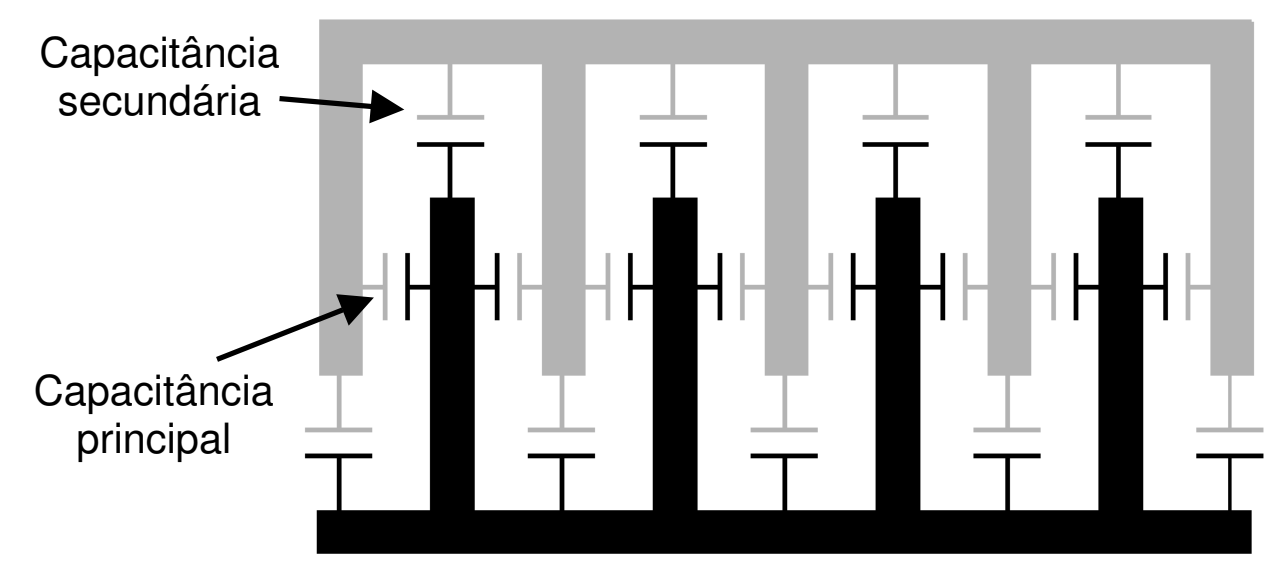

Figura 4.4- Modelo de capacitores considerado para a simulação do comportamento elétrico sensor

Também, é importante considerar a formação de capacitores entre as pontas dos dedos e a base do outro pente de eletrodos (capacitância secundária). Esse valor de capacitância é muito menor que a capacitância principal. Há um grande espaçamento ente a ponta de um dedo e a base do pente correspondente (tipicamente $200 \mu \mathrm{m})$ e o comprimento de emparelhamento é pequeno $(50 \mu \mathrm{m}$ a $100 \mu \mathrm{m})$. Mas, como existe uma grande quantidade desses capacitores, é importante considerá-los para aprimorar o modelo.

As simulações apresentadas neste trabalho foram realizadas para modelos bidimensionais, usando-se o aplicativo ANSYS baseado no Método dos Elementos Finitos. Testes prévios indicaram que havia boa concordância entre os valores obtidos por simulações de modelos bidimensionais e de modelos tridimensionais. Como os modelos tridimensionais são muito mais complexos, exigindo grande quantidade de operações e um longo tempo de processamento, foi dada preferência aos modelos bidimensionais. Foi considerado um corte de uma secção transversal dos eletrodos, como mostra a figura 4.5. B é um comprimento extra deixado entre a extremidade do modelo e os eletrodos das extremidades, $\mathbf{L}$ é a largura de um eletrodo, G o espaçamento entre um par de eletrodos, SS a espessura do substrato e DD a espessura do dielétrico (combustível). 


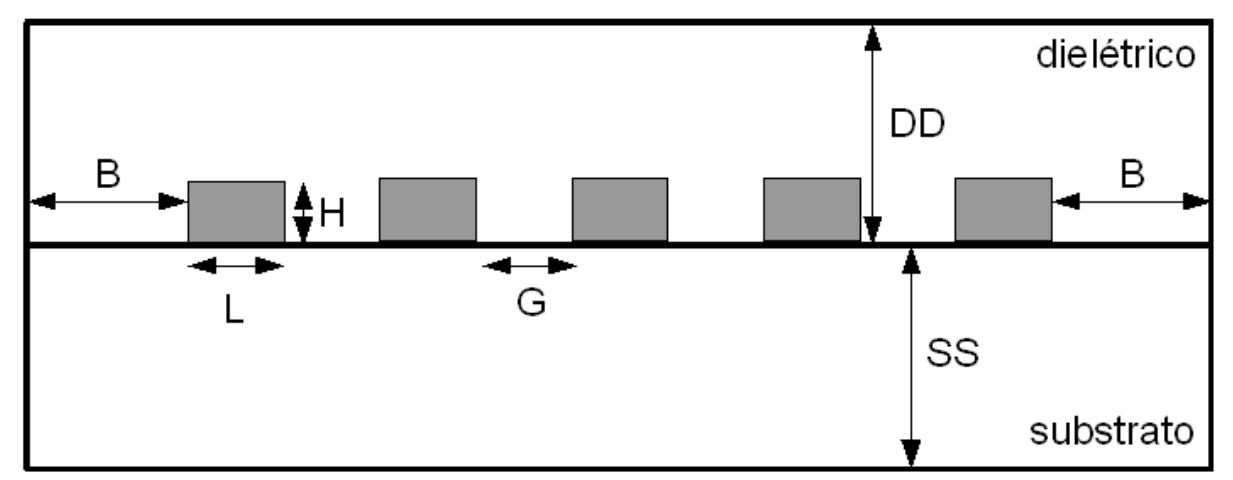

Figura 4.5- Modelo montado para a simulação do comportamento elétrico do sensor.

Foram realizadas simulações para modelos com um número razoável de eletrodos, geralmente 9 ou 21. Dessa forma, foram obtidas as capacitâncias para um sensor contendo 8 ou 20 capacitores, respectivamente. O ANSYS pode realizar simulações bidimensionais para obtenção da distribuição do potencial eletrostático, da distribuição de campo elétrico, e para cálculo da capacitância por unidade de comprimento (profundidade) dos eletrodos. O resultado deve ser multiplicado pelo comprimento de emparelhamento entre eletrodos (LL) para obtenção da capacitância do modelo. Por outro lado, para obter um valor de capacitância correspondente ao protótipo real, com milhares de capacitores, o valor da simulação é dividido pelo número de capacitores do modelo e multiplicado pelo número total de capacitores da amostra que se queira simular.

Para as simulações bidimensionais foi escolhido o elemento denominado PLANE121 do ANSYS, recomendado para análises eletrostáticas. A dimensão da malha foi escolhida como sendo $8 \mu \mathrm{m}$ ou $10 \mu \mathrm{m}$, dando uma boa relação entre tempo de processamento e exatidão dos resultados. Durante a simulação, a discretização em malhas é feita apenas para os materiais dielétricos (combustível e substrato de alumina), enquanto que os eletrodos são deixados inalterados. Para o cálculo do potencial elétrico e do campo elétrico, são aplicadas as condições de contorno $0 \mathrm{~V}$ e 0,3V nas superfícies de eletrodos alternados, como mostrado na figura 4.6. 


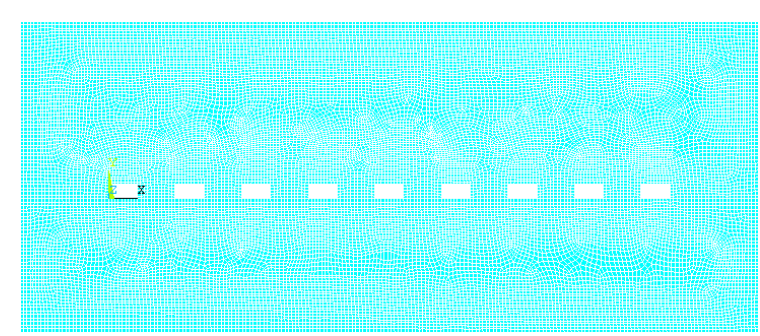

(a)

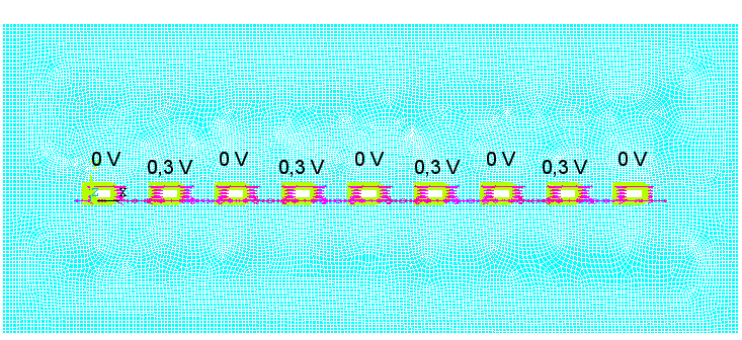

(b)

Figura 4.6- Discretização no ANSYS para: (a) cálculo da capacitância, (b) determinação do potencial e do campo elétrico.

De maneira geral, para o substrato foi adotada constante dielétrica da alumina $\mathrm{K}_{\mathrm{al}}=9,9$, para o dielétrico, constante dielétrica do etanol $\left(\mathrm{K}_{\mathrm{et}}=24,3\right)$, ou $\mathrm{K}=2$ (querosene, aguarrás, gasolina A).

Foram realizados dois tipos de simulação. Um variando parâmetros do sensor como G, H e L para avaliar a influência de cada um deles na capacitância. Outro tipo de simulação foi realizado utilizando-se as dimensões de amostras utilizadas na caracterização. O objetivo é comparar resultados experimentais com simulados.

As simulações para comparação com resultados experimentais foram realizadas para o etanol anidro e para o querosene. Foram escolhidos esses dois compostos por serem os que apresentam valores de constante dielétrica mais imunes aos efeitos de eventuais contaminantes. A constante dielétrica da água apresenta grande variação dependendo de sais dissociados e de partículas contaminantes, inviabilizando a comparação com medidas experimentais. Por outro lado, as misturas de combustíveis apresentam constantes dielétricas com valores intermediários difíceis de serem estimados por cálculos, sendo também inviabilizados para comparação com resultados experimentais. $O$ mesmo acontece com a gasolina $\mathrm{C}$ que é uma mistura de gasolina $\mathrm{A}$ (pura) e etanol. 


\section{PROCEDIMENTO EXPERIMENTAL}

Esta seção descreve o processo de fabricação de protótipos, bem como os procedimentos de caracterização dos micro-sensores.

\subsection{MÁSCARA}

As máscaras utilizadas na fabricação foram desenhadas em um software tipo cad e impressas em fotolito. Foram desenhadas máscaras positivas e negativas para que durante a fabricação houvesse também a possibilidade de utilização dos dois tipos de fotorresiste, conforme a necessidade.

\subsection{FABRICAÇÃO}

Protótipos do sensor foram fabricados no laboratório de Microfabricação do Laboratório Nacional de Luz Síncrotron (LNLS) localizado em Campinas interior de São Paulo. As amostras foram fabricadas em substrato de alumina utilizando-se técnicas de microfabricação. Os eletrodos são fabricados em níquel por eletrodeposição. $O$ processo de fabricação segue essencialmente as seguintes etapas:

Deposição de uma camada de Titânio para promoção de adesão com o substrato

Deposição de uma camada condutora de Ouro

Fotolitografia

Deposição de níquel por eletrodeposição

Remoção do Fotorresiste

Remoção da camada de Ouro

Remoção da camada de Titânio

A figura 5.1 ilustra essas etapas de fabricação, que serão descritas mais detalhadamente a seguir. 


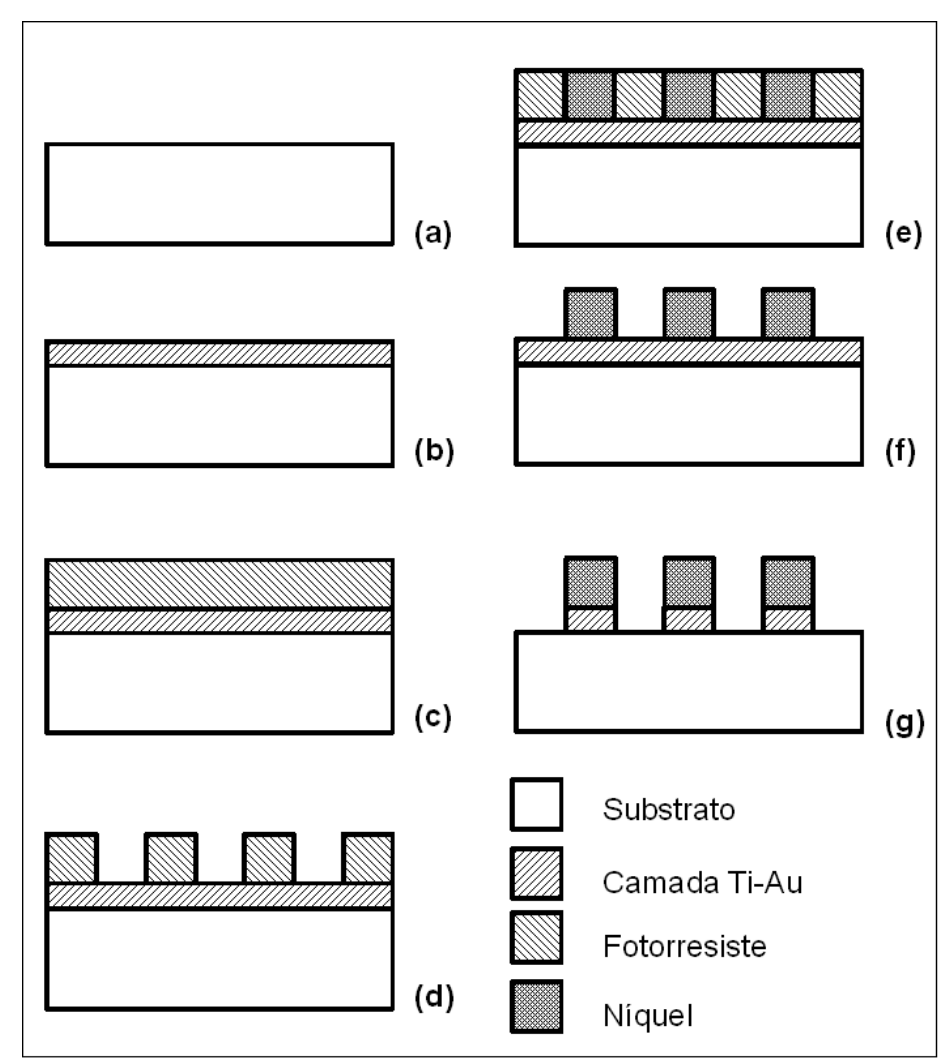

Figura 5.1 - Perfil das estruturas durante etapas de fabricação; a) lâmina antes do processo; b) após etapas 1 e 2 Deposição das camadas titânio-ouro; c) após a deposição do fotorresiste que faz parte da litografia; d) após a revelação do fotorresiste completando a litografia; e) após processo de eletro-deposição; f) após a remoção do fotorresiste; g) após a remoção das camadas titânio-ouro.

\subsubsection{Deposição de camadas de adesão de Titânio e de ouro}

As camadas de Titânio e de ouro foram depositadas por sputtering seguindo padrões internos do LNLS. A função dessas camadas é promover boa adesão e servir como suporte ao níquel que será depositado a seguir já que o processo de eletrodeposição utilizado necessita de uma superfície condutora.

\subsubsection{Litografia com radiação ultra-violeta}

Na litografia foi utilizada uma expositora Karl Suss MJB3UV 300. A lâmpada tem comprimento de onda de 250 a 400nm. Foram utilizados dois tipos de fotorresiste, o fotorresiste negativo SU-8 25 da marca Micro Chem Corp. e o fotorresiste positivo AZ4620 da marca Clariant. O procedimento de se utilizar os dois tipos de fotorresiste se deve às características de cada um deles. O SU-8 apresenta a vantagem de oferecer maior espessura e paredes mais retas após a revelação. Por outro lado, o AZ4620 apresenta maior facilidade de remoção. Assim, o processo 
de fabricação utilizando fotorresiste negativo SU-8 tende a produzir amostras de melhor qualidade e capacitância mais alta. Porém, a remoção do SU-8 foi extremamente difícil mesmo utilizando agitação por ultra-som. A litografia apresenta algumas variações de um fotorresiste para outro. Por isso a litografia com cada um deles será descrita separadamente a seguir.

\subsubsection{Litografia com Fotorresiste negativo NANO SU-8 25}

$O$ fotorresiste negativo utilizado pode atingir espessuras de aproximadamente $44 \mu \mathrm{m}$ (dado pelo fabricante). A litografia com esse tipo de fotorresiste segue essencialmente as seguintes etapas:

\section{1- Aplicação do fotorresiste}

O fotorresiste é aplicado sobre a lâmina presa ao spinner. Então o spinner é acionado a 1000rpm por 30 segundos a fim de se obter uma espessura entre $30 \mu \mathrm{m}$ e $40 \mu \mathrm{m}$.

\section{2- Pré-baking}

Após a aplicação, o SU-8 precisa ser aquecido a $95^{\circ} \mathrm{C}$ tomando-se o cuidado de evitar trincas devidas a choque térmico. Isso ocorre por causa da diferença entre os coeficientes de expansão térmica do fotorresiste e do substrato. Por isso deve ser feita uma rampa de temperatura.

Como as placas aquecedoras utilizadas não têm rampa de temperatura, foram utilizadas duas placas aquecedoras com temperaturas diferentes. Uma das placas foi aquecida à temperatura de $65^{\circ} \mathrm{C}$. As lâminas são colocadas nela durante aproximadamente 5 minutos. Após esse tempo, as lâminas são colocadas na outra chapa, que está aquecida à $95^{\circ} \mathrm{C}$. Nesta chapa, as lâminas ficam por 15 minutos. Após esse tempo, as lâminas voltam para a chapa de $65^{\circ} \mathrm{C}$ e ficam nela por mais 5 minutos. Após isso as lâminas são retiradas da chapa e resfriadas à temperatura ambiente em uma caixa de isopor para que resfrie mais lentamente. 


\section{3- Exposição à luz ultravioleta}

Após o pré baking, as amostras com SU-8 foram expostas à luz ultravioleta na expositora. A potência é $9,5 \mathrm{mWcm} 2$ e o comprimento de onda $300 \mathrm{~nm}$. O tempo de exposição foi de aproximadamente 40 segundos.

\section{4- Pós baking}

Após a exposição as lâminas devem voltar para as placas aquecedoras (exigência desse tipo de fotorresiste). As lâminas ficam 15 minutos na placa de $95^{\circ} \mathrm{C}$ depois 3 minutos na placa de $65^{\circ} \mathrm{C}$. Após o pós baking as lâminas são resfriadas à temperatura ambiente no isopor.

\section{5- Revelação}

$\mathrm{Na}$ revelação é utilizado o SU-8 Developer, revelador fornecido pelo fabricante do fotorresiste. A revelação é feita à temperatura ambiente sob agitação. O tempo de revelação é de aproximadamente 4 minutos.

\subsubsection{Litografia com Fotorresiste positivo AZ 4620}

O fotorresiste positivo pode atingir espessuras de aproximadamente $35 \mu \mathrm{m}$ (dado pelo fabricante). Isso é uma desvantagem se comparado ao fotorresiste SU-8. No entanto, esse fotorresiste é removido muito mais facilmente que o SU-8. A litografia com esse tipo de fotorresiste segue as seguintes etapas:

\section{1- Aplicação de promotor de aderência: HMDS (hexamethyldisilazane)}

A aplicação do HMDS foi realizada com o spinner com rotação de 2000rpm durante 30 segundos.

\section{2- Baking 1}

A lâmina é colocada na placa aquecedora a $95^{\circ} \mathrm{C}$ por 5 minutos. $\mathrm{O}$ resfriamento à temperatura ambiente é feito na caixa de isopor. 


\section{3- Aplicação o fotorresiste}

Após a evaporação do solvente do HMDS, é aplicado o fotorresiste positivo. A rotação do spinner é 2000rpm por 30 segundos para espessuras em torno de $10 \mu \mathrm{m}$. Para espessuras em torno de $35 \mu \mathrm{m}$, a rotação começa em 200rpm pelos 27 primeiros segundos sendo elevada para 1000rpm nos últimos 3 segundos.

\section{4- Baking 2}

Após a aplicação do fotorresiste, as lâminas vão para a placa aquecedora a $45^{\circ} \mathrm{C}$ por 4 minutos e depois a $90^{\circ} \mathrm{C}$ por 1 hora.

\section{5- Exposição à luz ultravioleta}

Para este fotorresiste, utilizou-se a mesma expositora que para o fotorresiste negativo. O tempo de exposição foi de 240 segundos. O comprimento de onda é $300 \mathrm{~nm}$. A potência é $9,5 \mathrm{~mW} / \mathrm{cm}^{2}$.

\section{6- Revelação}

$\mathrm{Na}$ revelação foi utilizado o revelador $\mathrm{AZ} 400 \mathrm{~K}$, revelador fornecido pelo fabricante do fotorresiste, na proporção de 1 parte de revelador para 3 partes de água. Esse processo foi realizado em temperatura ambiente por aproximadamente 5 minutos sob agitação magnética.

\section{7- Hard Baking}

Após a revelação, a amostra deve voltar à placa aquecedora e permanecer a $90^{\circ} \mathrm{C}$ por 10 minutos. Após esse tempo deve ser colocada no isopor para que se resfrie até a temperatura ambiente.

\subsubsection{Eletrodeposição}

Após a litografia, as lâminas apresentam um molde de fotorresiste. A próxima etapa é a deposição dos eletrodos de níquel. O metal é depositado por eletrodeposição sobre a camada de ouro preenchendo o molde formado pelo fotorresiste. Foi utilizado um banho Watts contendo a composição listada na tabela 5.1. Em uma primeira geração de sensores, o banho de níquel foi agitado através de um agitador magnético. Em uma segunda geração o processo de agitação foi 
otimizado através de um sistema de refluxo. A solução sai da cuba, passa por uma bomba, responsável pelo movimento, e retorna à cuba. Esse procedimento melhora a velocidade e a qualidade da deposição, pois tais parâmetros sofrem grande influência da agitação do banho.

Tabela 5.1- Composição do banho Watts utilizado na deposição de níquel.

$\begin{array}{cc}\text { Sulfato de Níquel } & 300 \mathrm{~g} \\ \text { Cloreto de Níquel } & 60 \mathrm{~g} \\ \text { Ácido bórico } & 45 \mathrm{~g} \\ \text { Abrilhantador DWK 720 } & 2 \mathrm{ml} \\ \text { Nivelador DWK 720 } & 10 \mathrm{ml} \\ \text { Molhador DWK 720 } & 6 \mathrm{ml}\end{array}$

A medida em que vai sendo depositado, o níquel vai preenchendo o molde deixado pelo fotorresiste e dando forma ao sensor. Quando a camada de níquel atinge a altura da camada de fotorresiste, a eletrodeposição deve ser interrompida. Caso contrário, as paredes de níquel não cresceriam mais verticalmente, mas começariam a crescer também para os lados dificultando a remoção do fotorresiste e causando curtos-circuitos.

As eletrodeposições foram realizadas utilizando-se densidades de corrente de $23 \mathrm{~mA} / \mathrm{cm}^{2}$ a $58 \mathrm{~mA} / \mathrm{cm}^{2}$. O tempo total para o crescimento de cada lâmina foi de aproximadamente 1 hora a uma hora e meia. $O$ crescimento foi realizado em etapas de 20 minutos e as vezes 10 minutos. Após cada etapa, a espessura era conferida com o perfilômetro, um Dektak3 ST. Esse equipamento também foi utilizado para medir a espessura do fotorresiste e das amostras depois de fabricadas.

\subsubsection{Remoção do fotorresiste}

Após o crescimento do níquel o fotorresiste é retirado. Para retirar o fotorresiste negativo SU-8, foi utilizado o removedor fornecido pelo fabricante com o auxilio de ultra-som. Em geral a remoção demora várias horas.

Quanto ao fotorresiste positivo, este foi retirado com acetona. Sua remoção, bem mais simples, é realizada em alguns segundos. 


\subsubsection{Remoção das camadas Titânio-ouro}

Após o crescimento do níquel e remoção do fotorresiste, as camadas titânioouro devem ser removidas. $\mathrm{O}$ processo de remoção destas camadas é rápido. $\mathrm{A}$ camada de ouro foi removida utilizando-se uma solução comercial da marca Degussa composta de $\mathrm{KCN}$, água e um sal não revelado pelo fabricante. A camada de titânio foi removida por uma solução de HF 10\%. Estas soluções removem seletivamente o ouro e o titânio dispensando a utilização de máscaras.

A remoção dessas camadas retira o curto-circuito e deixa pronta a estrutura do sensor.

\subsection{CARACTERIZAÇÃO}

Os protótipos fabricados foram utilizados em diversas medições utilizando um medidor RLC, modelo PM6306 da FLUKE. A faixa de freqüência é de $50 \mathrm{~Hz}$ a $1 \mathrm{MHz}$, com aplicação de tensão senoidal de 0 a $2 \mathrm{~V}$ rms. Pode, também, ser aplicada uma tensão $\mathrm{CC}$ de bias de 0 a $4 \mathrm{~V}$. $\mathrm{O}$ instrumento possui assessório para medição de resistência CC. Foram realizadas medições da capacitância, do ângulo de fase e da resistência do combustível. $O$ equipamento possui interface serial através da qual foi conectado a um computador. A linguagem de programação utilizada na interface entre o computador e o instrumento foi QBasic em ambiente MS-DOS, seguindo o manual de programação do instrumento. O sistema operacional DOS, apesar de antigo, é muito adequado à tarefa de aquisição de dados de instrumentos de medição. Esse sistema operacional não é multi-tarefas, o que o faz ficar concentrado na conexão com o equipamento no momento das medições. A montagem do aparato de medição pode ser visto na figura 5.2.

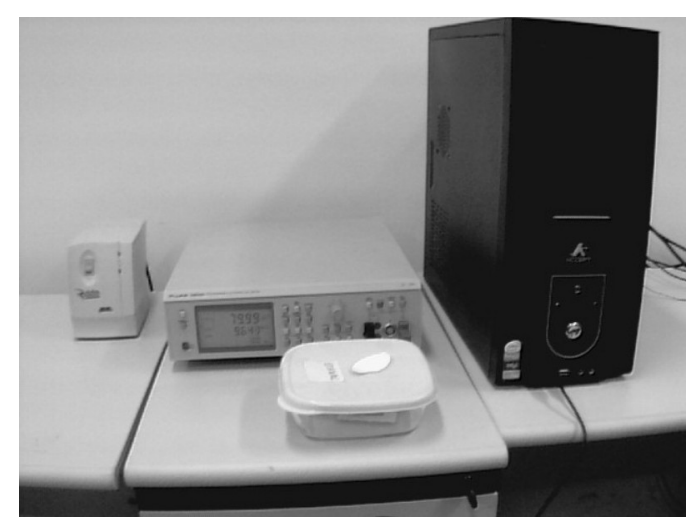

Figura 5.2- Aparato utilizado nas medições. 
Para realizar as medições, fios condutores foram soldados aos contatos das amostras. Foi utilizado um recipiente fechado para evitar evaporação. Foram desenvolvidos diferentes programas para a aquisição de dados. Através desses programas, é possível variar a amplitude e freqüência do sinal CA enquanto se mede capacitância, ângulo de fase e resistência. Também é possível aplicar um sinal de corrente contínua (CC) adicional durante as medições (tensão de bias). 0 APÊNDICE B deste trabalho mostra exemplo de rotina utilizada.

Foram realizadas medições em dois tipos de combustíveis utilizados no Brasil, o álcool combustível e a gasolina C. Inicialmente, foi obtida a curva de calibração utilizando-se álcool anidro grau PA (adquirido de um distribuidor de produtos químicos) de concentração 99,5\% (em massa) e água deionizada. Também, foi adquirido álcool hidratado combustível de um posto certificado. Quanto à gasolina, foi utilizada uma amostra obtida em um posto certificado da Grande São Paulo; e foram adquiridos querosene e aguarrás, vendidos comercialmente como solventes, para simulação de adulteração da gasolina. Foram realizadas medições com a gasolina no estado em que veio do posto (gasolina tipo C, com adição de até $23 \%$ em volume de álcool anidro), e também com adição controlada de quantidade adicional de álcool anidro grau PA, querosene e aguarrás. 


\section{RESULTADOS DE SIMULAÇÕES}

A simulação computacional oferece a possibilidade de analisar a sensibilidade de diferentes configurações geométricas de protótipos antes de sua fabricação. Nestas simulações, foram levadas em conta diversas restrições impostas pelos processos de microfabricação em instalações a que o grupo tem acesso. Assim, foi

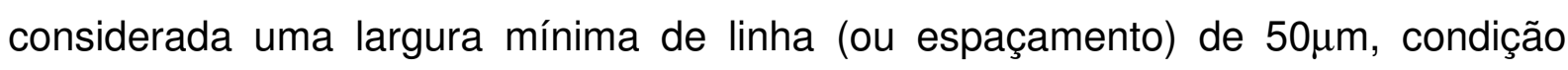
imposta pelo tipo de máscara utilizado, ou seja, fotolito.

Além disso, foram consideradas duas limitações do processo de eletrodeposição de níquel para formação dos eletrodos interdigitais. Por experiências anteriores de trabalhos em conjunto com a equipe do Laboratório de Microfabricação do LNLS, sabe-se que os moldes para a eletrodeposição (feitos em fotorresiste SU-8 ou AZ4620) não devem apresentar razão de largura da abertura pela altura muito reduzida. Ou seja, quanto mais larga for a abertura do molde e quanto menor for a espessura da estrutura eletrodepositada, melhor a qualidade resultante.

Assim, as simulações foram restritas a modelos com larguras de pelo menos $50 \mu \mathrm{m}$, e espessura nunca superior a $40 \mu \mathrm{m}$. As simulações foram feitas com o aplicativo ANSYS.

\subsection{SIMULAÇÕES DE CAPACITÂNCIA DO MODELO DO SENSOR}

$\mathrm{Na}$ tabela 6.1 são apresentados resultados de diversas simulações para variações de diferentes parâmetros do sensor. Para todas essas simulações foram utilizados modelos com 9 eletrodos, o que corresponde a 8 capacitores. Os modelos foram descritos em detalhe na Seção 4.2 desta dissertação. Os valores de capacitância encontrados foram normalizados para um sensor fictício de mil capacitores e comprimento de emparelhamento de dedos $L L=800 \mu \mathrm{m}$. As espessuras

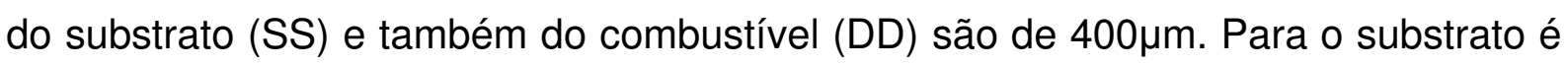
considerada a constante dielétrica da alumina $\mathrm{K}_{\mathrm{al}}=9,9$, para o combustível é considera uma constante dielétrica $\mathrm{K}=2$, valor de constante semelhante ao da 
gasolina $A$, querosene e aguarrás. Na figura 6.1 é mostrado um modelo simplificado onde aparecem 5 eletrodos.

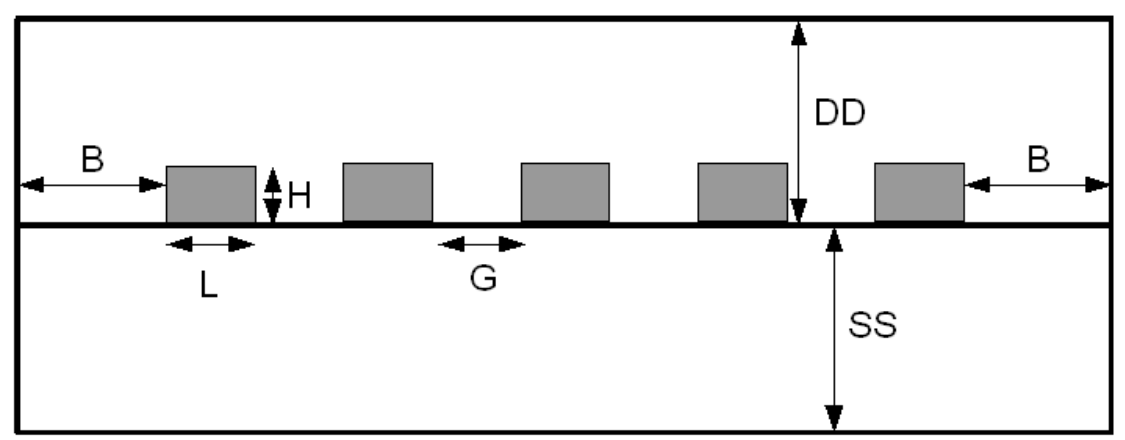

Figura 6.1- Modelo para simulação de um sensor a fim de se descobrir as dimensões mais apropriadas.

Diversas simulações foram realizadas para modelos bidimensionais, usando o elemento PLANE121 do ANSYS, e definindo a dimensão do elemento de discretização como sendo $8 \mu \mathrm{m}$. A tabela 6.1 apresenta os valores dos parâmetros geométricos de cada modelo e os respectivos valores calculados de capacitância para uma normalização de 1000 capacitores.

Tabela 6.1- diferentes simulações variando parâmetros do sensor.

\begin{tabular}{|c|c|c|c|c|}
\hline Simulação & $\begin{array}{c}\text { Altura do } \\
\text { eletrodo } \\
\mathbf{H}(\mu \mathrm{m})\end{array}$ & $\begin{array}{c}\text { Largura do } \\
\text { eletrodo } \\
\mathbf{L}(\boldsymbol{\mu m})\end{array}$ & $\begin{array}{c}\text { Espaçamento } \\
\text { entre eletrodos } \\
\mathbf{G}(\mu \mathrm{m})\end{array}$ & $\begin{array}{c}\text { Capacitância } \\
\text { para 1000 } \\
\text { capacitores }(\mathbf{p F})\end{array}$ \\
\hline 1 & 30 & 50 & 50 & 54,65 \\
\hline 2 & 30 & 50 & 75 & 45,82 \\
\hline 3 & 30 & 50 & 100 & 40,67 \\
\hline 4 & 30 & 100 & 100 & 49,72 \\
\hline 5 & 30 & 100 & 50 & 66,31 \\
\hline 6 & 35 & 100 & 50 & 67,74 \\
\hline 7 & 40 & 100 & 50 & 69,17 \\
\hline 8 & 25 & 100 & 50 & 64,87 \\
\hline 9 & 25 & 150 & 50 & 72,75 \\
\hline 10 & 25 & 50 & 50 & 53,20 \\
\hline
\end{tabular}

Analisando-se os resultados da tabela 6.1, é possível observar o aumento da capacitância com a redução do espaçamento entre eletrodos e com o aumento da altura. Esses parâmetros têm uma certa limitação devido aos processos de 
fabricação disponíveis. Além disso, o espaçamento entre eletrodos não pode ser demasiadamente reduzido pois há o risco de o combustível não entrar no canal.

Os resultados das simulações também mostram outra maneira de se elevar o valor da capacitância. Comparando-se os resultados das simulações 8,9 e 10, percebe-se que ao aumentar a largura do eletrodo, também há aumento da capacitância. Esse comportamento se deve ao fato de existirem linhas de campo saindo da parte de cima de um eletrodo e chegando ao outro. Vale lembrar que os capacitores do sensor não apresentam comportamento de capacitor de placas planas infinitas. Dessa maneira, um aumento na largura do eletrodo também aumenta a área efetiva do capacitor. Entretanto, o espaçamento efetivo também aumenta, limitando o efeito do aumento da capacitância. Em conclusão, a capacitância do sensor pode ser aumentada com o aumento da largura do eletrodo, mas só até um certo limite (deve ocorrer saturação desse efeito). Além disso, a elevação da largura dos eletrodos também aumenta as dimensões finais do sensor.

\subsection{SIMULAÇÕES DE CAMPO ELÉTRICO}

Os resultados dessa seção mostram a distribuição do campo para diferentes parâmetros do sensor e dois dielétricos diferentes, o etanol e a gasolina. Para a gasolina foi utilizada constante dielétrica $\mathrm{K}_{\mathrm{g}}=2$. Esse valor corresponde à constante dielétrica da gasolina pura, ou de alguns outros dielétricos apolares como querosene, aguarrás etc. Para o etanol foi utilizada constante dielétrica $K_{\mathrm{et}}=24,3$.

As simulações consideram uma diferença de tensão elétrica de $0,3 \mathrm{~V}$ aplicada entre eletrodos consecutivos, ver figura 4.6. Esse valor foi adotado pois nas medições reais de capacitância com o medidor $R C L$ foi aplicado um sinal senoidal de $0,3 \mathrm{~V}$ rms pelo instrumento.

A figura 6.2 mostra uma série de simulações feitas considerando o etanol como dielétrico entre os eletrodos, enquanto que a figura 6.3 mostra a série de simulações correspondentes para a gasolina. Analisando-se os resultados mostrados nas figuras 6.2 e 6.3 pode-se chegar a várias conclusões. Comparandose sensores com as mesmas dimensões e dielétricos diferentes, o campo tende a ser mais alto para a gasolina que para o etanol. Esse resultado está de acordo com a equação 3.5 e a teoria de polarização de dielétricos apresentada na seção 3.3. Se 
a constante dielétrica é maior (caso do etanol), há maior polarização. Então o campo E' oposto ao campo aplicado $\mathrm{E}_{0}$ será maior. Assim o campo resultante no dielétrico será menor.
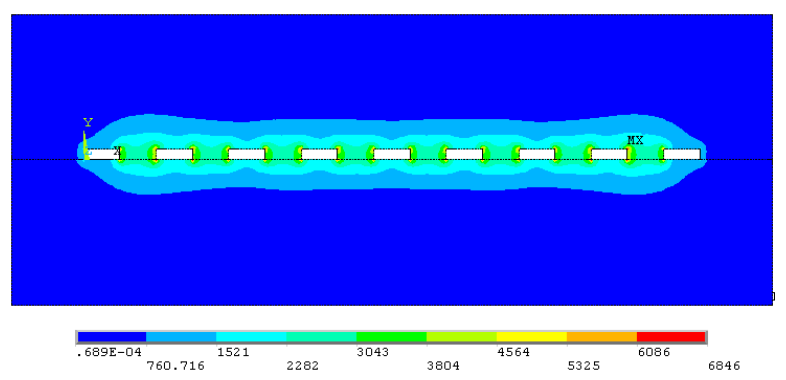

(a) $L=100 \mathrm{G}=100$

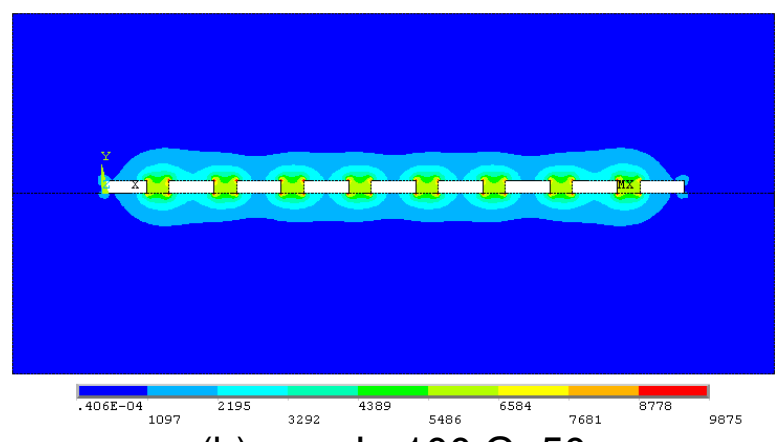

(b)

$\mathrm{L}=100 \mathrm{G}=50$

Figura 6.2- Distribuição do campo elétrico em etanol para diferentes larguras e espaçamentos entre eletrodos.

(d)
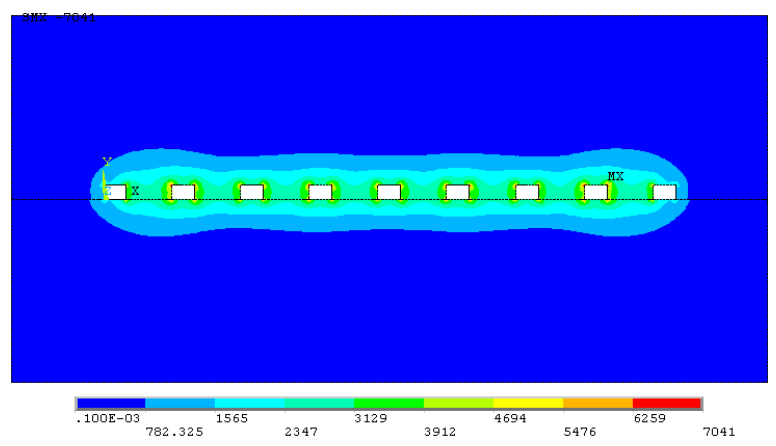

(c) $\mathrm{L}=50 \mathrm{G}=100$

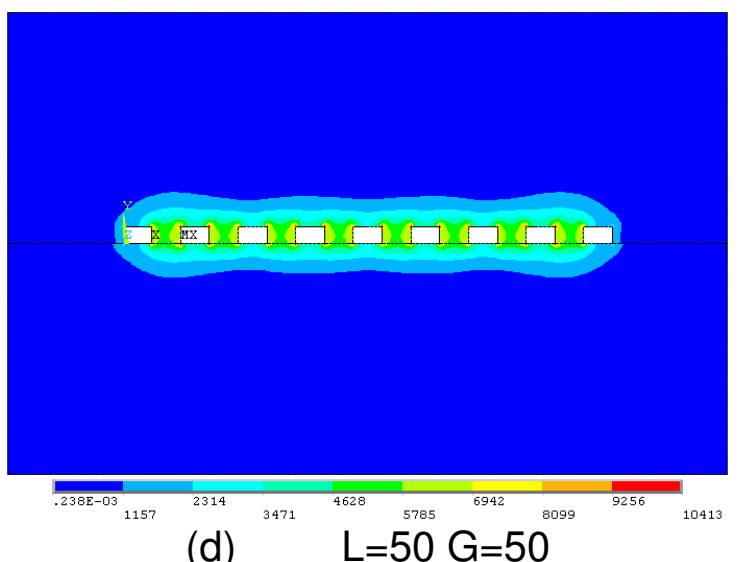

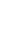




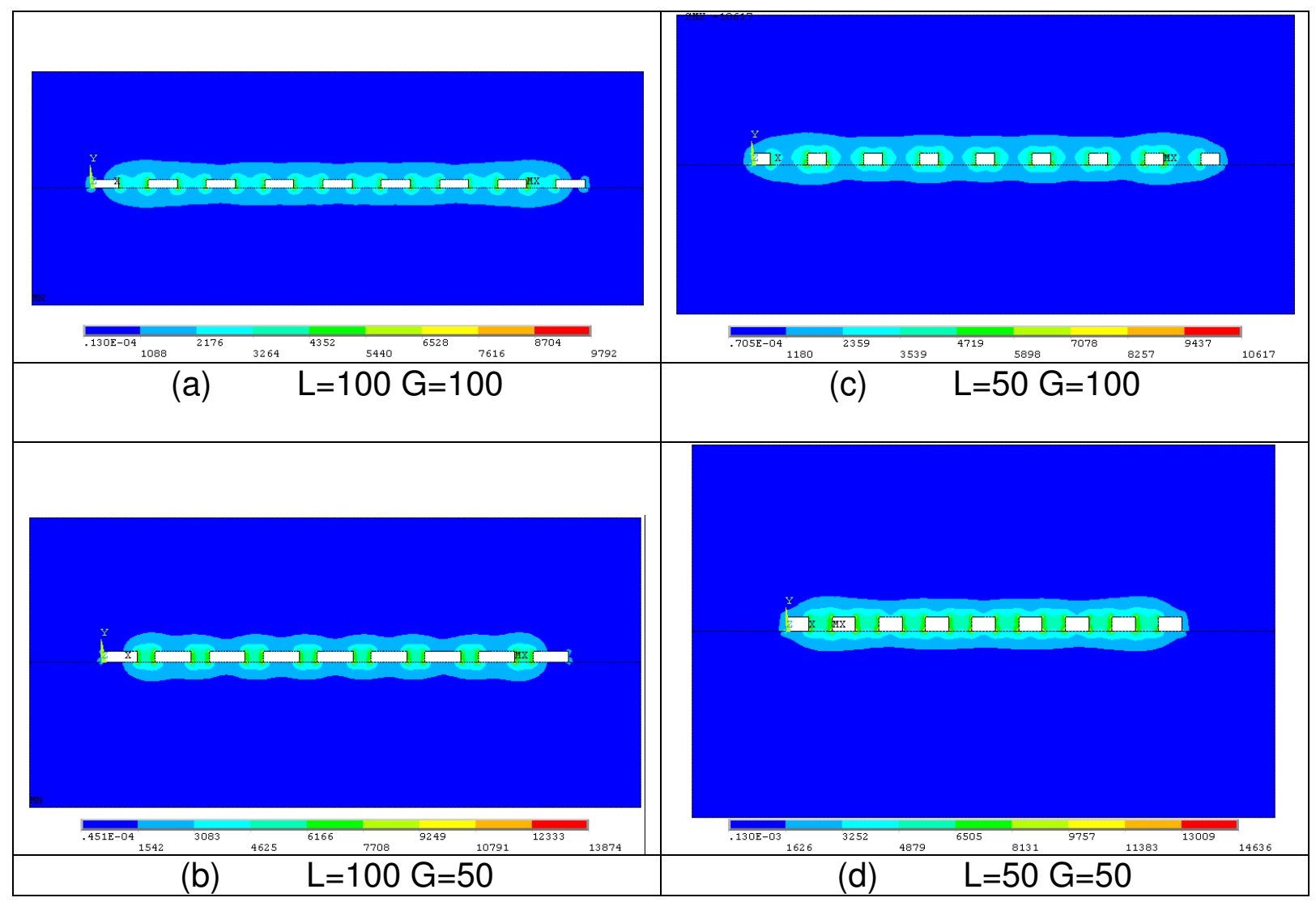

Figura 6.3- Distribuição do campo elétrico em gasolina para diferentes larguras e espaçamentos entre eletrodos.

De acordo com resultados dessa seção e da seção 6.1, foi observado que as melhores dimensões para o sensor são um espaçamento pequeno entre os eletrodos e uma largura relativamente grande do eletrodo. Com um $L$ relativamente grande, eleva-se os valores de capacitância e reduz-se efeitos de ponta. $O$ espaçamento pequeno entre eletrodos também eleva a capacitância mas também eleva o campo e efeito bordas. Além disso, quanto maior a altura do eletrodo, maior será a capacitância.

Para a fabricação do sensor, entretanto há algumas limitações. A redução do espaçamento entre eletrodos é limitada pelo processo de fabricação. O processo de fabricação adotado nesse estudo permite com segurança e uniformidade, resoluções

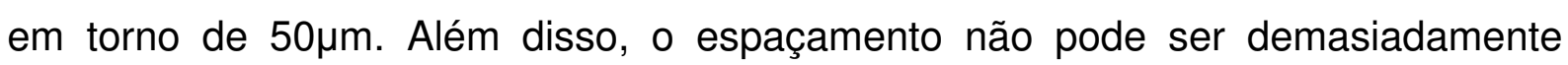
reduzido pois pode dificultar ou impedir a entrada do combustível entre os eletrodos. Esforços no sentido de elevar a altura para alem de $30 \mu \mathrm{m}$, não trazem grande retorno. Isso poderia resultar em paredes menos uniformes e perda na qualidade da amostra como um todo. Espessuras muito superiores a $30 \mu \mathrm{m}$ exigiriam processos 
menos acessíveis. O aumento da largura do eletrodo também aumenta a capacitância poupando algum esforço na elevação da altura. Entretanto, a partir de um certo valor, ocorrerá saturação desse efeito. Além disso, larguras muito elevadas aumentam as dimensões finais do sensor.

Estabeleceu-se então que as melhores dimensões para 0 sensor, considerando o processo, seria: altura de eletrodos $H=30 \mu m$, largura $L=100 \mu m$ e espaçamento entre eletrodos $\mathrm{G}=50 \mu \mathrm{m}$.

\subsection{SIMULAÇÕES DE AMOSTRAS FABRICADAS E CARACTERIZADAS}

Os resultados exibidos a seguir simulam uma situação em que uma das amostras fabricadas do sensor é imersa no combustível e são realizadas as medições.

\subsubsection{Simulação para sensor imerso em querosene}

Para a simulação do sensor imerso em querosene, foram considerados espessura do substrato de alumina SS de $300 \mu \mathrm{m}$, espessura do dielétrico (combustível) DD de $400 \mu \mathrm{m}$ constante dielétrica da alumina $\mathrm{K}_{\mathrm{al}}=9,9$, constante dielétrica do querosene, $K_{q}=2$. A amostra simulada tem $G=85 \mu m, L=65 \mu m, H=33 \mu m$ e tem 1590 capacitores. Essa amostra é denominada sensor S1 e suas dimensões aparecem na tabela 7.1 .

A figura 6.4 mostra a distribuição de potencial aplicado nos eletrodos. Foi aplicada uma diferença de potencial de $0,3 \mathrm{~V}$. Na figura 6.5 é mostrada a distribuição do campo elétrico entre os eletrodos. 


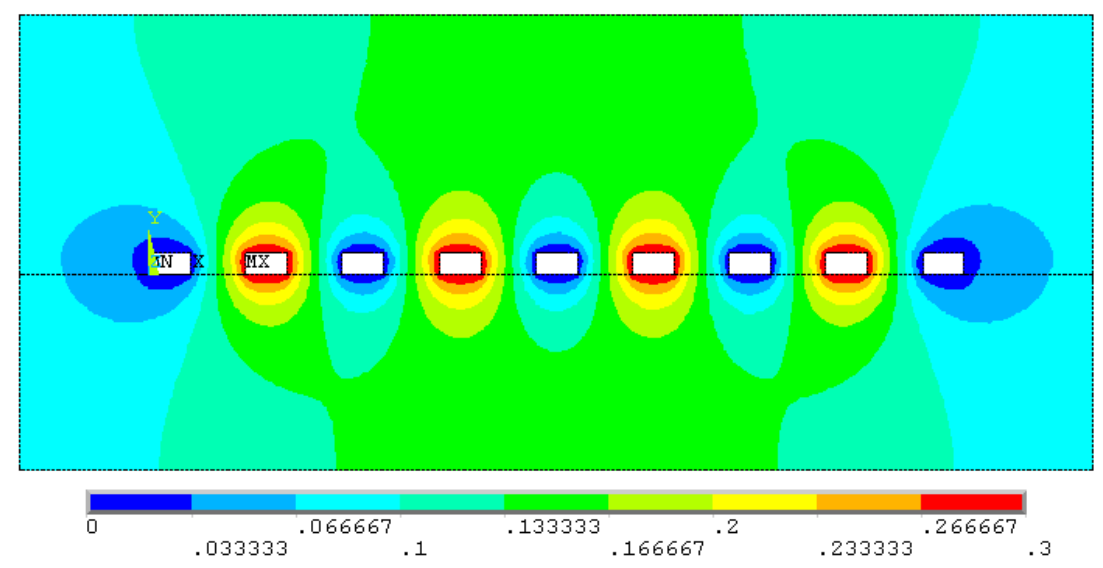

Figura 6.4- Distribuição de potencial pelos dielétricos querosene e alumina (substrato) para o sensor S1. Na simulação foram aplicadas tensões de 0V e 0,3V em eletrodos alternados.

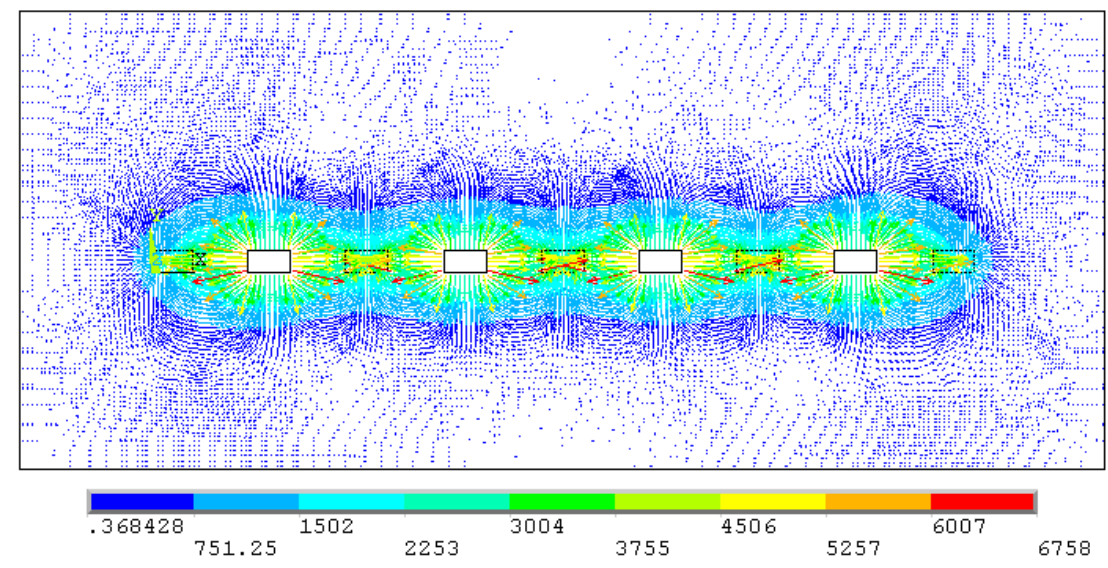

Figura 6.5- Distribuição do campo elétrico pelos dielétricos querosene e alumina (substrato) para o sensor S1. Simulação com aplicação de tensões de 0V e 0,3V em eletrodos alternados.

$\mathrm{Na}$ figura 6.5 é possível observar diversos aspectos importantes. A distribuição do campo mostra que a espessura adotada no modelo é suficiente para a simulação pois a maior parte do campo se concentra em regiões próximas aos eletrodos. O substrato influencia o valor de capacitância pois o campo também se distribui dentro do mesmo. Sendo a constante dielétrica da alumina maior que a do combustível, o substrato representa grande parte do valor da capacitância. Os vetores mostram altos valores de campos nos cantos e arestas. Nas medições experimentais esse efeito é reduzido devido ao processo de fabricação que suaviza os cantos e arestas. 
Para essa simulação foi encontrada capacitância $\mathrm{C}=75,16$ pF para capacitância principal (entre dedos emparelhados), ver figura 4.4. Considerando a capacitância entre as pontas dos dedos e a base do pente correspondente, a capacitância sobe para $\mathrm{C}=83,81 \mathrm{pF}$. Exemplo de rotina utilizada para aquisição de capacitância pode ser vista no APÊNDICE C.

\subsubsection{Simulação para sensor imerso em etanol}

Para a simulação do sensor imerso em etanol, foram considerados os mesmos parâmetros que o querosene quanto ao substrato e espessura de dielétrico $\left(\mathrm{SS}=300 \mu \mathrm{m}, \mathrm{DD}=400 \mu \mathrm{m}, \mathrm{K}_{\mathrm{al}}=9,9\right)$. Para o dielétrico foi considerada constante do etanol $K_{e t}=24,3$. A amostra simulada tem $G=55 \mu m, L=100 \mu m, H=33$ e tem 2388 capacitores. Essa amostra é denominada sensor S2 (tabela 7.1).

Para a capacitância principal (sem considerar as pontas) foi encontrado $\mathrm{C}=597,76 \mathrm{pF}$. Considerando as pontas foi encontrado $\mathrm{C}=674,02 \mathrm{pF}$. 


\section{RESULTADOS EXPERIMENTAIS E DISCUSSÕES}

Nesta seção serão apresentados os principais resultados encontrados durante medições realizadas com os protótipos do sensor conforme descrito na seção 5.3. Os resultados foram obtidos através de diferentes protótipos do sensor. Os quais apresentam diferentes espaçamentos entre eletrodos e diferentes quantidades de capacitores. A tabela 7.1 mostra características de cada um desses sensores. Fotografias dos sensores são apresentadas nas figuras 7.1 e 7.2.
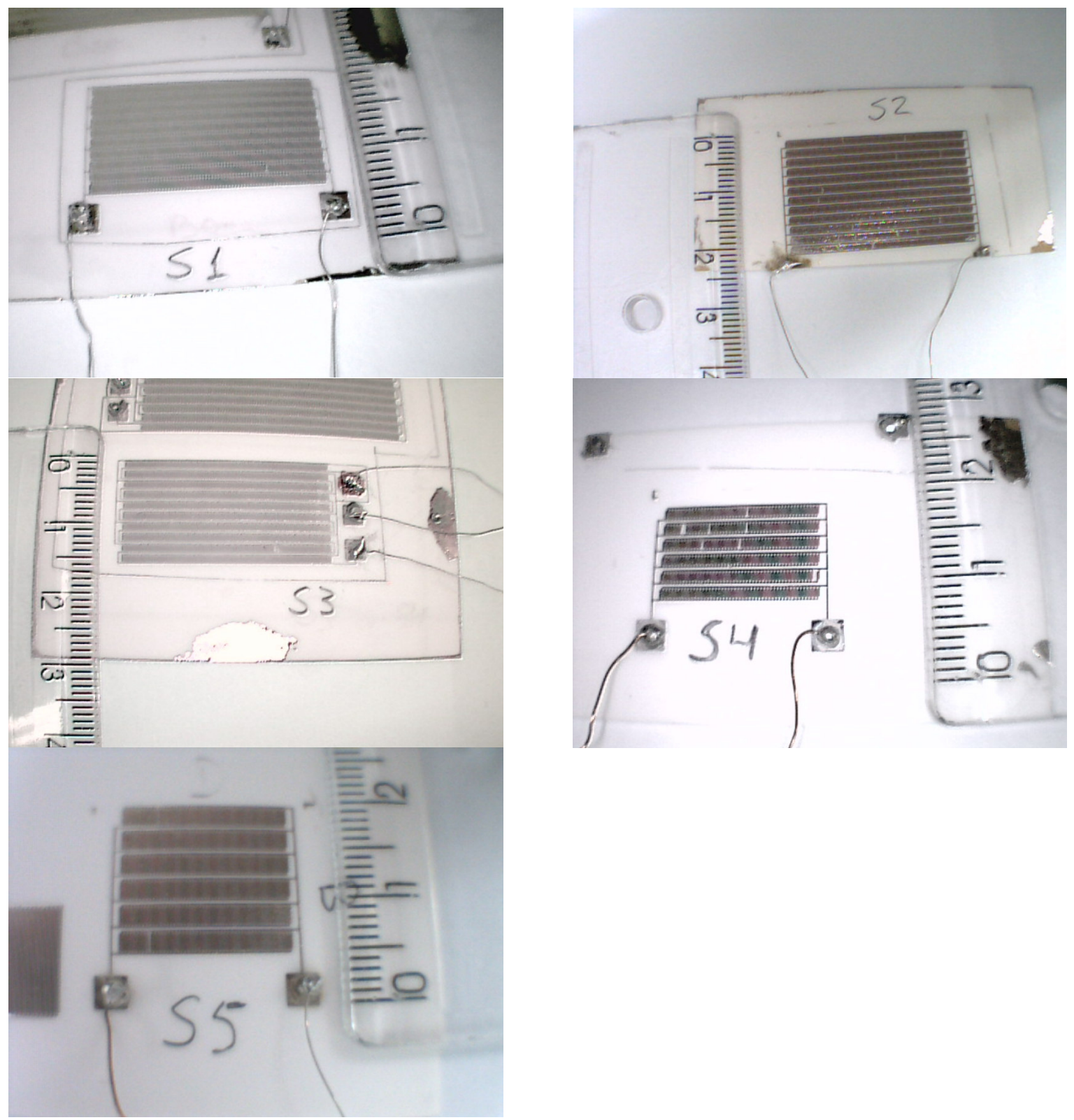

Figura 7.1- Fotos de amostras fabricadas e caracterizadas. 


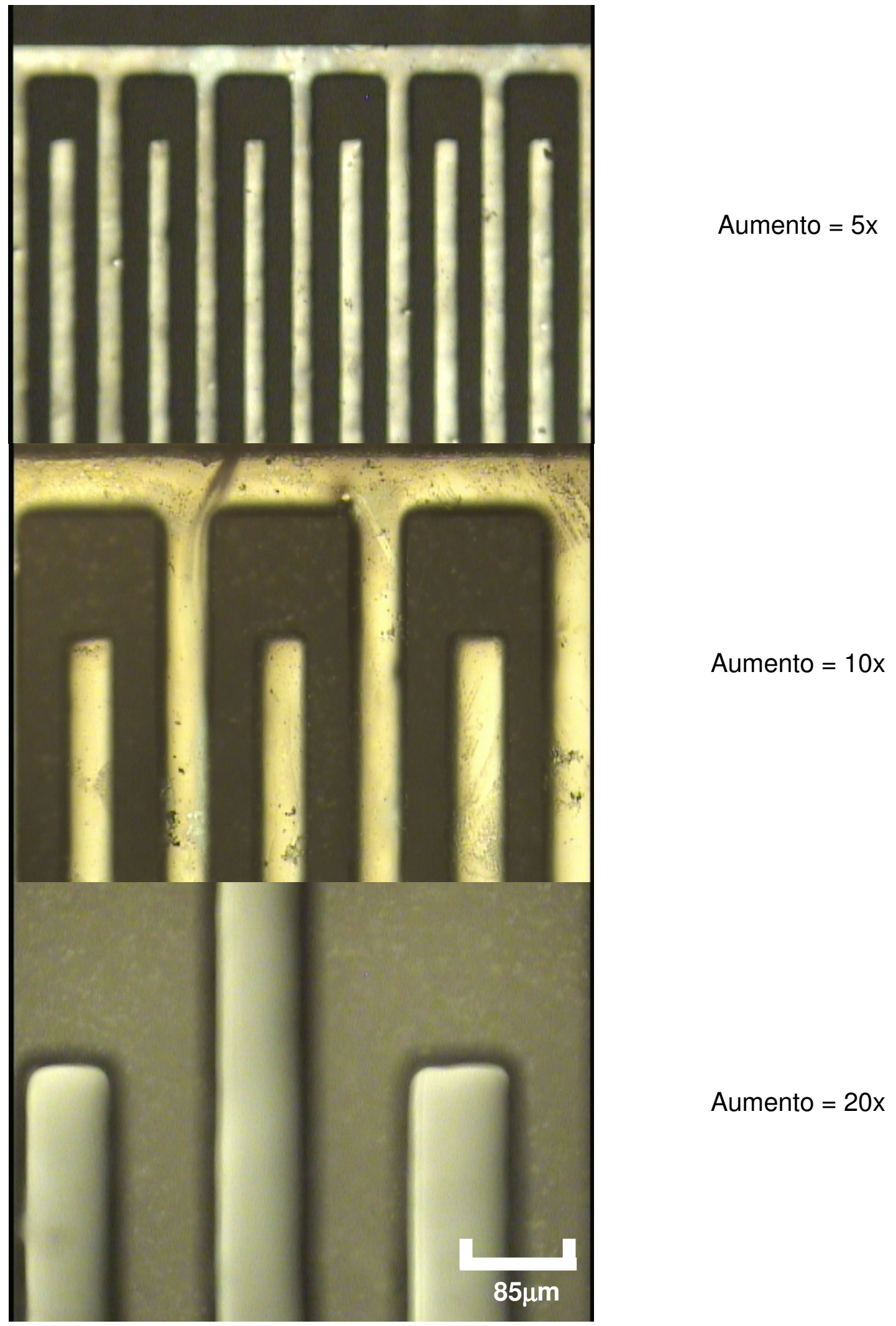

Figura 7.2- Detalhes da amostra S5 ampliados ao microscópio. 
Tabela 7.1- Características dos protótipos utilizados nas medições.

\begin{tabular}{|c|c|c|c|c|c|}
\hline & Sensor S1 & Sensor S2 & Sensor S3 & Sensor S4 & Sensor S5 \\
\hline Gap na máscara $(\mu \mathrm{m})$ & 100 & 50 & 100 & 80 & 80 \\
\hline Gap real $(\mu \mathrm{m})$ & 85 & 60 & 98 & 55 & 75 \\
\hline $\begin{array}{c}\text { Largura da linha na } \\
\text { máscara }(\mu \mathrm{m})\end{array}$ & 50 & 100 & 50 & 80 & 80 \\
\hline Largura real da linha $(\mu \mathrm{m})$ & 65 & 100 & 52 & 105 & 85 \\
\hline $\begin{array}{c}\text { Comprimento de } \\
\text { emparelhamento dos dedos } \\
(\mu \mathrm{m})\end{array}$ & 800 & 800 & 800 & 1600 & 1600 \\
\hline $\begin{array}{c}\text { Numero de pentes } \\
\text { Capacitores por pente }\end{array}$ & 10 & 12 & 10 & 6 & 6 \\
\hline Quantidade de capacitores & 159 & 199 & 199 & 99 & 99 \\
\hline Altura $(\mu \mathrm{m})$ & 33 & 2388 & 1990 & 594 & 594 \\
\hline
\end{tabular}

Os resultados mostrados a seguir foram obtidos utilizando-se o medidor RCL conforme descrito na seção 5.3. O sinal AC utilizado foi de $300 \mathrm{mV}$ rms com freqüência de $500 \mathrm{kHz}$.

\subsection{MEDIÇÕES COM ÁLCOOL COMBUSTÍVEL}

Os resultados mostrados nessa seção tratam da adulteração do álcool combustível. Esse combustível passou a ser mais utilizado pelos brasileiros nessa década de 2000 devido principalmente aos carros flex. Com isso, a adulteração desse combustível se torna mais atraente para os fraudadores.

\subsubsection{Comparação de álcool de posto com misturas de referência}

A figura 7.3 mostra gráficos de medições para uma Mistura de Referência etanol anidro e água de-ionizada realizadas utilizando-se o sensor S3. Foi utilizado etanol anidro grau PA de concentração 99,5\% em massa (99,5 INPM) e água deionizada obtida no Laboratório de Sistemas Integráveis da Escola Politécnica da USP (LSI-EPUSP). Foram preparadas algumas misturas com diferentes concentrações. Essas misturas serviram como padrão para comparação com o álcool hidratado combustível. O AEHC foi adquirido em um posto de combustíveis da Grande São Paulo.

A curva com indicação etanol puro refere-se ao álcool anidro grau PA de 99,5\% sem adição de água. As porcentagens que se vêem nos gráficos são dadas em volume. A mistura com $6 \%$ de água (volume) equivale a aproximadamente $7 \%$ 
em massa, ou seja, álcool 93INPM, teor alcoólico exigido pela ANP para o álcool hidratado combustível. Esta mistura tem por objetivo simular o álcool hidratado assegurando a concentração legal e conhecida de água.

$\mathrm{Na}$ figura 7.4, são mostrados, novamente, as curvas de capacitância ocultando-se a curva para água pura para melhor visualização dos valores de cada concentração. As figuras 7.3a e 7.4 mostram que a capacitância do sensor está sendo influenciada pela concentração do dielétrico, no caso a mistura etanol-água. Quanto maior a concentração de água, maior a capacitância.

A capacitância da mistura tem seus valores e variações relacionados a efeitos de polarização. Todo material dielétrico sofre uma polarização elétrica quando submetido a um campo elétrico. A polarização é menor nos materiais apolares pois estes têm apenas dipolos induzidos pelo campo. Materiais polares apresentam polarização adicional por conta de seus dipolos permanentes. Tanto a água como o etanol são materiais polares, sendo que a água tem momento de dipolo permanente maior que o etanol. Por isso, a água têm maior constante dielétrica $\left(K_{a g}=78,85\right)$ (e conseqüentemente maior capacitância). Assim, um aumento na concentração de água eleva e capacitância.

Ainda no gráfico da capacitância é possível observar que o álcool de posto apresenta valores de capacitância muito próximos aos do álcool com $6 \%$ de água. Isso é um indício de que o teor de água deste álcool está dentro do permitido pela ANP.

Os resultados obtidos nos gráficos de capacitância mostram que o sensor tem a capacidade de detectar a adulteração de álcool por água. A adulteração pode ser detectada ainda que a água seja destilada ou ainda que o álcool apenas não tenha sido destilado adequadamente. Como a adulteração por água é a mais utilizada, esse sensor deve funcionar bem para o álcool combustível.

Quanto ao ângulo de fase, as curvas não seguem uma tendência tão coerente como a capacitância. A resistência, apesar de mostrar uma certa tendência, assim como o ângulo de fase não se mostrou uma grandeza confiável para esse tipo de análise como será visto a seguir. 


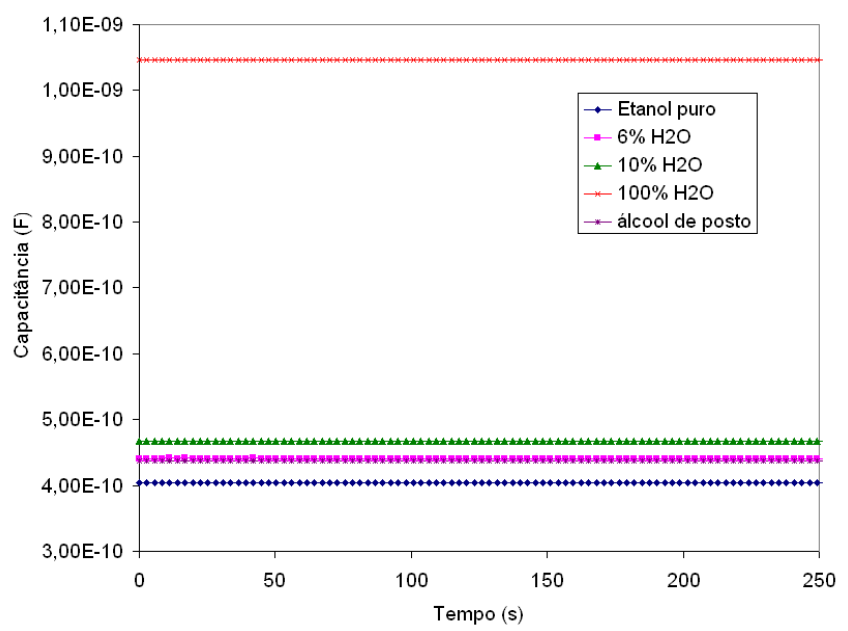

(a) Capacitância

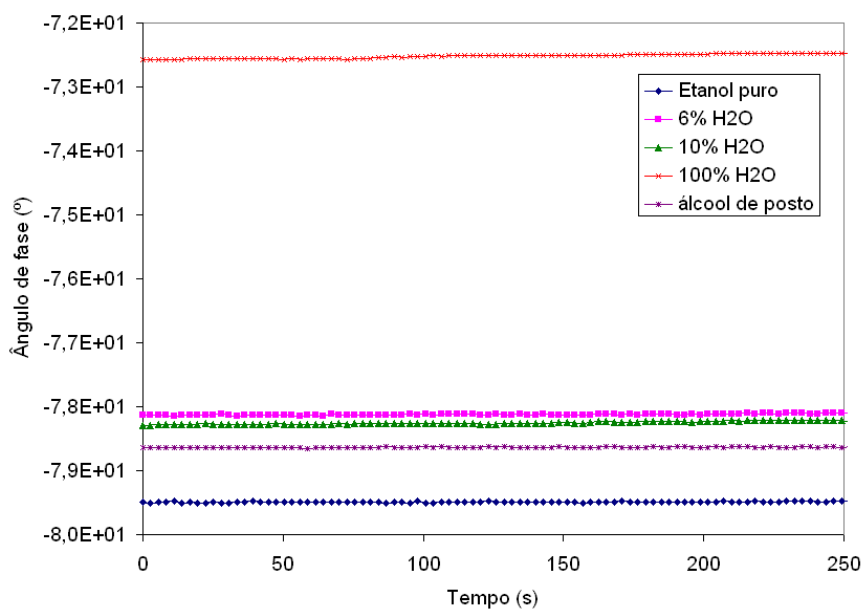

(b) Ângulo de Fase

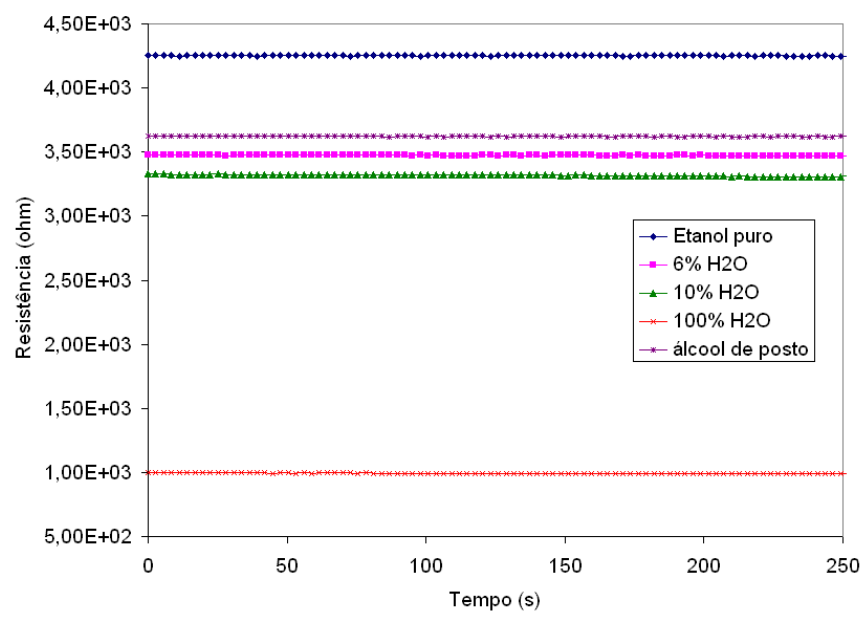

(c) Resistência

Figura 7.3- Gráficos para medições com a mistura álcool-água DI. 


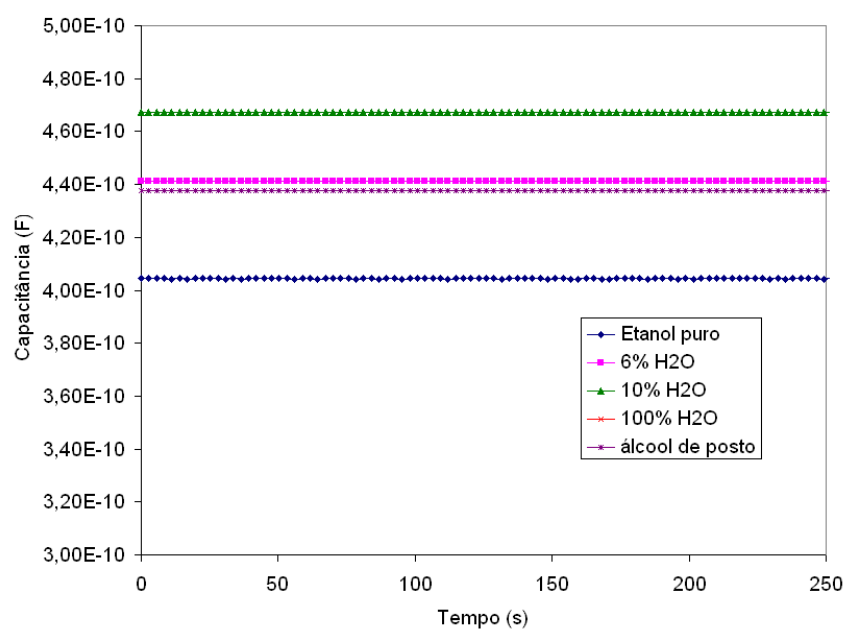

Figura 7.4- Gráfico da capacitância (sem mostrar curva da água pura) para medições com a mistura álcool-água DI.

\subsubsection{Medições com etanol para variações pequenas}

Outro teste foi realizado com misturas etanol-água para avaliar o comportamento do sensor diante de pequenas variações na concentração. Os resultados são mostrados na figura 7.5.

Nesse experimento também foi utilizado etanol anidro grau PA de concentração 99,5\% (em massa) e água deionizada. Foi utilizado o sensor S2. A concentração de água foi variada em passos de um por cento.

Para os valores de capacitância o sensor se mostrou capaz de distinguir as pequenas variações, e os resultados seguem uma seqüência bem definida: quanto maior a quantidade de água, maior a capacitância.

Por outro lado, os valores de resistência e ângulo de fase não seguem nenhuma tendência. Os valores de algumas concentrações consecutivas se confundem e algumas curvas apresentam uma instabilidade no começo das medições. $O$ ângulo de fase e a resistência sofrem efeito da mobilidade dos portadores de carga presentes na mistura. A água apresenta maior mobilidade de portadores e conseqüentemente, maior condutividade (seção 3.3.3 desta dissertação). Mas a concentração desses portadores depende não só da concentração de água na mistura, mas também de fatores como o nível de contaminação. Além disso, podem estar ocorrendo processos químicos cujo estudo não fez parte do escopo desse trabalho. Assim o ângulo de fase e a resistência não seguem uma tendência confiável como a capacitância. A capacitância foi o único 
parâmetro que não se mostrou influenciável por esses efeitos. Assim, esse tipo de análise (mistura de compostos polares) deve ser feito baseando-se somente na capacitância.

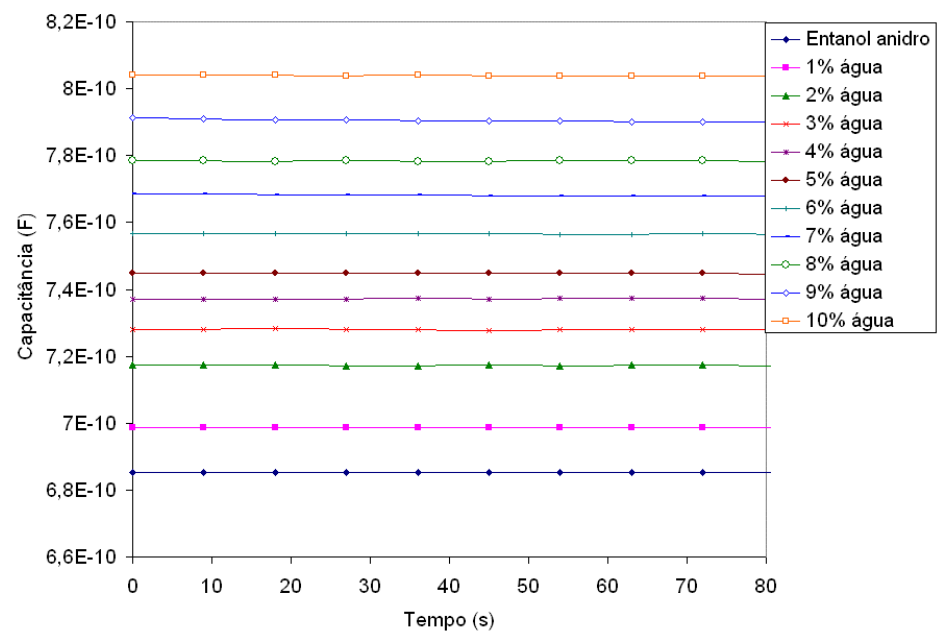

(a) Capacitância

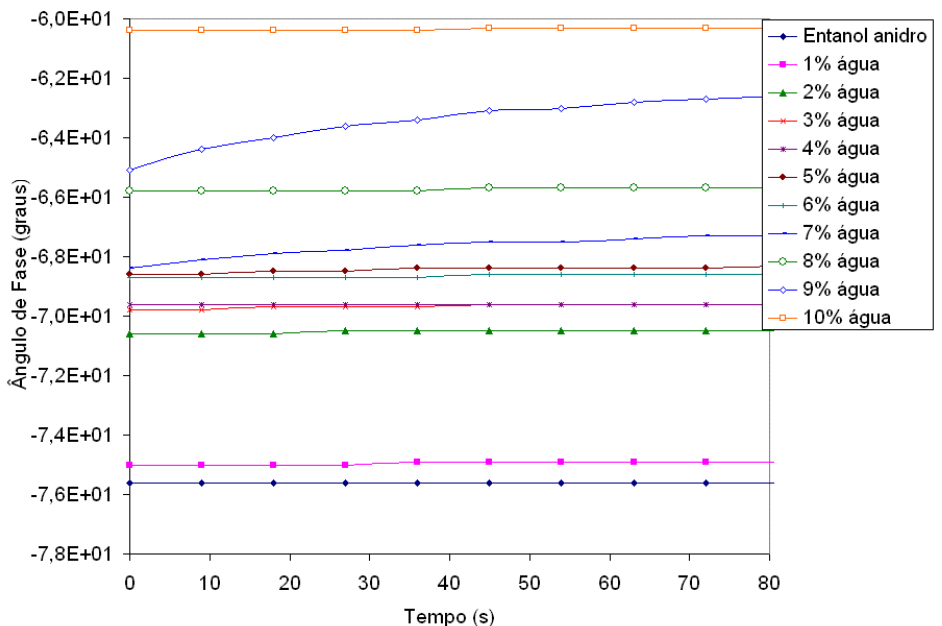

(b) Ângulo de Fase

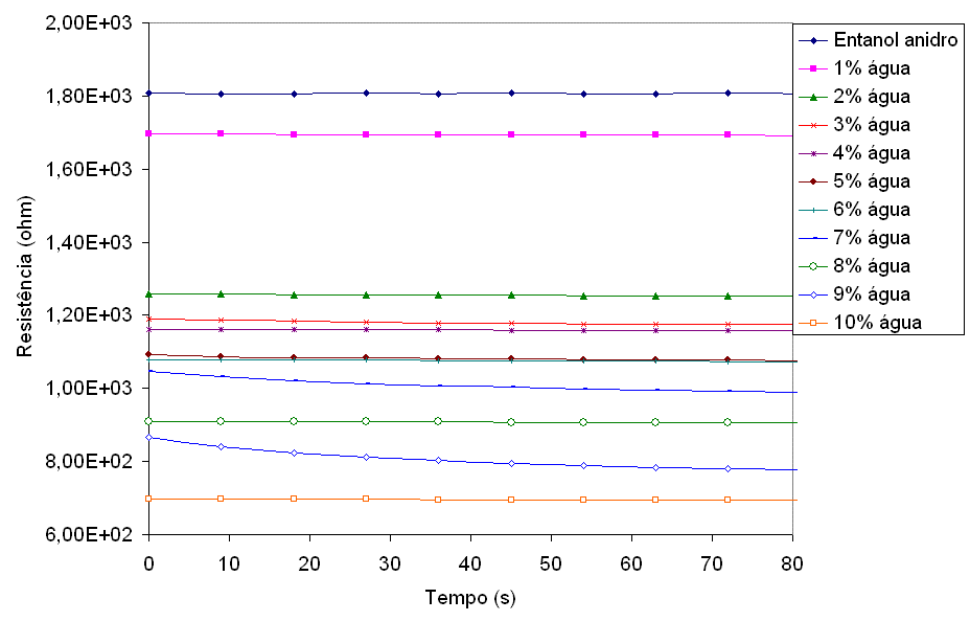

(c) Resistência

Figura 7.5- Medições para mistura etanol-água com variações pequenas. 
Algumas medidas podem ser adotadas para a melhoria da sensibilidade do sensor. A melhoria consistiria em elevar o valor da capacitância total do sensor para que haja maior variação. Duas maneiras de se fazer isso são reduzir o espaçamento entre os eletrodos e aumentar a altura dos eletrodos. Essas soluções exigem melhores máscaras e processos de fabricação mais elaborados. Aumentar o número de placas é uma solução que apresenta limitações, pois aumenta as dimensões finais do sensor. Outra maneira é aumentar a largura dos eletrodos, como visto nos resultados de simulações. Mas vale lembrar que esse aumento tem um limite pois o efeito tem um limiar. Além disso, também há o aumento do tamanho sensor.

\subsection{MEDIÇÕES COM GASOLINA}

\subsubsection{Mistura Gasolina-Etanol}

A figura 7.6 mostra os gráficos das medições com a mistura gasolina-álcool (etanol anidro). Todas as concentrações são em volume. Foi utilizado o sensor S1.

A concentração $23 \%$ em volume álcool (etanol) é uma amostra de gasolina obtida em um posto de combustível da grande São Paulo. As medições foram realizadas partindo do pressuposto que a gasolina em questão apresenta os $23 \%$ de álcool permitidos pela ANP na ocasião de sua aquisição. Para as demais concentrações, foi calculada a quantidade de álcool a ser adicionada levando-se em conta que já havia $23 \%$ antes da mistura.

O álcool utilizado nas misturas para realização destas medições também foi o etanol anidro grau PA 99,5 INPM.

Observando os gráficos da figura 7.6 nota-se que as curvas dos parâmetros medidos seguem uma tendência de acordo com a concentração de álcool. A capacitância aumenta com o aumento da concentração de álcool. O módulo do ângulo de fase cai com o aumento na concentração de álcool. A resistência cai com o aumento da concentração de álcool. 


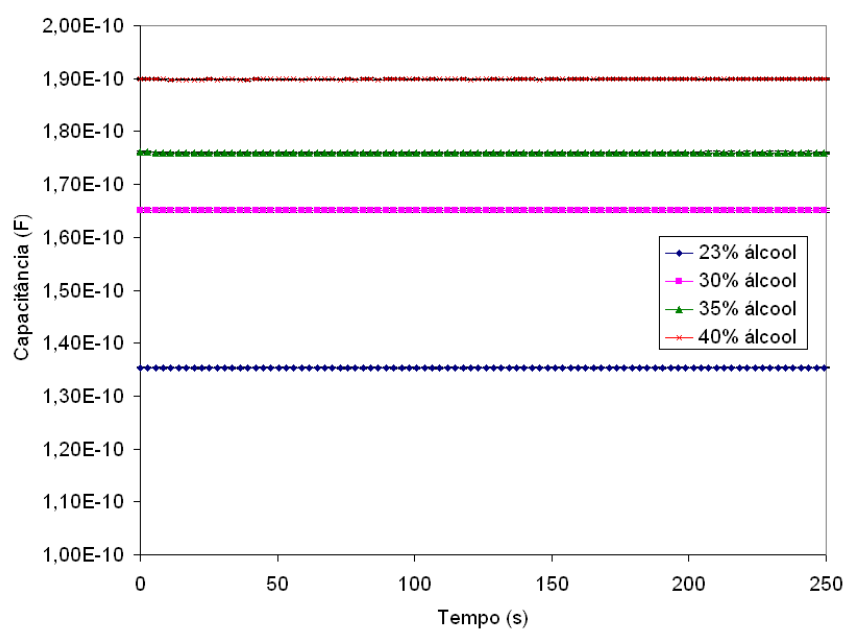

(a) Capacitância

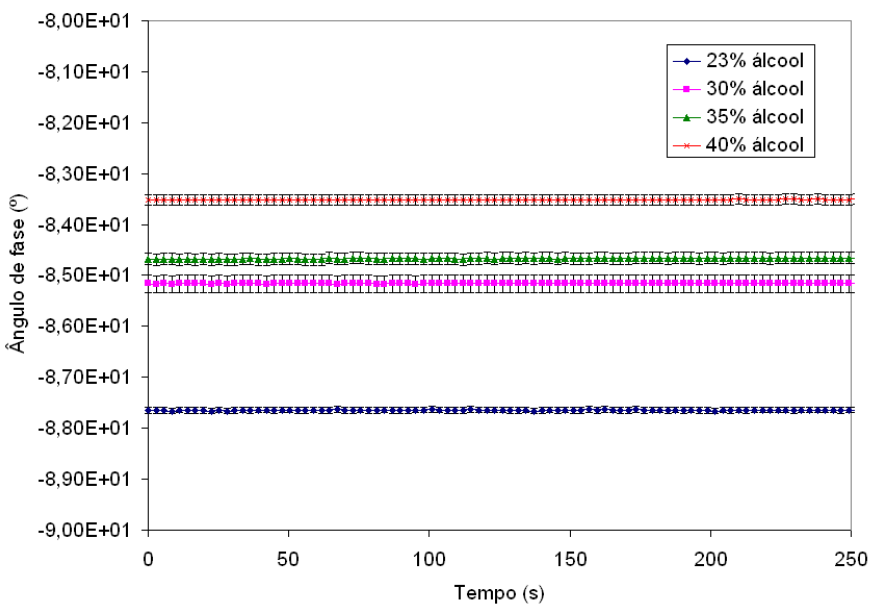

(b) Ângulo de Fase

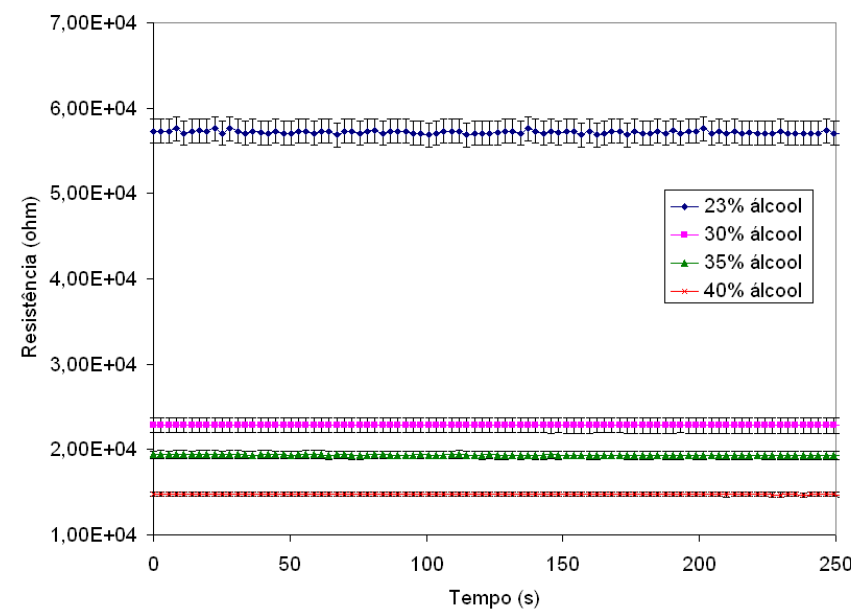

(c) Resistência

Figura 7.6- Gráficos para medições com a mistura gasolina-etanol anidro.

Também neste caso há uma grande diferença entre as constantes dielétricas dos combustíveis que compõem a mistura. A gasolina tipo A é um dielétrico apolar, sofrendo polarização devida exclusivamente a dipolos induzidos. Essa polarização é do tipo eletrônica, devido à baixa intensidade do campo elétrico aplicado, conforme a 
seção 3.3.1. Assim sendo, a gasolina tipo A apresenta baixo valor de constante dielétrica (em torno de 2). O etanol é um dielétrico polar (apresenta dipolo permanente), apresentando constante dielétrica mais alta (em torno de 24,3). A gasolina tipo $C$ apresenta um valor intermediário $K_{g c}$ entre os dois valores, pois é uma mistura dos dois compostos. Ao ser adicionado mais etanol à mistura (adulteração simulada no experimento) o valor da constante dielétrica aumenta. A falsa mistura apresentará uma constante dielétrica com valor entre a constante da gasolina $\mathrm{C}$ e a do etanol. Isso explica o aumento da capacitância com o acréscimo de álcool anidro à mistura. A queda da resistência com o acréscimo de álcool se deve á maior polarizabilidade e maior condutividade do etanol.

Nos gráficos da figura 7.6 são mostradas ainda, barras de erros relativas a variações ocorridas entre os valores de 10 medições. Foram obtidas calculando-se a média e o desvio padrão. Para essa faixa de variação de concentração, o sensor apresentou uma boa repetitividade e boa reprodutibilidade dos resultados, principalmente para os valores de capacitância. Isso mais uma vez mostra que a capacitância é o parâmetro mais confiável para análise de combustíveis.

Assim o princípio de medição deste sensor se mostra capaz de detectar adulteração da gasolina por álcool que é uma das mais utilizadas pelos fraudadores.

\subsubsection{Medições com mistura gasolina-álcool para variações pequenas}

Nos gráficos da figura 7.7 são mostrados resultados para misturas gasolinaálcool, mas para pequenas variações de concentração. O objetivo do teste é verificar se o sensor tem sensibilidade suficiente para identificar pequenas variações na concentração da mistura. Nesse teste foi utilizado o sensor S1.

Para essa mistura, os três parâmetros medidos seguem uma tendência para a faixa de concentrações utilizada. $O$ ângulo de fase e a resistência não apresentam cruzamento nem inclinações nas curvas como no caso da mistura etanol-água. Neste caso, a concentração de portadores de carga é muito menor. A maior parte da mistura é composta por gasolina (compostos apolares). Os compostos polares sofrem maior influência da mobilidade de portadores. Os portadores presentes no etanol não se mostraram capazes de causar o mesmo efeito ocorrido na mistura etanol-água. De qualquer forma, o sensor foi projetado para análise por capacitância. Deve-se sempre priorizar essa grandeza nas análises. 


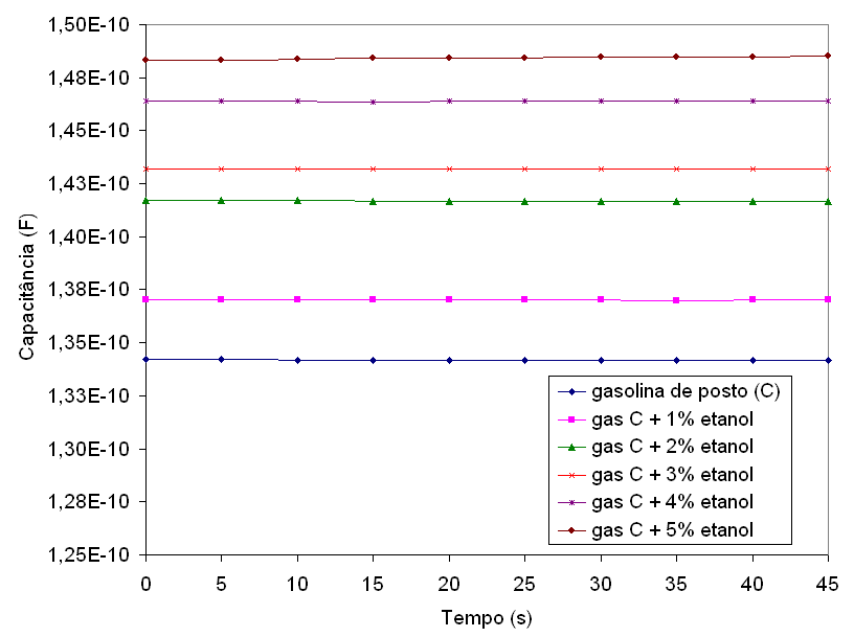

(a) Capacitância

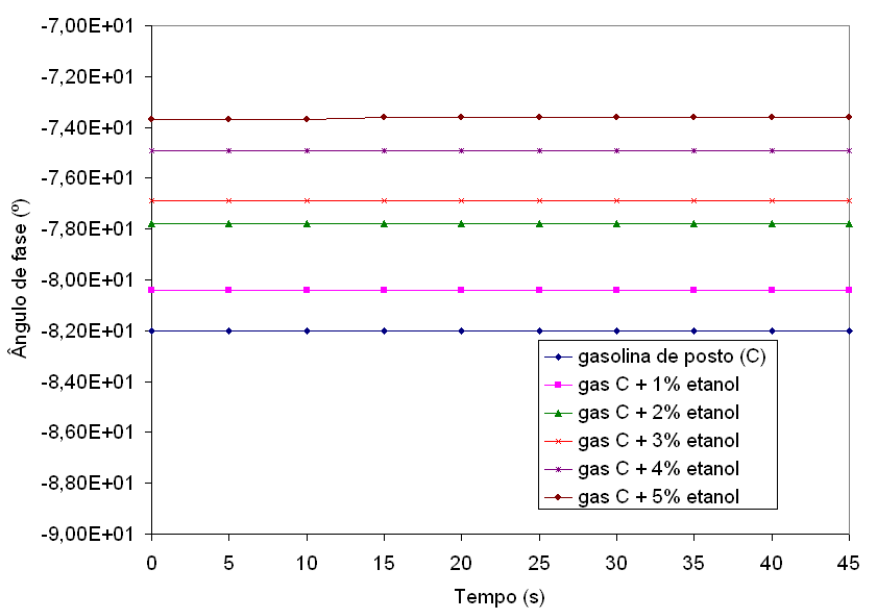

(b) Ângulo de Fase

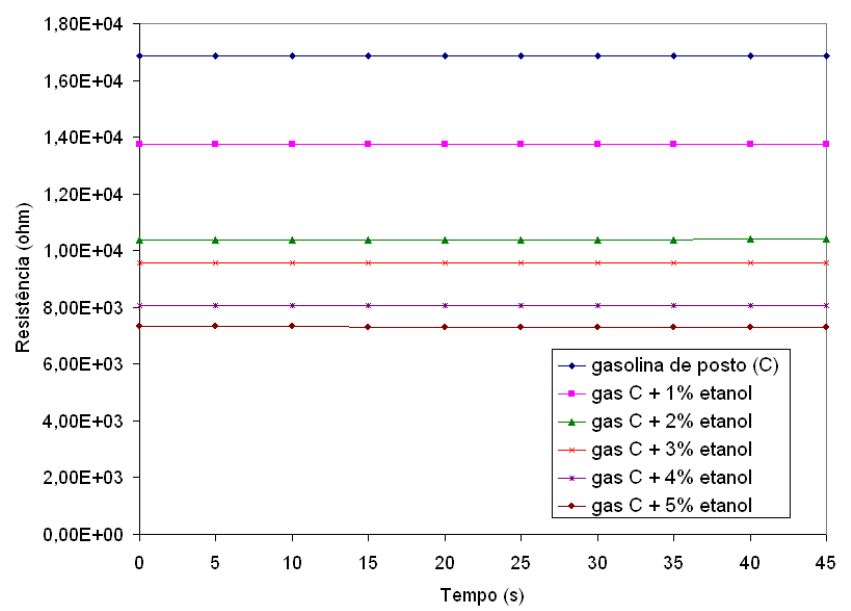

(c) Resistência

Figura 7.7- Gráficos para medições com a mistura gasolina-etanol anidro em pequenas concentrações.

O problema dessa análise é a baixa variação nos valores de capacitância. Neste caso ainda mais baixa que a mistura etanol-água devido à menor diferença entre as constantes dielétricas do combustível e do adulterante. Geralmente os 
adulteradores não utilizam quantidades tão baixas de adulterantes. Mas a sensibilidade do sensor pode ser melhorada como explicado na seção 7.1.2.

\subsubsection{Misturas de Gasolina com solventes orgânicos apolares}

Como os fraudadores de gasolina também utilizam solventes orgânicos apolares como aguarrás, tíner, óleo diesel, querosene e rafinados, foram feitas análises com querosene e aguarrás para avaliação do sensor.

\subsubsection{Mistura Gasolina-querosene}

Foram feitas medições variando a concentração de querosene em gasolina utilizando-se os sensores S1 e S2. A gasolina utilizada foi adquirida em um posto de combustível da grande São Paulo. Os dois sensores utilizados apresentam diferentes parâmetros quanto ao espaçamento entre eletrodos e o número de capacitores. O sensor S2 tem aproximadamente o dobro da capacitância do sensor S1.

Observando os gráficos da figura 7.8 percebe-se uma certa variação na capacitância, que cai com o acréscimo de querosene. Esse efeito é inverso do causado pelo álcool. Essa variação na capacitância ocorre devido ao fato de a gasolina utilizada no Brasil possuir álcool anidro em sua composição. O álcool anidro já presente na gasolina $\mathrm{C}$ eleva sua constante dielétrica para um valor $\mathrm{K}_{\mathrm{gc}}$ entre $2 \mathrm{e}$ 24,3. Quando é adicionado querosene ou outro solvente apolar, a constante dielétrica volta a cair provocando a queda da capacitância. A exemplo das misturas anteriores, as variações se devem a diferenças de polarizabilidade dos componentes e de suas concentrações.

A variação, entretanto, é menos perceptível que no caso da mistura gasolinaetanol. Uma maneira de melhorar a precisão do sensor é aumentar a capacitância como já mencionado anteriormente.

O ângulo de fase também segue uma tendência. $O$ sensor se torna mais capacitivo com 0 acréscimo de querosene. A resistência aumenta com a concentração de querosene, também oposto ao que ocorre com o álcool. Entretanto, como a gasolina adulterada pode ser uma mistura complexa contendo solventes, etanol e água, esses dois parâmetros devem ser usados com maior cautela. 


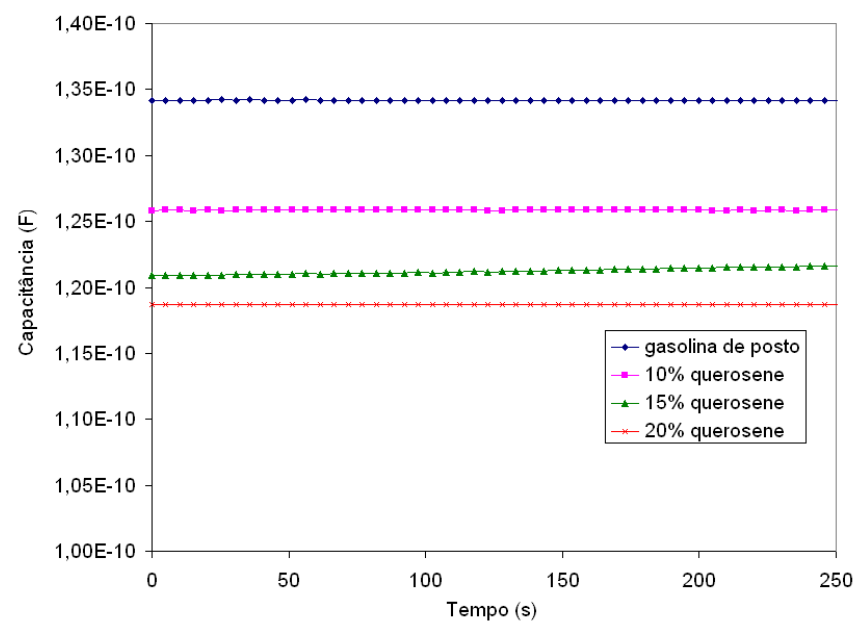

(a) Capacitância

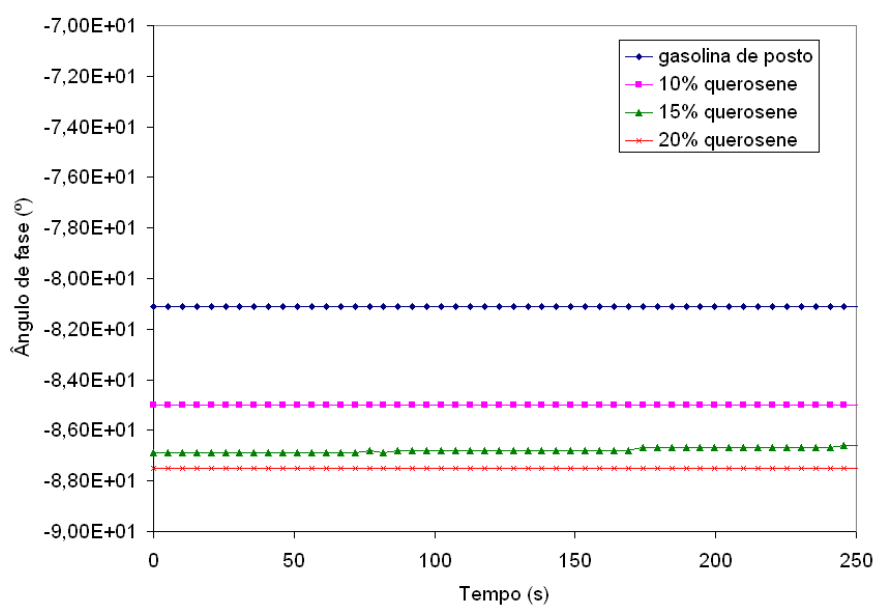

(b) Ângulo de Fase

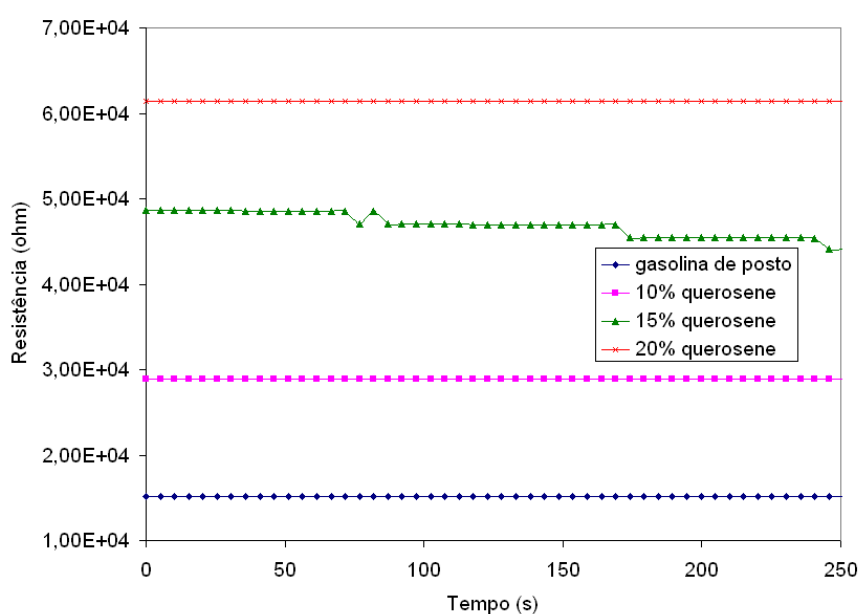

(c) Resistência

Figura 7.8- Gráficos para medições com a mistura gasolina-querosene para o sensor S1.

A figura 7.9 mostra dados das medições para as mesmas misturas para o sensor S2. 


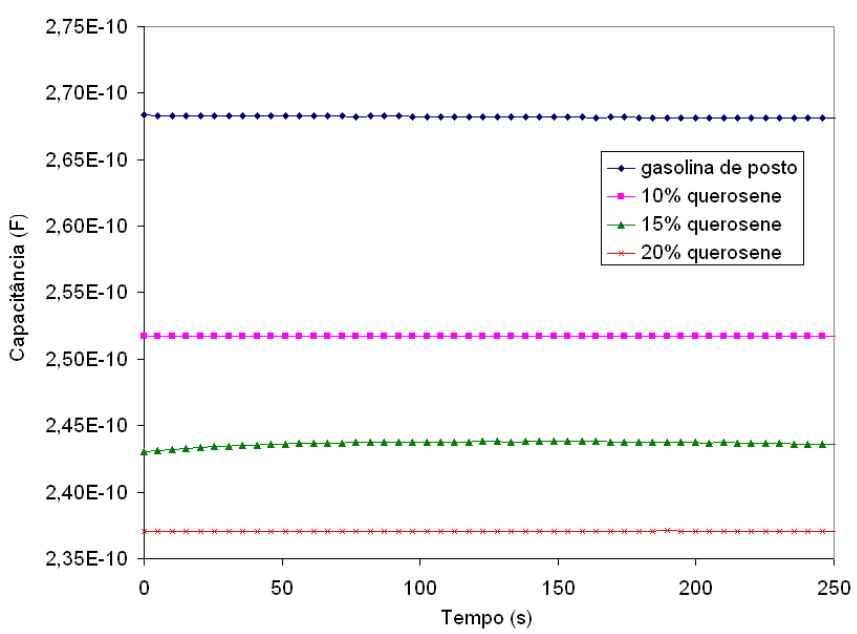

(a) Capacitância

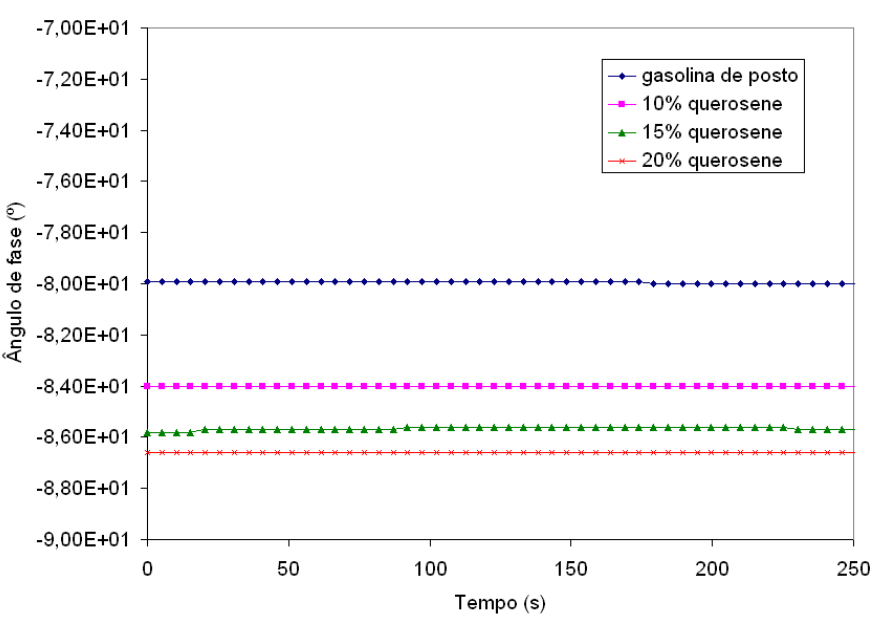

(b) Ângulo de Fase

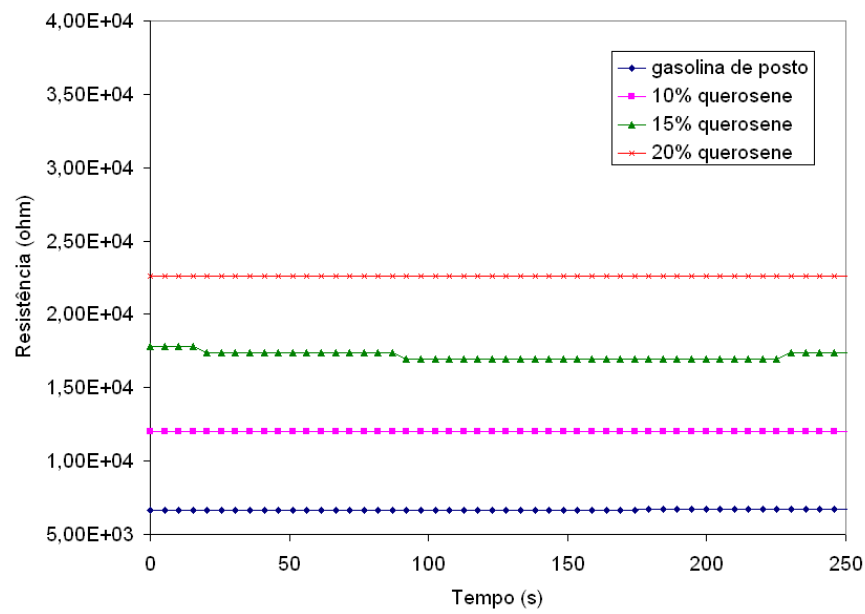

(c) Resistência

Figura 7.9- Gráficos para medições com a mistura gasolina-querosene para o sensor S2.

Esse sensor facilita a análise devido a sua maior capacitância. O espaçamento entre seus eletrodos $(G)$ é menor do que para o sensor $S 1$, e a largura dos eletrodos (L) é maior do que em S1. Esses dois parâmetros contribuem para o aumento da capacitância. Além disso, o número total de capacitores em S2 é 
maior que em S1. Entretanto, a área ocupada pelo sensor S2 é maior que para S1, o que pode ser claramente notado pelas fotos do Apêndice $A$.

Ao projetar um sensor, portanto, deve-se ter em mente a resolução do circuito que medirá a capacitância e quais as dimensões que o sensor pode ter. Esse equilíbrio pode ser otimizado na fase de projeto, com as técnicas de modelagem e simulação.

\subsubsection{Mistura Gasolina - Aguarrás}

Foram feitas medições para uma mistura gasolina-aguarrás utilizando-se o sensor S1. Foram utilizados os mesmos parâmetros que a mistura gasolinaquerosene e gasolina da mesma fonte. Os resultados desse teste são mostrados na figura 7.10 .

Os resultados são muito semelhantes aos do querosene. Os dois solventes têm propriedades dielétricas muito semelhantes. A semelhança se dá devido ao fato das duas substâncias serem apolares e compostas por hidrocarbonetos. As constantes dielétricas são próximas. O sensor não irá identificar exatamente qual é o adulterante presente na gasolina. Indicará sim a presença de um adulterante polar como etanol ou um adulterante apolar como querosene, aguarrás, rafinados etc.

\subsubsection{Mistura de gasolina com compostos polares e apolares simultaneamente}

Os resultados a seguir se referem à simulação de uma situação de adulteração em que são utilizados compostos polares e apolares simultaneamente. Isso acontece em alguns casos de adulteração em que o fraudador adiciona etanol e compostos apolares á gasolina. Esse teste tem o objetivo de avaliar a eficiência do sensor frente a esse tipo de adulteração. Essa avaliação se faz necessária devido aos efeitos opostos causados pelos dois tipos de adulterantes, como mostrado nos resultados anteriores.

Esses efeitos opostos se devem ao álcool anidro presente na gasolina C. Assim um aumento da concentração de querosene (ou outro apolar) diminui a concentração de material polar, reduzindo a capacitância. $O$ aumento da concentração de álcool aumenta a concentração de material polar, elevando a capacitância. 


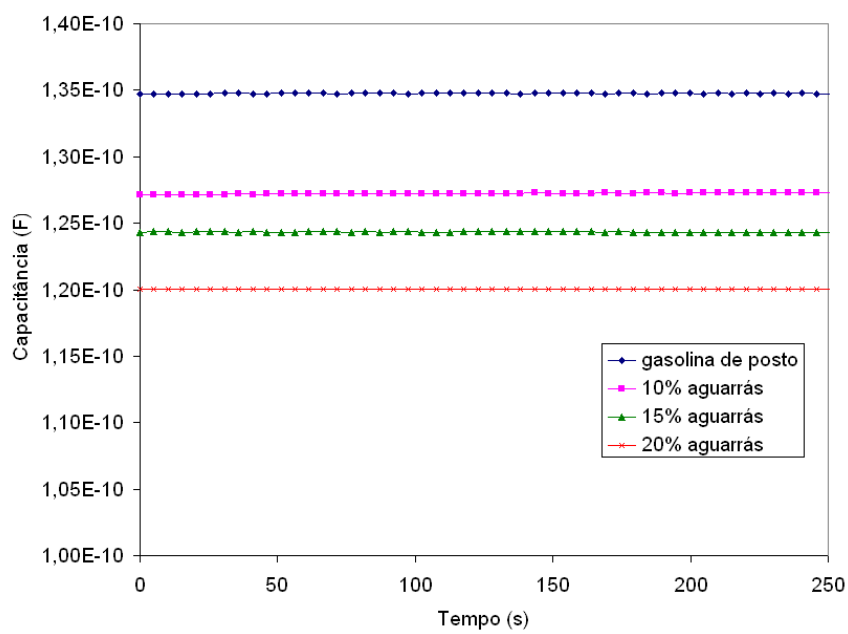

(a) Capacitância

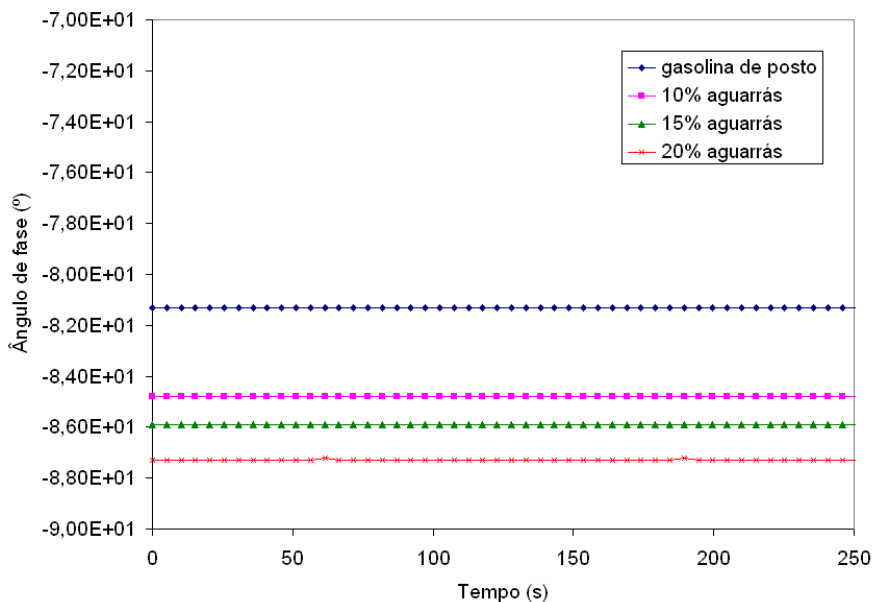

(b) Ângulo de Fase

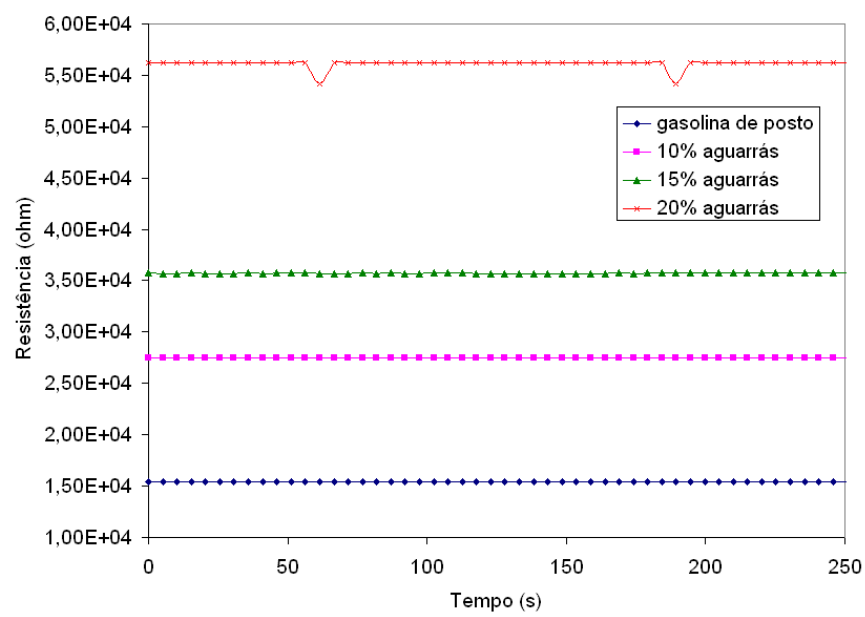

(c) Resistência

Figura 7.10- Gráficos para medições com a mistura gasolina-aguarrás para o sensor S1.

Nesse teste foi utilizado o sensor S1. As medições foram feitas da seguinte maneira: Primeiramente os parâmetros foram medidos para a gasolina C. Em seguida adicionou-se uma certa quantidade de querosene a essa gasolina. Depois foi acrescentado álcool pouco a pouco para obtenção das curvas para cada 
concentração. As proporções de álcool e querosene não são aqui reveladas a fim de se evitar o incentivo à fraude. Os resultados são mostrados na figura 7.11.

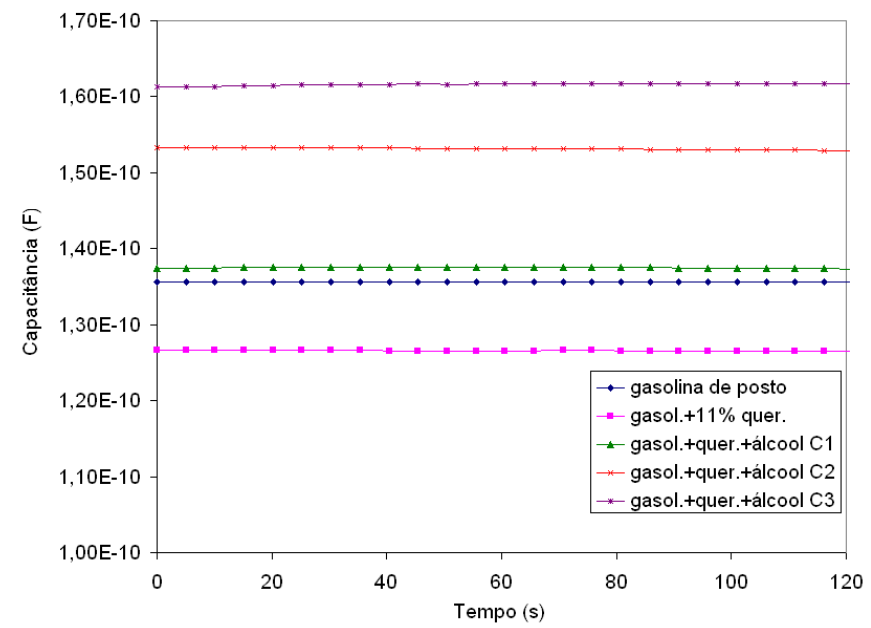

(a) Capacitância

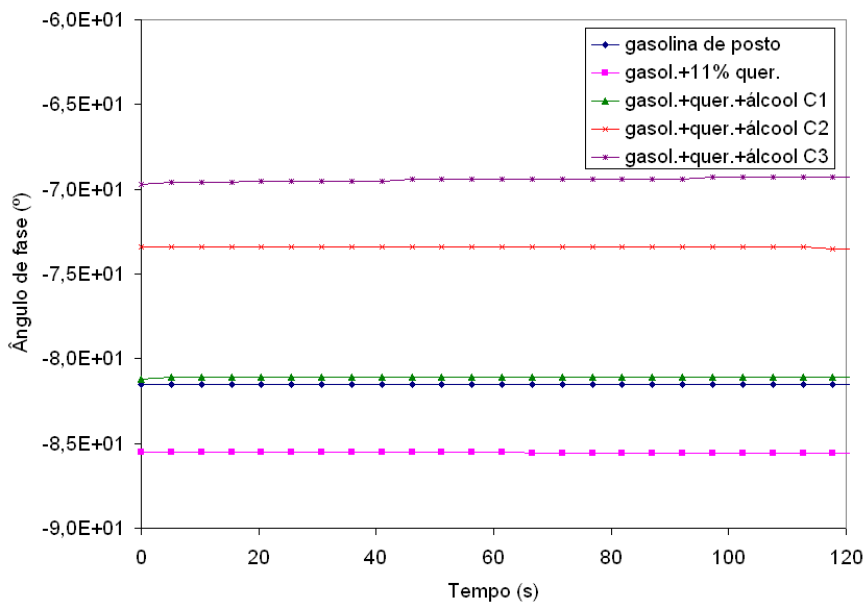

(b) Ângulo de Fase

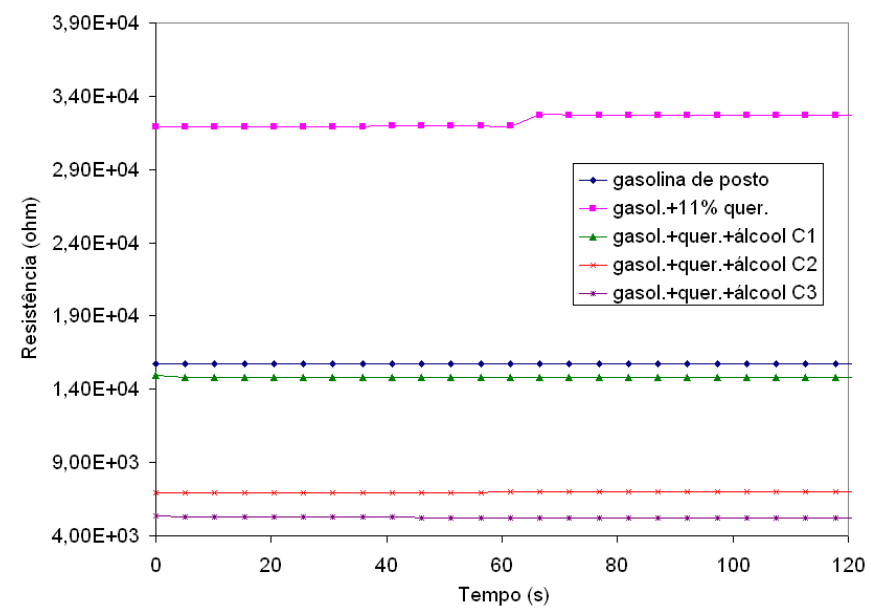

(c) Resistência

Figura 7.11- Gráficos para mistura gasolina + querosene + álcool onde $\mathrm{C} 1<\mathrm{C} 2<\mathrm{C} 3$ representam diferentes concentrações de álcool e querosene. 
Como era previsível, a capacitância caiu quando adicionado querosene à mistura e subiu quando adicionado etanol.

Infelizmente, a mistura de concentração $\mathrm{C} 1$, é composta por gasolina $\mathrm{C}$, álcool e querosene e apresenta os parâmetros muito próximos aos da gasolina $C$ verdadeira. Isso indica que é possível se preparar uma mistura falsa contendo etanol e compostos apolares que adicionada à gasolina, é capaz de enganar o sensor.

Essa é uma limitação do sensor. Entretanto esse efeito ocorre para uma proporção bem definida de compostos polares e apolares. Criar esse coquetel exigiria meios mais sofisticados de adulteração ou prévio conhecimento do princípio de funcionamento do sensor e da proporção da mistura.

\subsection{TESTE PARA CARROS FLEX}

$\mathrm{Na}$ figura 7.12 são apresentados resultados para misturas de gasolina com álcool hidratado combustível (AEHC).

A gasolina e o AEHC foram obtidos em um posto de combustível da grande São Paulo. O teste tem por objetivo verificar se o sensor pode ser utilizado em um carro flex para analisar a proporção da mistura gasolina-álcool. Foi utilizado o sensor S1.

A figura 7.12 mostra que a capacitância segue a tendência de aumentar seu valor conforme é aumentada a concentração de álcool hidratado. Entretanto, o ângulo de fase e a resistência mudam de tendência a um certo valor de concentração. Da mesma forma que na mistura etanol-água, o comportamento imprevisível desses dois parâmetros podem estar sendo influenciados por efeitos de mobilidades de portadores de material contaminante. A gasolina é apolar, mas o álcool tem uma certa quantidade de portadores que é mais alta ainda que o álcool anidro devido à presença de água. Portanto, como já discutido em outros resultados, a análise deve ser feita com base na capacitância. 


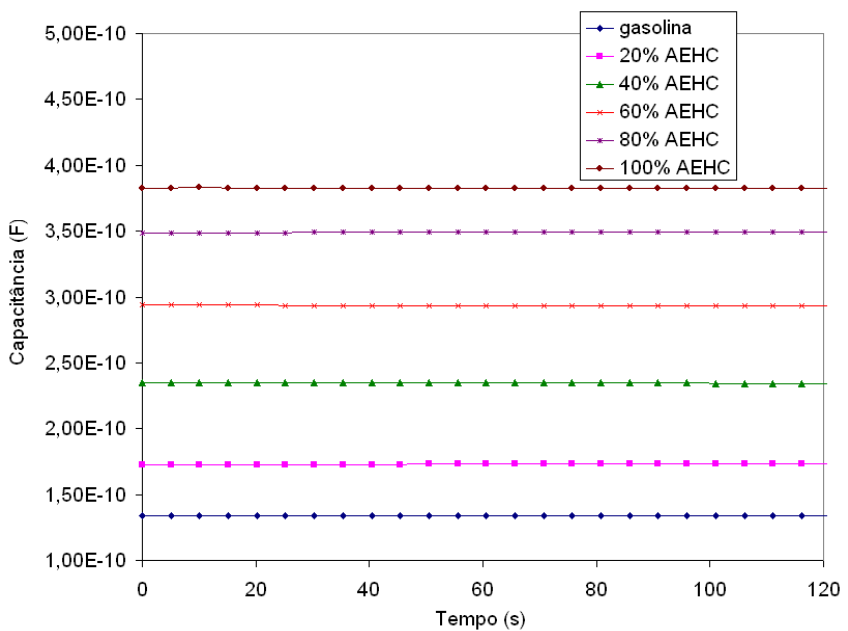

(a) Capacitância

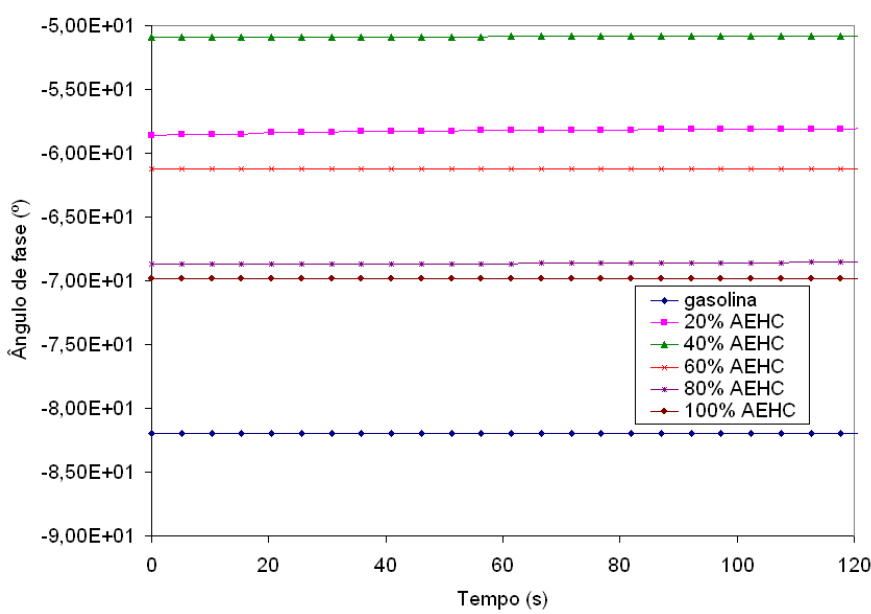

(b) Ângulo de Fase

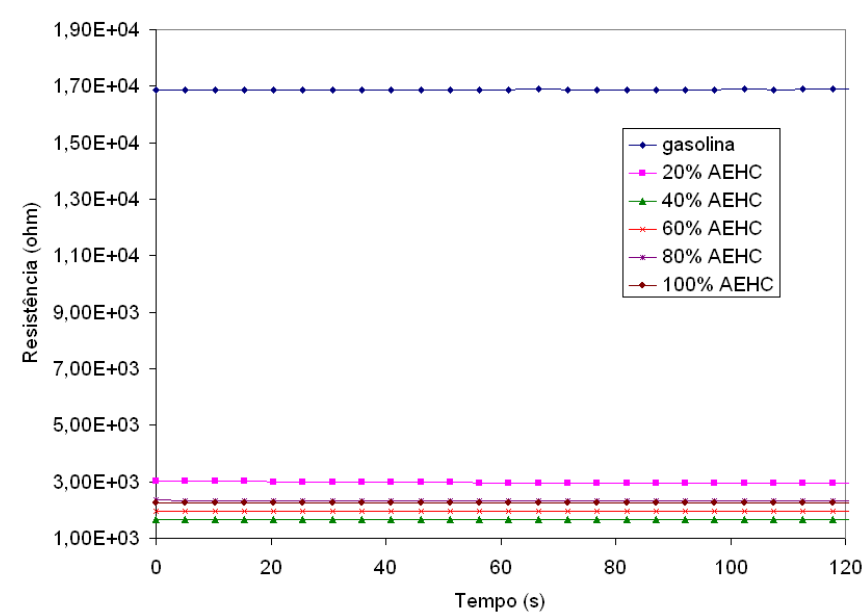

(c) Resistência

Figura 7.12- Gráficos para mistura gasolina álcool hidratado para simulação de misturas que podem ocorrer num carro flex.

\subsection{MEDIÇÕES COM COMPOSTOS APOLARES}

Os resultados mostrados na figura 7.13 foram obtidos com o objetivo de se avaliar o desempenho do sensor ao analisar uma mistura composta somente de 
compostos apolares, cujas constantes dielétricas assumem valores baixos e semelhantes entre si.

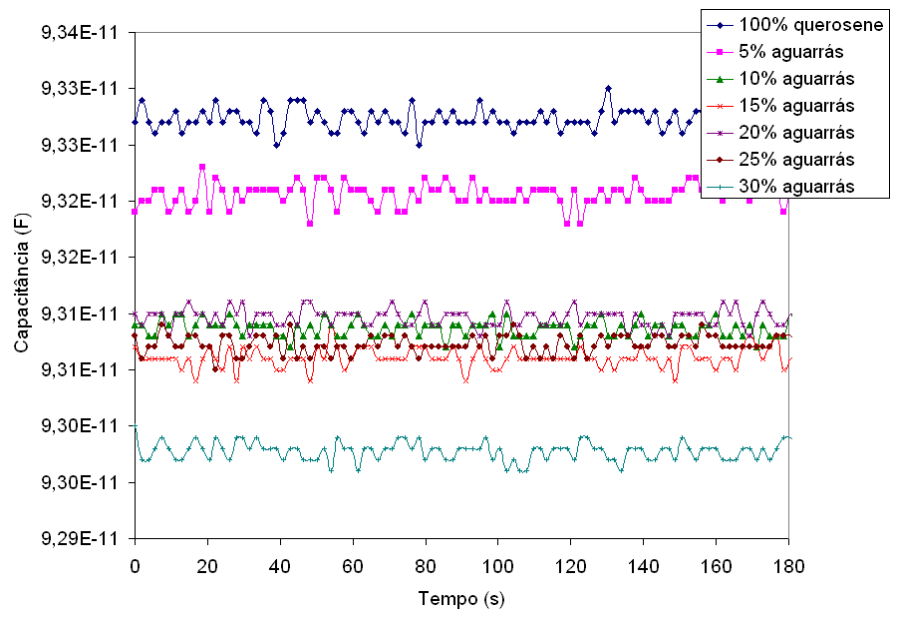

(a) Capacitância

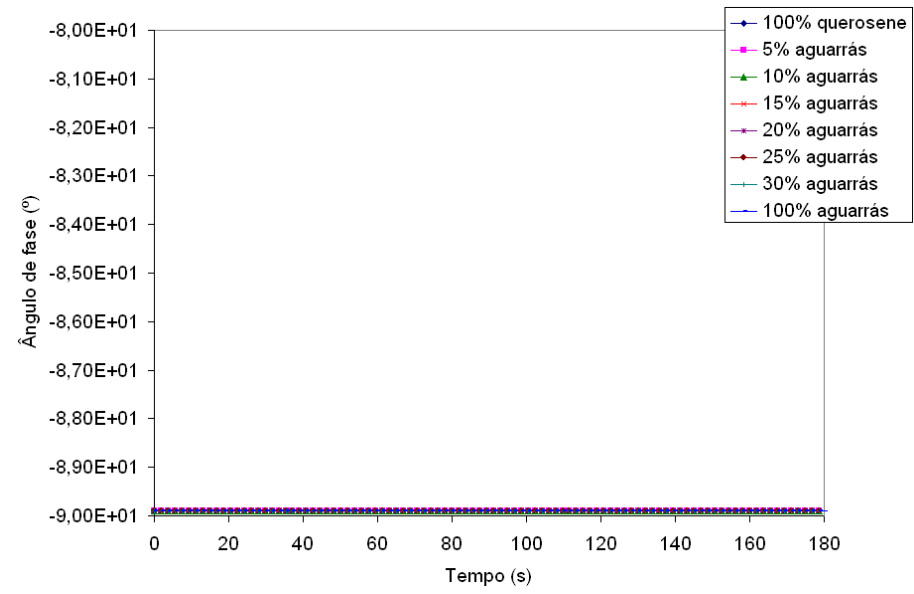

(b) Ângulo de Fase

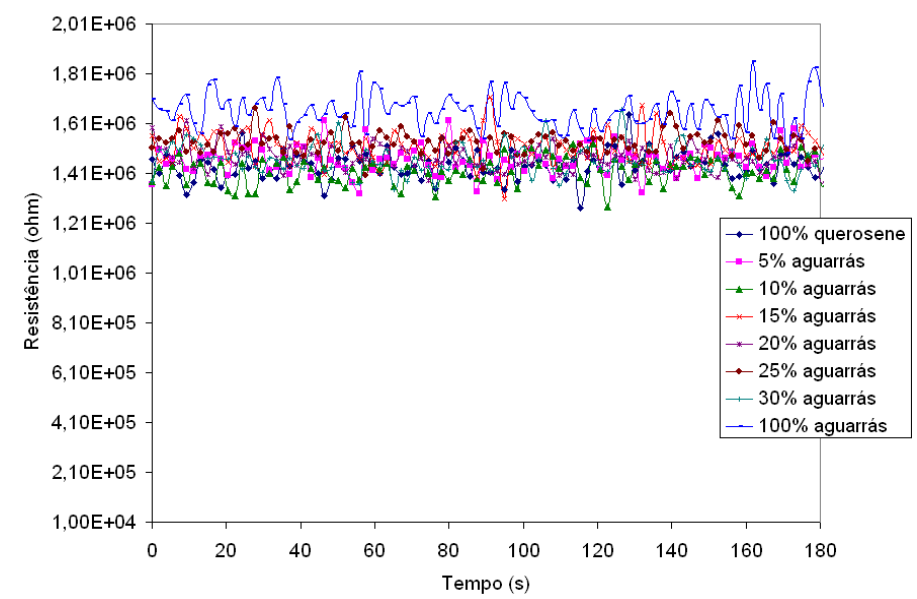

(c) Resistência

Figura 7.13- Gráficos para misturas de aguarrás e querosene

Como não foi obtida gasolina tipo A para realizar testes, utilizaram-se misturas de querosene e aguarrás. Essa mistura é suficiente para cumprir o objetivo desse teste. Foi utilizado o sensor S1. 
Como pode ser observado na figura 7.13 , a variação nos valores dos parâmetros medidos é muito pequena. O que era previsível, pois ambos compostos são apolares e originários do processo de refino do petróleo, tendo constantes dielétricas de valores muito próximos.

Se a gasolina não fosse adicionada de etanol, sua adulteração por compostos apolares dificilmente seria perceptível a este tipo de sensor.

\subsection{RESULTADOS COM APLICAÇÃO DE TENSÃO DE BIAS CC}

Quando se aplica uma tensão Bias CC ao sensor durante as medições, ocorrem mudanças nos valores de capacitância e ângulo de fase e resistência. Essa tensão CC pode causar oxidação da amostra nos casos em que há água na mistura. A oxidação ocorre devido à eletrólise da água, com liberação de oxigênio gasoso.

Foram feitas algumas medições para avaliar a o efeito de diferentes valores de tensão CC nos diferentes dielétricos envolvidos neste trabalho.

\subsubsection{Efeito da tensão de Bias CC no Etanol Anidro}

Nessa seqüência foi utilizado o sensor S4 mergulhado em etanol anidro. As medições foram realizadas aplicando-se diferentes tensões CC. Os resultados são mostrados na figura 7.14 .

Observando-se a figura 7.14 (a) notas-se que há uma variação no valor da capacitância com o acréscimo da tensão CC. O valor se eleva no início da medição e tende a adquirir um valor estável que depende do valor da tensão $C C$ aplicada.

Para tensões de bias CC baixas ( $1 \mathrm{~V}$ a $2 \mathrm{~V}$ ), houve pouca mudança nos valores de capacitância medidos. Para valores a partir de $3 \mathrm{~V}$ aproximadamente, a tensão contínua afeta os valores de capacitância. O sinal contínuo tende a orientar os dipolos permanentes e formar dipolos induzidos. Como resultado da maior polarização, o valor da capacitância aumenta. Os dipolos levam um certo tempo para adquirir uma nova posição de equilíbrio. Por isso há uma variação nos valores da capacitância, principalmente no início das medições, antes de tenderem a um valor estável.

Aplicando-se valores mais altos de tensão CC, a capacitância também apresentará valores mais altos. 
O ângulo de fase e a resistência se comportam de maneira menos previsível devido a fatores já especulados como mobilidade de portadores.

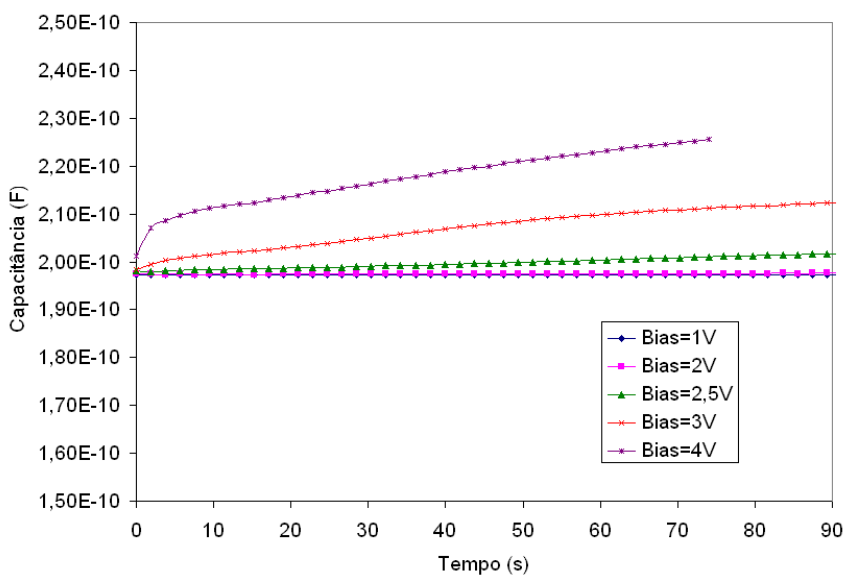

(a) Capacitância

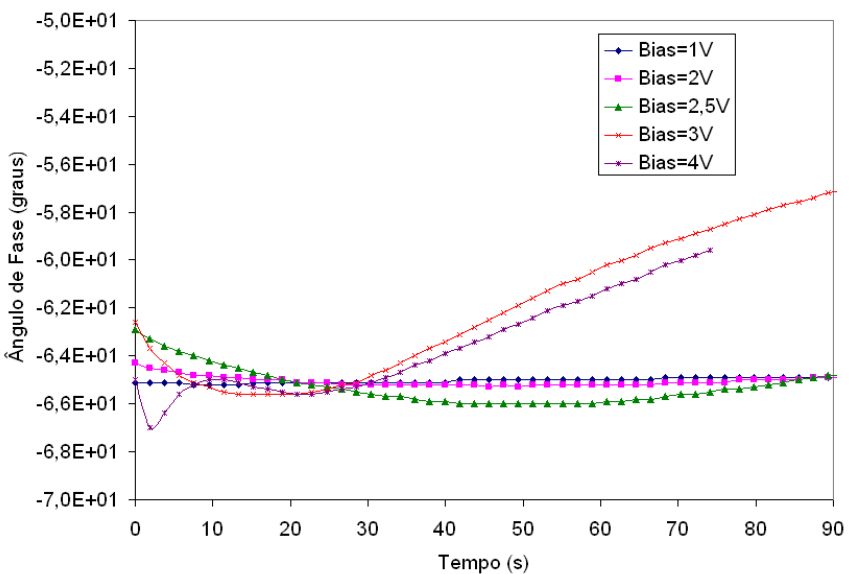

(b) Ângulo de Fase

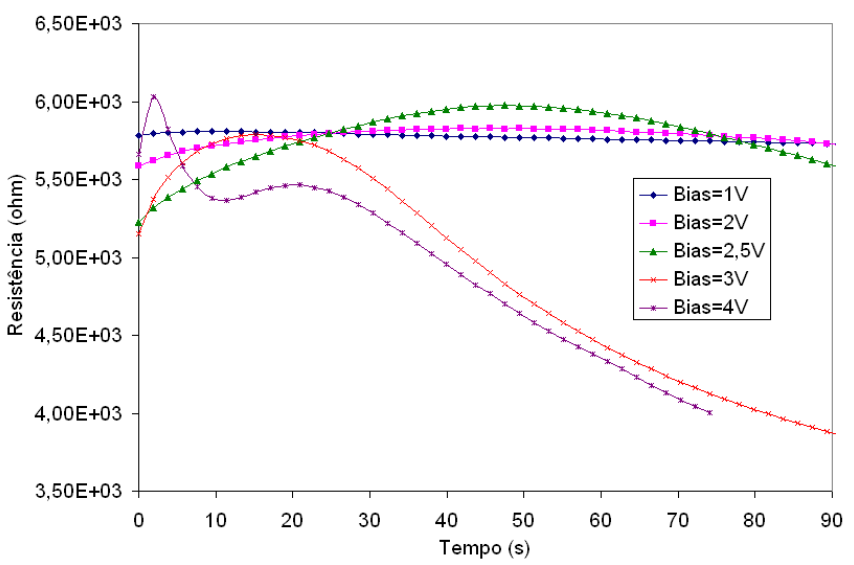

(c) Resistência

Figura 7.14- Medições com diferentes tensões de bias CC aplicadas ao sensor S4 mergulhado em etanol anidro.

\subsubsection{Efeito da tensão de bias CC na água}

Para a água também foi utilizado o sensor S4. Os resultados podem ser vistos na figura 7.15 . 


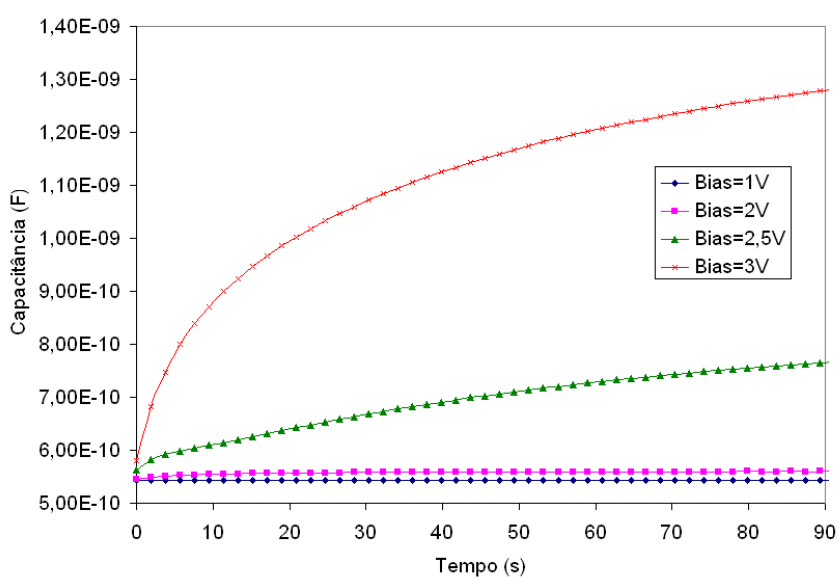

(a) Capacitância

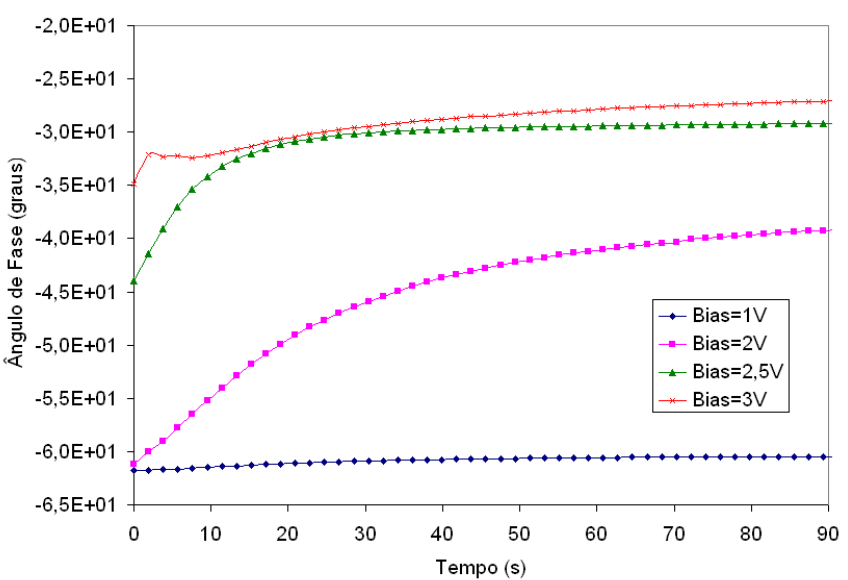

(b) Ângulo de Fase

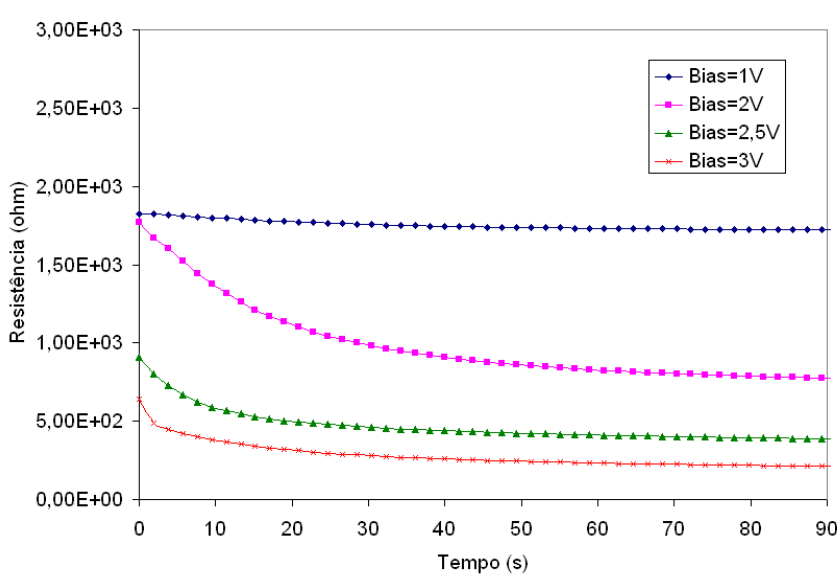

(c) Resistência

Figura 7.15- Medições com diferentes tensões CC aplicadas ao sensor mergulhado em água.

O efeito é similar ao que ocorre no etanol, porém muito mais pronunciado. A capacitância adquire valores bem mais altos com o acréscimo da tensão CC. $O$ maior aumento da capacitância devido à tensão CC comparada ao etanol se deve à maior polarizabilidade da água. 
Durante o experimento, para os valores mais altos da tensão CC (2,5V e 3V) foi observada a formação de bolhas.

A formação de bolhas indica que está ocorrendo eletrólise da água e oxidação de um dos eletrodos. O processo de eletrólise da água promove a liberação de oxigênio gasoso próximo a um dos eletrodos, podendo promover a oxidação desses eletrodos. Em uma análise anterior com outra amostra do sensor, observou-se oxidação quando aplicada tensão CC a partir de 3V por alguns minutos. Por isso essa análise foi feita em menor tempo e tensões até $3 \mathrm{~V}$ para evitar a oxidação. A figura 7.16 mostra a oxidação do sensor, que pode ser notada pela diferença no brilho dos dois eletrodos.
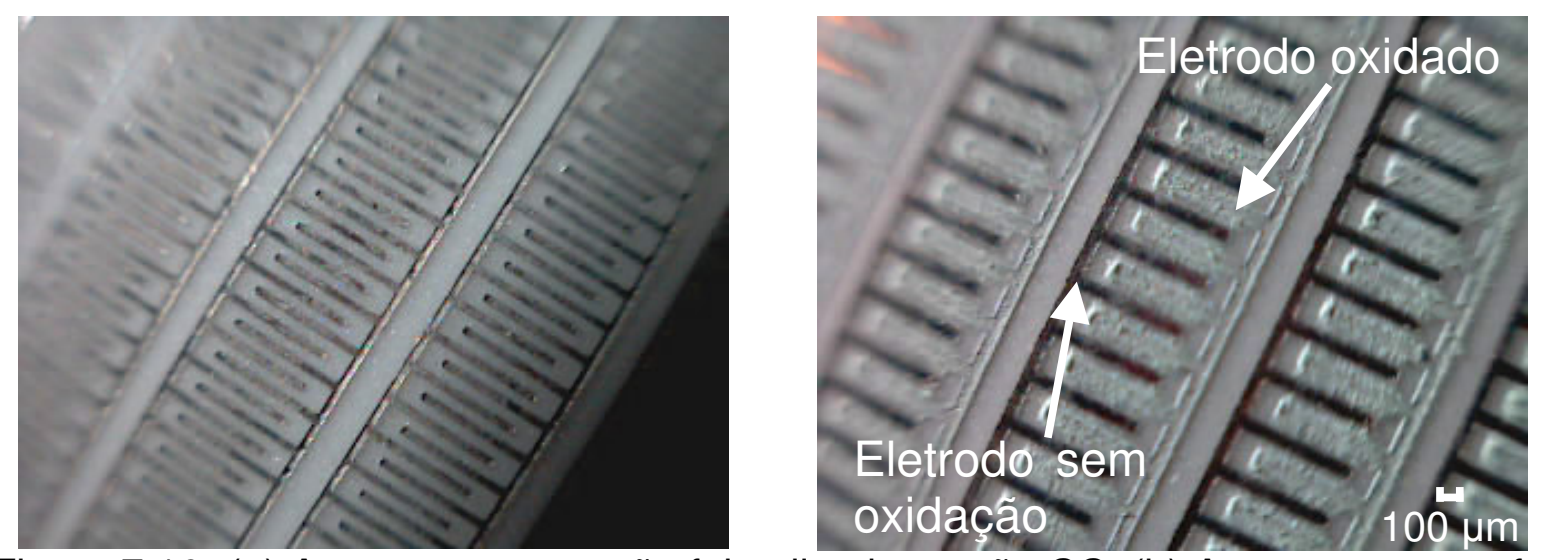

Figura 7.16- (a) Amostra em que não foi aplicada tensão CC. (b) Amostra em que foi aplicada uma tensão CC de 3V. Um dos eletrodos sofreu oxidação.

\subsubsection{Efeito da tensão de bias CC em compostos apolares}

O objetivo desse teste é verificar se a tensão CC aplicada influencia as medições quando há somente líquidos apolares na mistura. Foi realizado com querosene. Não poderia ser feito com gasolina $C$ devido à adição de álcool anidro em sua composição. Foi utilizado o sensor S2.

Como pode ser observado nos gráficos da figura 7.17, a aplicação de tensão CC não causa influências significativas no valor da capacitância em querosene. Isso se deve ao fato de o querosene ser um composto apolar. Sendo assim não há dipolos permanentes que sofram mudanças na orientação devido à tensão CC aplicada. Apenas os dipolos induzidos é que sofrem uma pequena orientação com o campo elétrico constante da tensão CC aplicada. 


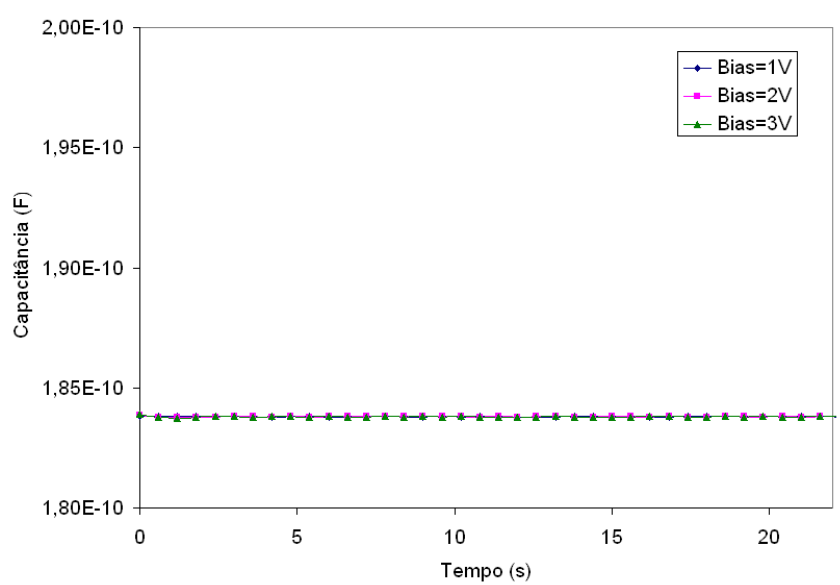

(a) Capacitância

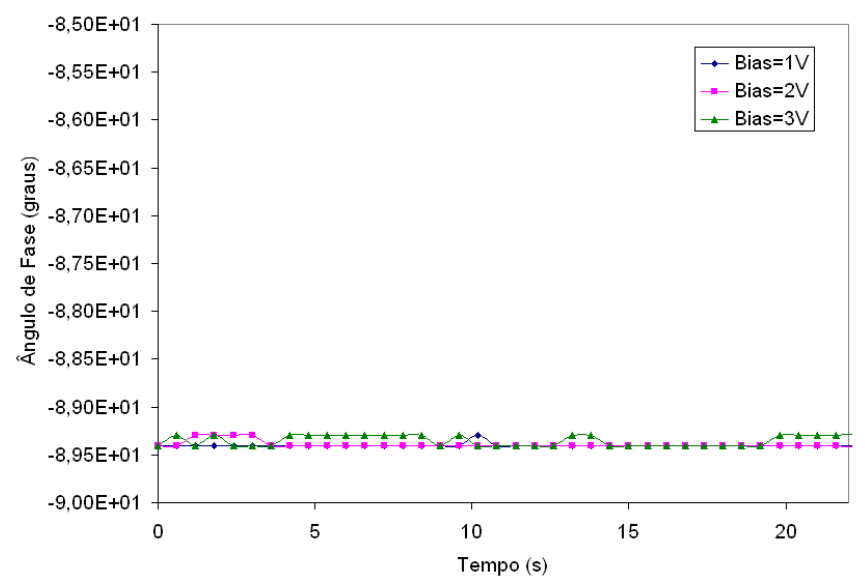

(b) Ângulo de Fase

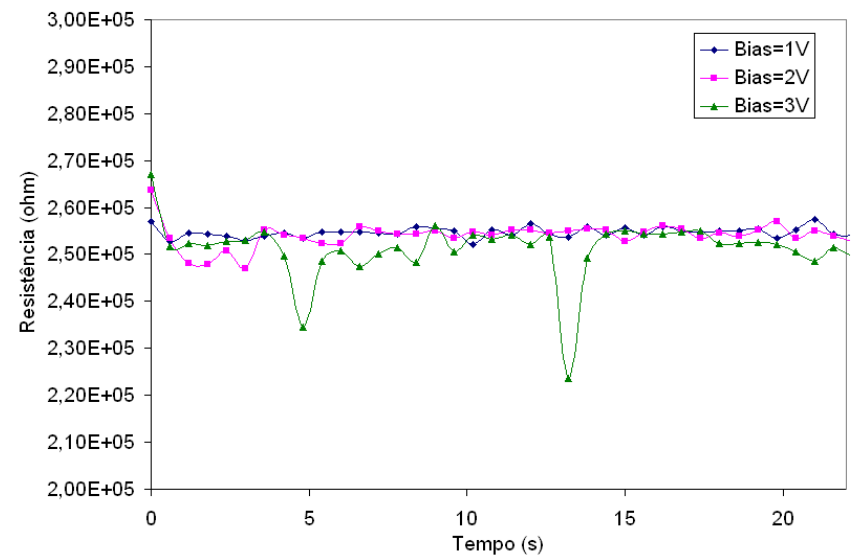

(c) Resistência

Figura 7.17- Medições com diferentes tensões CC aplicadas ao sensor mergulhado em querosene.

\subsubsection{Efeito da tensão de bias CC na mistura gasolina-álcool}

$\mathrm{Na}$ figura 7.18 são mostradas curvas extraídas com diferentes tensões CC para uma mistura de gasolina C com $6 \%$ de etanol anidro. Foi utilizado o sensor S5. 


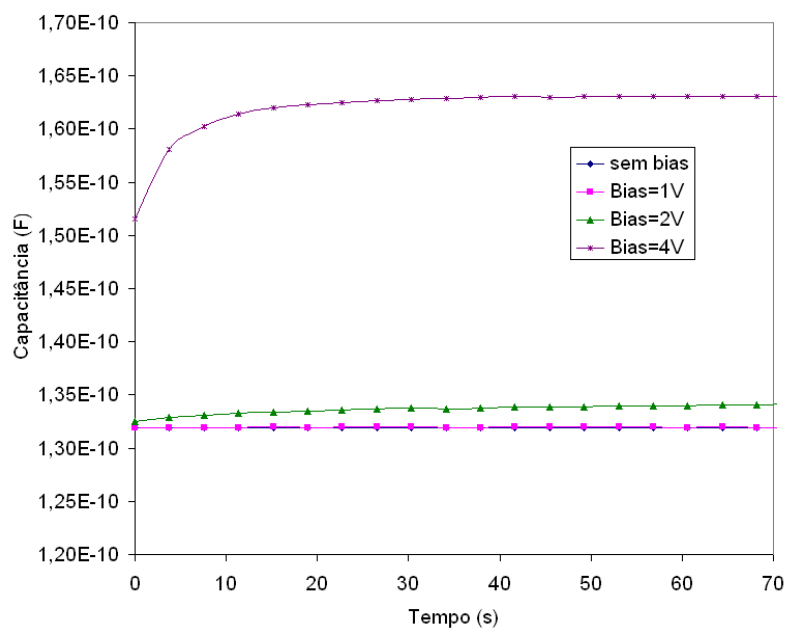

(a) Capacitância

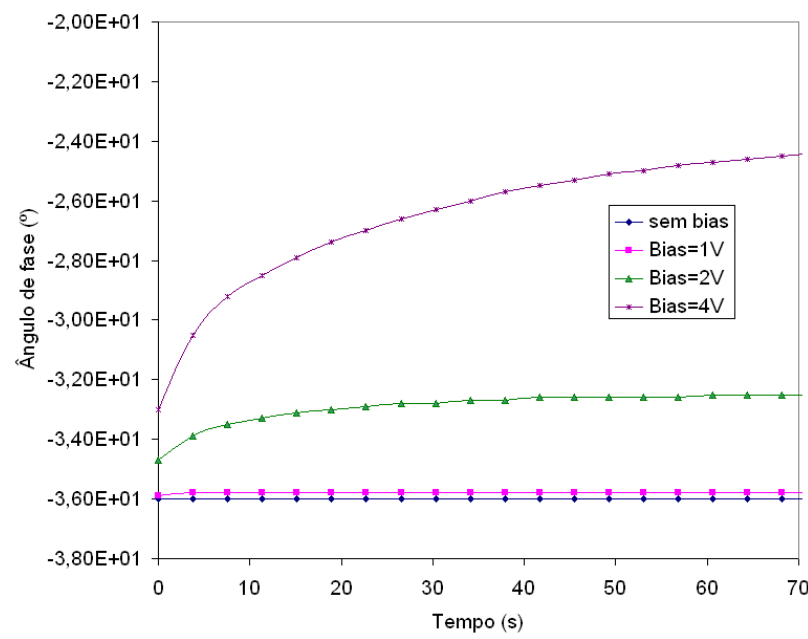

(b) Ângulo de Fase

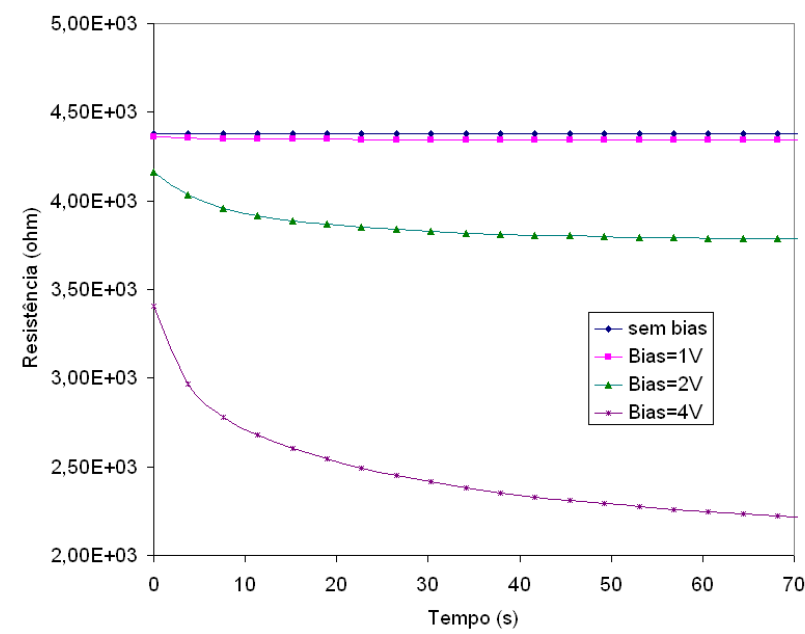

(c) Resistência

Figura 7.18- Medições com diferentes tensões CC aplicadas ao sensor mergulhado em mistura gasolina-etanol.

A exemplo dos compostos polares, um baixo valor de tensão $\mathrm{CC}$, causa poucas mudanças nas curvas. Mas quando esse valor é elevado, há mudanças nos três parâmetros medidos. A capacitância apresenta uma variação no começo das medições e tende a se estabilizar com o tempo a um valor mais alto que nas 
medições sem bias e com bias baixas. Esse efeito se deve à reorientação das moléculas do etanol presentes na mistura.

\subsection{COMPARAÇÃO DE RESULTADOS SIMULADOS E EXPERIMENTAIS}

$\mathrm{Na}$ seção 6.3.2, foram mostrados resultados de simulações de capacitância para o sensor $\mathrm{S} 1$ imerso em querosene. Para essa simulação foi encontrado valor de capacitância de $83,81 \mathrm{pF}$. O valor experimental equivalente está na curva do querosene da figura 7.13a. Esse valor foi de 93pF. Essa discrepância entre os dois valores se deve a possíveis imprecisões ocorridas durante as medições das dimensões reais do sensor. Podem ter ocorrido erros nas medições da altura dos eletrodos, largura e/ou espaçamento entre os mesmos.

A simulação para o sensor imerso em etanol foi realizada utilizando-se parâmetros do sensor S2. Os resultados são mostrados na seção 6.3.2. O valor de capacitância encontrado foi $674,02 \mathrm{pF}$. O valo experimental equivalente está na curva do etanol anidro da figura 7.5a. Esse valor foi de $685 \mathrm{pF}$. Neste caso houve uma boa concordância entre os valores experimental e simulado.

Assim, com base nos resultados obtidos, pode-se considerar a equação 7.1 para o valor de capacitância medido pelo sensor.

$$
\mathrm{C}=\varepsilon_{0} \mathrm{~K} \frac{\mathrm{LL} \cdot \mathrm{H}}{\mathrm{G}} \mathrm{fF} \cdot \mathrm{CAP}
$$

Onde

C é a capacitância

$\epsilon_{0}$ é a permissividade do vácuo

K é a constante dielétrica do dielétrico

LL é o comprimento em que há emparelhamento de dedos.

$\mathrm{H}$ a altura dos dedos

G, o gap (espaçamento) entre os eletrodos

$\mathrm{f}_{\mathrm{F}}$ é um fator de forma

CAP é o número de capacitores

O uso do fator de forma serve para corrigir diferenças devidas ao fato de 0 sensor não seguir o modelo do capacitor de placas planas infinitas. 


\section{CONCLUSÕES}

As etapas de modelagem e simulação computacional do sensor estudado neste trabalho contribuíram para a compreensão de diversos comportamentos observados experimentalmente. Além disso, foi um método muito importante de projeto, possibilitando a previsão de diversas características antes mesmo da fabricação do sensor.

Durante os testes foram simuladas diferentes situações de adulteração de álcool hidratado combustível (AEHC) e gasolina. O sensor se mostrou capaz de identificar adulteração de álcool por água, gasolina por álcool e gasolina por compostos orgânicos. A eficiência é tanto melhor quanto maior for a diferença nos valores de constante dielétrica entre o combustível e o adulterante.

Compostos polares e apolares causam efeitos opostos na constante dielétrica da gasolina. Assim, a identificação de adulterações de gasolina por compostos apolares como querosene e aguarrás, é possível devido ao etanol presente na gasolina tipo C. Isso faz com que haja uma diferença entre a constante dielétrica da gasolina $\mathrm{C}$ e os adulterantes apolares. Haveria grandes dificuldades em se identificar adulterações de gasolinas de baixa constante dielétrica (próxima a 2) por compostos apolares. Contudo, há uma tendência de se adicionar etanol à gasolina também em outros países como a mistura chamada E10 nos EUA. O sensor proposto poderia ser utilizado também em países que utilizem esse tipo de combustível.

Eventualmente pode ser preparada uma mistura de álcool e um composto apolar em uma proporção específica que apresenta constante dielétrica semelhante à gasolina $\mathrm{C}$. Uma mistura nessa proporção, que é muito específica, pode dificultar a análise. Entretanto, para qualquer outra proporção, a fraude será identificada. A concentração dessa mistura não será revelada a fim de se evitar o incentivo à fraude. Além disso, o uso de diferentes solventes encarece o processo de adulteração. Para o caso de uma adulteração com apenas um dos tipos de compostos, o sensor apresentou bom desempenho.

O sensor apresentou boa sensibilidade, identificando variações de um por cento em simulações de adulteração de álcool e de gasolina. 
Além da identificação de adulteração de combustíveis, o sensor pode ser utilizado em automóveis flex na identificação de diferentes proporções da mistura gasolina-álcool.

O sensor apresenta diversas características que favorecem seu uso em automóveis. Entre elas, a simples fabricação, baixo custo de produção, baixo consumo de energia e sua boa eficiência na identificação de misturas em diferentes proporções.

Esse trabalho demonstrou a viabilidade de utilização do micro-sensor do tipo capacitivo para a análise dos principais tipos de adulteração de combustíveis, e para a medição da concentração da mistura álcool-gasolina em carros flex. Estudos futuros poderão ser feitos para adequar o sensor à produção em escala comercial, incluindo: sua integração com um circuito de medição, encapsulamento e dimensões finais mais reduzidas. 


\section{SUGESTÕES DE TRABALHOS FUTUROS}

Para trabalhos futuros poderão ser estudadas maneiras de se colocar 0 sensor em um automóvel. Um dos locais em que deve ser colocado é próximo à entrada de combustível. Nesta posição o sensor detectaria uma adulteração do combustível durante o abastecimento. Outra posição importante é antes do bico de injeção. Neste caso o sensor analisaria a mistura para controle dos sistemas de injeção e ignição.

Resultados de simulação serão melhor aproveitados para a otimização das dimensões do sensor levando em consideração fatores físicos e limitações do processo de fabricação utilizado.

Também poderão ser estudadas maneiras de se calcular a constante dielétrica das misturas analisadas. $O$ cálculo pode ser feito assumindo-se para 0 sensor a equação do capacitor de placas planas acrescida de um fator de forma. Uma vez calibrado, o sensor poderá determinar a constante dielétrica de qualquer proporção de uma mistura. Desta maneira poderão ser obtidas curvas de constante dielétrica, além da capacitância.

De acordo com alguns resultados deste trabalho, o sensor apresenta uma limitação quando em uma adulteração há utilização de compostos polares e apolares numa proporção tal que a constante dielétrica resultante seja semelhante à da gasolina $\mathrm{C}$ verdadeira. Para trabalhos futuros, pretende-se incorporar um módulo, que utilize um princípio diferente de medição e que seja capaz de distinguir solventes apolares da gasolina tipo A. Entre as possibilidades de princípio de funcionamento do novo sensor está a medida de alguma propriedade que dependa da densidade ou viscosidade. O novo sensor trabalharia em conjunto com o sensor capacitivo. As informações dos dois sensores seriam cruzadas para que a limitações fossem mutuamente corrigidas, o que elevaria a eficiência da análise do combustível.

O sensor deverá ser acoplado a um circuito de medição de capacitância de dimensões reduzidas e com possibilidade de comunicação com um sistema de controle microprocessado. Já existem no mercado alguns circuitos integrados adequados à medição de capacitância de sistemas micro-eletro-mecânicos (MEMS). 
Poderão ser elaborados sistemas de controle, baseados em microcontroladores, com características adequadas ao uso em automóveis e em postos de gasolina.

Poderá ser estudado algum algoritmo computacional que melhore a precisão e exatidão dos resultados. 


\section{REFERÊNCIAS BIBLIOGRÁFICAS}

ABNT, INMETRO, SBM. Guia para a Expressão da Incerteza de Medição. INMETRO, Brasil, 1998.

A CIDADE. 6 out. 2007. Disponível em:

<http://www.jornalacidade.com.br/noticias/?noticiald=59682>. Acesso em 23 out. 2007.

AGENCIA BRASIL. 28 mar. 2007. Disponível em:

$<$ http://www.agenciabrasil.gov.br/noticias/2007/03/28/materia.2007-03-

28.3368221729/view>. Acesso em: 23 jan. 2008.

ALONSO, M. R. Análise da Lucratividade de Produtos e Clientes: O Caso da Logística de Óleos Lubrificantes Básicos Parafínicos na Petrobrás. 2001. $108 f$. Dissertação (Mestrado)- Universidade Federal de Santa Catarina, Florianópolis, 2001.

ANP - AGÊNCIA NACIONAL DO PETRÓLEO, GÁS NATURAL E BIOCOMBUSTÍVEIS. Disponível em: <www.anp.gov.br>. Acesso em: 13 set. 2007.

AUTOPLAST MOTORES. Disponível em:

<http://www.autoplast.com.br/produtos/limpeza/carbonizacao.htm>. Acesso em: 3 jun. 2008.

BANNATYNE, R. The Sensor Explosion and Automotive Control Systems, Sensors, vol. 17, 2000. Disponível em:

< http://archives.sensorsmag.com/articles/0500/92/index.htm>, acesso em: 22 abril 2008.

BECKMANN et al. Analysis of Complex impedances in CMOS for chemical sensor aplications.

Sensors and actuators A, v. 62, p. 734-738, 1997.

BOSCH. Disponível em <www.bosch.com.br> . Acesso em 15 abr. 2008.

BOSH, R. Manual de tecnologia automotiva. 05ํㅡㄹ. ed. Tradução

BROWN, W. H.; FOOTE, C. S.; IVERSON, B. L. Organic Chemistry. Belmont, CA : Thomson Brooks/Cole. 2005.

CALLE, F. R.; BAJAY, S. V.; HOTHMAN, H. Industrial Uses of Biomass Energy, 2000.

CRAING, D. Dielectric Analisysis of Pharmaceutical Systems. London, GBR: Taylor \& Francis, Limited, 1996. 
DIAS, J. A. et al, Entendendo a adulteração.3를 ed. Ministério Público Federal. Jul. 2007. Disponível em: <www.prsp.mpf.gov.br/marilia>. Acesso em: 23 jan. 2008.

EAR LOGAN, Jr. Thermodynamics: Processes and Applications. New York, NY, USA: Marcel Dekker Incorporated, 1999.

EDDY, D. S.; SPARKS, Douglas R. Application of MEMS technology in automotive sensors and actuators, Proceedings of the IEEE, vol. 86, No 8, 1998.

ESTADO DE HOJE. 19 out. 2007. Dispponível em: <http://www.estadao.com.br/estadaodehoje/20071019/not_imp67249,0.php>. Acesso em 23 out 2007.

FALATE, R. et al. Petroleum Hydrocarbon Detection with Long Period Gratings. SBMO/IEEE MTT-S International Microwave and Optoelectronics Conference Proceedings, 2003 SBMO/IEEE MTT-S International Microwave and Optoelectronics Conference - IMOC 2003, Proceedings, p. 907-910, 2003.

FALATE, R. et al. Fiber optic sensors for hydrocarbon detection. Sensors and actuators B, v.105, p.430-436, 2005.

FERNANDES, E. S. L.; COELHO, S. T. (Org.). Perspectivas do álcool combustível no Brasil. Sao Paulo : Instituto de Eletrotecnica e Nergia Usp, 1996.

FIGUEIRA, S. R. Os problemas de álcool como combustível nos EUA, no Japão e na União Européia e as possibilidades de exportação do Brasil. Piracicaba, 2005.

FLEMING, W. J. Overview of Automotive Sensors, IEEE Sensors Journal, vol. 1, p. 296-308, 2001.

FRADEN, J. Handbook of Modern Sensors: Physics, Designs, and Applications. Second edition. San Diego, California, 1996.

FRÖHLICH, H. Theory of Dielectrics: Dielectric Constant and Dielectric Loss. Oxford: Clarendon Press, 1968.

GALLAGHER, T. J. Simple Dielectric Liquids: Mobility, Conduction, and Breakdown. Oxford: Clarendon Press, 1975.

GALLO, W. L. R.; WALTER, A. C. S. Máquinas térmicas. 2ª edição. CABS, 1986.

GLOBO.COM. Disponível em:

<http://jornalnacional.globo.com/Jornalismo/JN/0,,AA1580932-3586,00-

AGROENERGIA+A+EUROPA+ENTRA+NA+CORRIDA+PELOS+BIOCOMBUSTIVEI

S.html >. Acesso em: 20 jun. 2008b.

GLOBO.COM. Disponível em:

$<$ http://jornalnacional.globo.com/Jornalismo/JN/0,,AA1581834-3586,00-

AGROENERGIA+A+PRODUCAO+AMERICANA.html>. Acesso em: 20 jun. 2008. 
GLOBO.COM-BOM DIA BRASIL. Disponível em:

<http://bomdiabrasil.globo.com/Jornalismo/BDBR/0,,AA1518534-3682,00-

ETANOL+EM+PAUTA.html> . Acesso em: 20 jun. 2008.

GLOBO.COM. G1. 19 abr. 2007. Disponível em:

<http://g1.globo.com/Noticias/SaoPaulo/0,,MUL24390-5605,00.html>. Acesso em 23 out. 2007a.

HALLIDAY, D.; RESNICK, R. Física v3. 2ª edição. Rio de Janeiro: Livros Técnicos e Cientificos, 1984.

HILL, N. E. et al. Dielectric properties and molecular behaviour. London; New York : Van Nostrand Reinhold, 1969.

HOFMANN, T. et al. Fluid Characterization Using Sensor Elements Based On Interdigitated Electordes. sensors and actuators B, v. 37, p. 37-42, 1996.

HOFMANN, T. et al. Comparison of a conventional with an advanced micromachined flexible-fuel sensor, sensors and actuator A, 61, pp. 319-322, 1997.

KEATING, E. L. Applied Combustion. Second Edition. Boca Raton, FL: CRC Press, 2007.

LEE, S.; SPEIGHT, J. G.; LOYALKA, S. K. Handbook of alternative Fuel Technology. Boca Raton, FL: CRC Press, 2007.

LIMA, J. O. et al. Biodiesel of tucum oil, synthesized by methanolic and ethanolic routes. Fuel, n. 87, p. 1718-1723, 2008.

LIMA J. P. A. et al. Photothermal Detection of Adulterants in Automotive Fuels. Analytical Chemistry, v. 76, p. 114-119, 2004.

MATWEB - MATERIAL PROPERTY DATA. Disponível em: <www.matweb.com>. Acesso em: 21 nov. 2007.

MENDONÇA, L. G. D.; IBRAHIM, R. C., Interdigitated-type Microsensor to Measure Solution Concentration, ABCM Symposium Series in Mechatronics, v. 2, p. 465-468, 2006, Disponível em:

<http://www.abcm.org.br/symposiumSeries/SSM_Vol2/ssMechatronicsSectionVI.sht $\mathrm{ml}>$.

MENDONÇA, L. G. D.; IBRAHIM, R. C., Microsensor for the Measurement of Concentration of Liquid Solutions, ECS Transactions - Microelectronics Technology and Devices SBMICRO2006, v. 4, p. 149-158, 2006.

MENDONÇA, L. G. D. et al. Interdigitated Capacitive Sensor to Verify the Quality of Ethanol Automotive Fuel, Proceedings of COBEM 2007, CD-ROM, article 2101, Brasilia, Brazil, 2007. 
MILTON, B. E. Thermodynamics, combustion and engines. 1st ed. London : Chapman \& Hall, 1995.

MINTEER, S. Alcoholic Fuels. Boca Raton, FL: CRC Press, 2006.

O GLOBO ONLINE. 12 out. 2007. Disponível em:

<http://oglobo.globo.com/sp/mat/2007/10/12/298143275.asp>. Acesso em: 23 out. 2007.

OMETTO, J. G. S. O Álcool combustível e o desenvolvimento sustentado. São Paulo: PIC, 1998.

PAIXÃO, T. R.. L. C.; CARDOSO, J. L.; BERTOTTI, M. The use of a copper microelectrode to measure the ethanol content in gasohol samples.

PETROBRAS DISTRIBUIDORA. Portal BR Disponível em: <www.br.com.br>. Acesso em: 27 set. 2007.

PORTAL DO BIODIESEL. Disponível em: < http://www.biodiesel.gov.br/ > Acesso em: 20jun. 2008.

REDE BAIANA DE BIOCOMBUSTÍVEIS. 6 jun. 2007. Disponível em: $<\mathrm{http}: / /$ www.rbb.ba.gov.br/index.php?prefixo=det\&menu=noticia\&id=241>. Acesso em: 23 jan. 2007.

ROCHA, M. S.; SIMÕES-MOREIRA, J. R. A simple impedance mothod for determining ehtanol and regular gasoline mixtures mass contents, 2005.

ROY, S. Fiber optic sensor for determining adulteration of petrol and diesel by kerosene. Sensors and Actuators B, 55, p. 212-216, 1999.

SANTOS, E. J. Determination of ethanol content in gasoline: theory and experiment. Proceedings SBMO/IEEE MTT-S IMOC, p. 349-353, 2003.

SOLOMONS, T. W. Graham. Fundamentals of organic chemistry. New York : Wiley, 1990.

SOLYMAR, L.; WALSH, D. Lectures on the Electrical Properties of Materials. Great Britain: Oxford University Press, 1993.

SPEIGHT, J. G. The Chemistry and Technolgy of Petroleum. Marcel Dekker, Inc., New York basel.

TAKESHITA, E. V. Adulteração de gasolina por adição de solventes: Análise dos parâmetros físico- químicos. 2006. 102f. Dissertação (Mestrado) - Centro Tecnológico, Universidade federal de Santa Catarina, Florianópolis, 2006.

TAREEV, B. Physics of Dielectric Materials. Moscow: Mir Publishers, 1979. 
TIPLER, P. A. Física. v2. Rio de Janeiro: Guanabara, 1990.

TOMITA, E. et al. In situ measurement of hydrocarbon fuel concentration near a spark plug in an engine cylinder using the $3.392 \mu \mathrm{m}$ infrared laser absorption method: application to an actual engine. Measurement Science and technology, $v 14$, n 8, p 1357-1363, August, 2003.

VENKATESH, P., MEMS in Automotive and Consumer Electronics. Sensors, Nov. 1, 2007. Disponível em: < http://www.sensorsmag.com/sensors/Automotive/MEMS-inAutomotive-and-Consumer-Electronics/ArticleStandard/Article/detail/473909>. acesso em: 22 abril 2008.

WEAST, R. C.; ASTLE, M. J.; BEYER, W. H. (Org.). CRC Handbook of Chemistry and Physics: a ready-reference book of chemical and physical data. $66^{\mathrm{TH}}$ edition. Boca Raton, Fla. : CRC Press, 1985.

WILLIAMS, P. R. D.; CUSHING, Colleen A.; SHEEHAN, Patrick J. Data Availiable for Evaluating the Risks and Benefits of MTBE and Ethanol as Alternative Fuel Oxygenates. Risk analysis, V. 23 No. 5, p. 1085-1115, 2003.

Yole Developpement. Disponível em < http://www.yole.fr/>. Acesso em 17 jul. 2008. 


\section{APÊNDICE A- EXEMPLO DE ROTINA UTILIZADA NA AQUISIÇÃO DE DADOS.}

Essa rotina utiliza um valor fixo de tensão e varia a freqüência do sinal durante as medições.

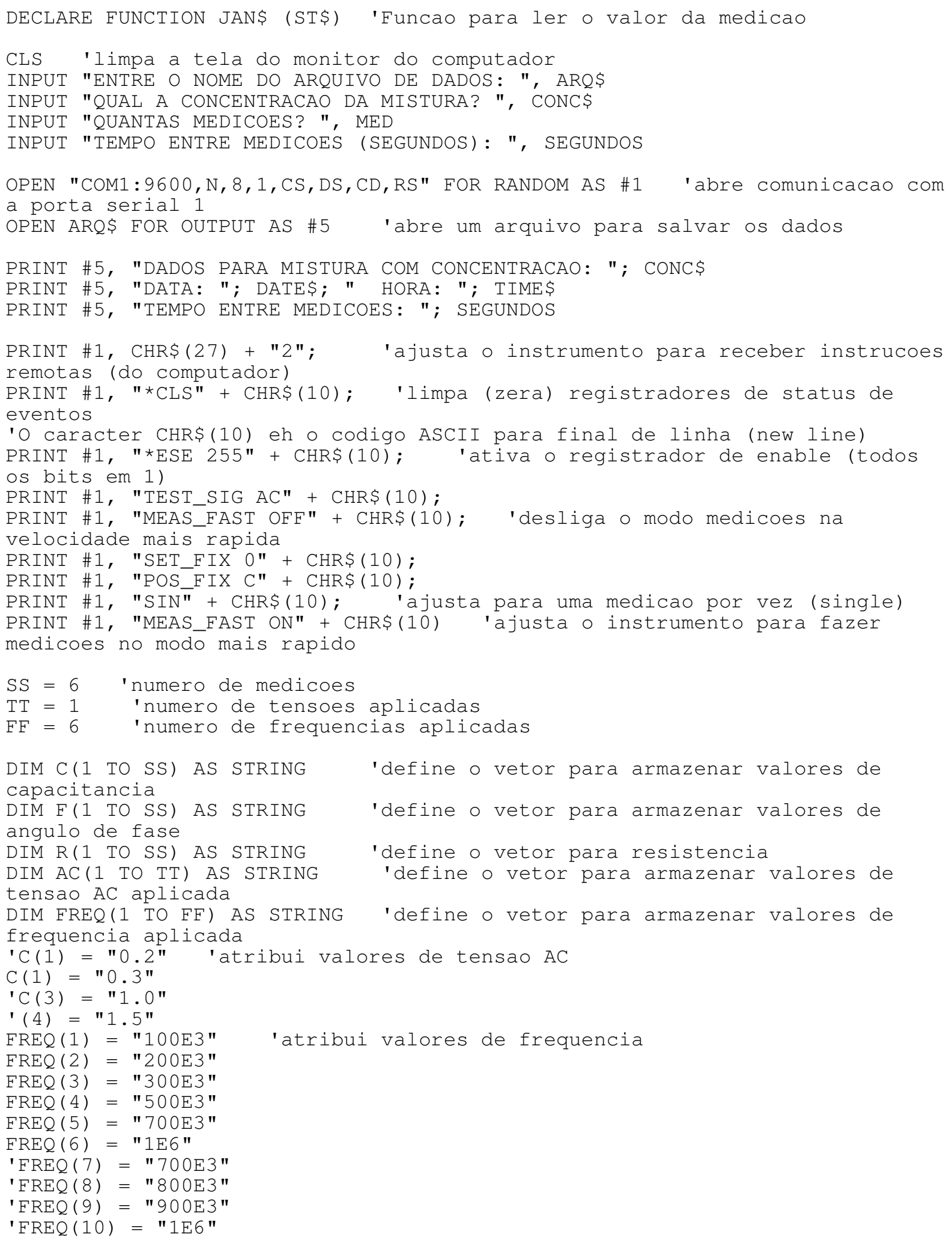




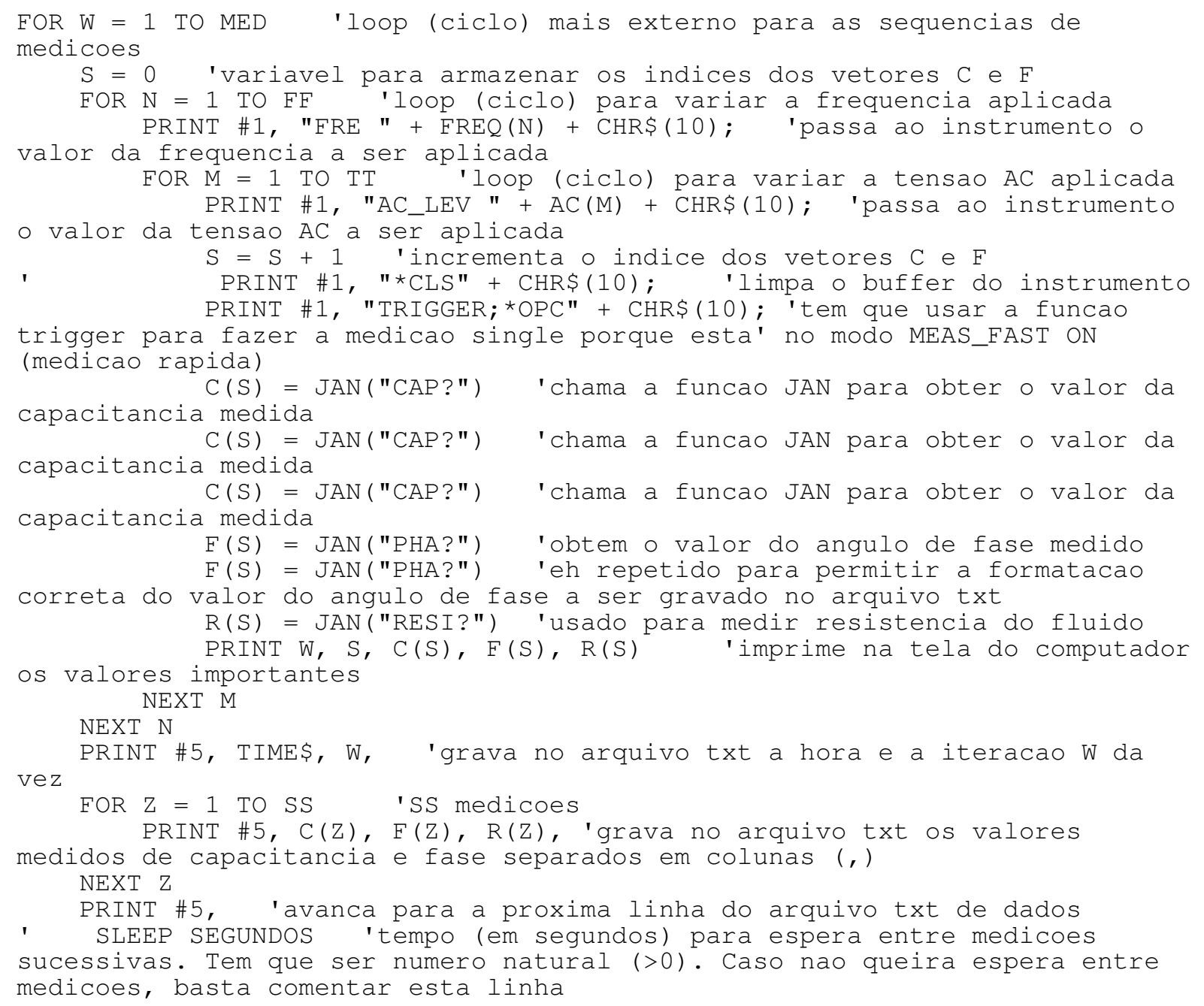

\section{NEXT W}

PRINT \#5, TIME\$ 'ao final de todas as medicoes, grava a hora no arquivo txt PRINT \#1, "*CLS" + CHR\$(10); 'limpa (zera) registradores de status de eventos

PRINT \#1, CHR\$(27) + "1"; 'passa o instrumento para modo local PRINT \#1, CHR\$ (27) + "1";

CLOSE \#1 'fecha o acesso ao instrumento

CLOSE \#5 'fecha o acesso ao arquivo txt

'FINAL DO PROGRAMA

FUNCTION JAN\$ (ST\$) 'funcao para ler o valor medido requisitado pelo parametro ST\$. Retorna o valor medido

FOR I = 1 TO 10000 'loop (ciclo) temporizador para esperar ate que a medicao seja terminada

$\mathrm{J}=2 \star \mathrm{I}$ 'loop temporizador

NEXT I 'loop temporizador, final

$\mathrm{STS}=\mathrm{ST}+"{ }^{*} \mathrm{OPC} "$

PRINT \#1, ST\$ + CHR\$(10); 'este comando faz o pedido de leitura do valor medido (capacitancia ou fase)

De1 = 1 'ajusta um valor maximo para o temporizador com a funcao TIMER REC1\$ = " " 'variavel string a ser usada para armazenar o valor medido. Inicialmente eh nula

$\mathrm{STP}=0$ 'variavel para guardar condicao de parada (interrupcao) do loop caso haja problemas com o instrumento

DO 'inicio do loop para ler caracter a caracter o valor medido 
TR! = TIMER 'variavel inteira de 16 bits para armazenar o valor da funcao TIMER do quickbasic

DO 'inicio do loop do temporizador

IF TIMER < TR! THEN TR! = TR! - 86400!

LOOP UNTIL (LOC $(1)>0)$ OR (TIMER - TR! > De1) 'encerra o loop se o instrumento nao estiver com o seu primeiro bit zerado (LOC(1)>0) ou se o temporizador passar do limite maximo (De1)

IF LOC $(1)=0$ THEN 'condicao para interromper o loop caso haja problemas com o instrumento (se nao tem nenhum valor armazenado o primeiro caracter e nulo, LOC $(1)=0)$

PRINT " receive timeout" $\mathrm{STP}=1$

ELSE 'caso nao haja problemas com o instrumento...

$\mathrm{C} 1 \$=\operatorname{INPUT}(1, \# 1)$ 'le o caracter da posicao atual do "cursor" IF NOT CI\$ = CHR\$(10) THEN 'O caracter CHR\$(10) eh o codigo ASCII para final de linha (new line) REC1\$ = REC1\$ + C1\$ 'a variavel tipo string REC1\$ guarda

- valor completo caracter a caracter END IF

END IF

LOOP UNTIL $((\operatorname{C} 1 \$=\operatorname{CHR}(10))$ OR $(\operatorname{STP}=1))$

PRINT \#1, "*CLS" + CHR\$(10); 'limpa (zera) registradores de status de eventos. Deve ser usado apos cada pedido de leitura de valor medido do instrumento

JAN\$ = REC1\$ 'retorna 0 valor de REC1\$ para a funcao

END FUNCTION 


\title{
APÊNDICE B: EXEMPLO DE ROTINA UTILIZADA EM SIMULAÇÃO DE CAPACITÂNCIA
}

\author{
/NOPR ! Suppress printing of UNDO process \\ /PMACRO ! Echo following commands to log FINISH ! Make sure we are at \\ BEGIN level \\ / clear, nostart \\ /PREP7 \\ MP,PERX, 1,1 !cria material "1" com permitividade 1 (vacuo, ar) \\ MP,PERX, 2,9.9 !cria material "2" com permitividade 9.9 (alumina) \\ MP, PERX, 3, 24.3 !cria material "3" com permitividade 22 (etanol) \\ MP, PERX, 4,2 !cria material "4" com permitividade 2 (gasolina) \\ ET, 1,PLANE121 !define o elemento a ser usado no meshing PLANE121
}

! ! SENSOR S1

$\mathrm{CAPAC}=1590$ ! Quantidade total de capacitores na amostra

$\mathrm{H}=33 \mathrm{e}-6$ !altura do eletrodo (espessura do filme eletrodepositado)

$\mathrm{L}=65 \mathrm{e}-6 \quad$ ! largura do eletrodo

$\mathrm{G}=85 \mathrm{e}-6$ !espacamento (gap) entre eletrodos consecutivos

$r=0.3{ }^{*} \mathrm{H} \quad$ !raio para suavizacao de cantos (uso opcional para aprimorar o modelo)

LL=800E-6 !comprimento (profundidade Z) dos eletrodos emparelhados

$\mathrm{B}=200 \mathrm{e}-6$ !comprimento extra deixado ao redor dos eletrodos das

extremidades

$\mathrm{SS}=300 \mathrm{e}-6$ !espessura do substrato

$\mathrm{DD}=400 \mathrm{e}-6$ !espessura da camada de dieletrico a simular

NN=9 !Numero de eletrodos a desenhar nesta simulacao

! Criacao dos eletrodos

! uso do comando BLC4 para criar area retangular ou volume prismatico

!help do comando: BLC4, XCORNER, YCORNER, WIDTH, HEIGHT, DEPTH

$\star \mathrm{DO}, \mathrm{I}, 1, \mathrm{NN}$

BLC $4,(I-1) *(L+G), 0, L, H$

$\star$ ENDDO

BLC4, $-\mathrm{B}, 0, \mathrm{NN} * \mathrm{~L}+(\mathrm{NN}-1) * \mathrm{G}+2 * \mathrm{~B}, \mathrm{DD}$ !CRIA O DIELETRICO, SERA A AREA NN+1

$\mathrm{BLC} 4,-\mathrm{B}, 0, \mathrm{NN} * \mathrm{~L}+(\mathrm{NN}-1) * \mathrm{G}+2 * \mathrm{~B},-\mathrm{SS}$ ! CRIA O SUBSTRATO, SERA A AREA NN+2

ASEL, S, AREA, , 1, NN, 1 ! seleciona o conjunto de areas numeradas de 1 a NN, com incremento 1

CM,'AR1',AREA !atribui nome 'AR1' ao conjunto de areas ja selecionadas ASEL, A, AREA, NN+1 ! seleciona mais uma area, $\mathrm{NN}+1$

NUMSTR, AREA, 100 !forca a numeracao de novos volumes a partir de 100 ASBA, NN+1, 'AR1', 'DELETE, KEEP !APOS A SUBTRACAO O DIELETRICO FICA COMO area 100

ALLSEL, all, all !seleciona tudo

APLOT

AGLUE, NN+2,100 !apos a colagem, o substrato fica como 101 e o dieletrico como 102

ASEL, S, AREA, , 101 !nova selecao: area 101 (substrato)

AATT, 2, 1,0 !atribui o material tipo 2 a area selecionada 


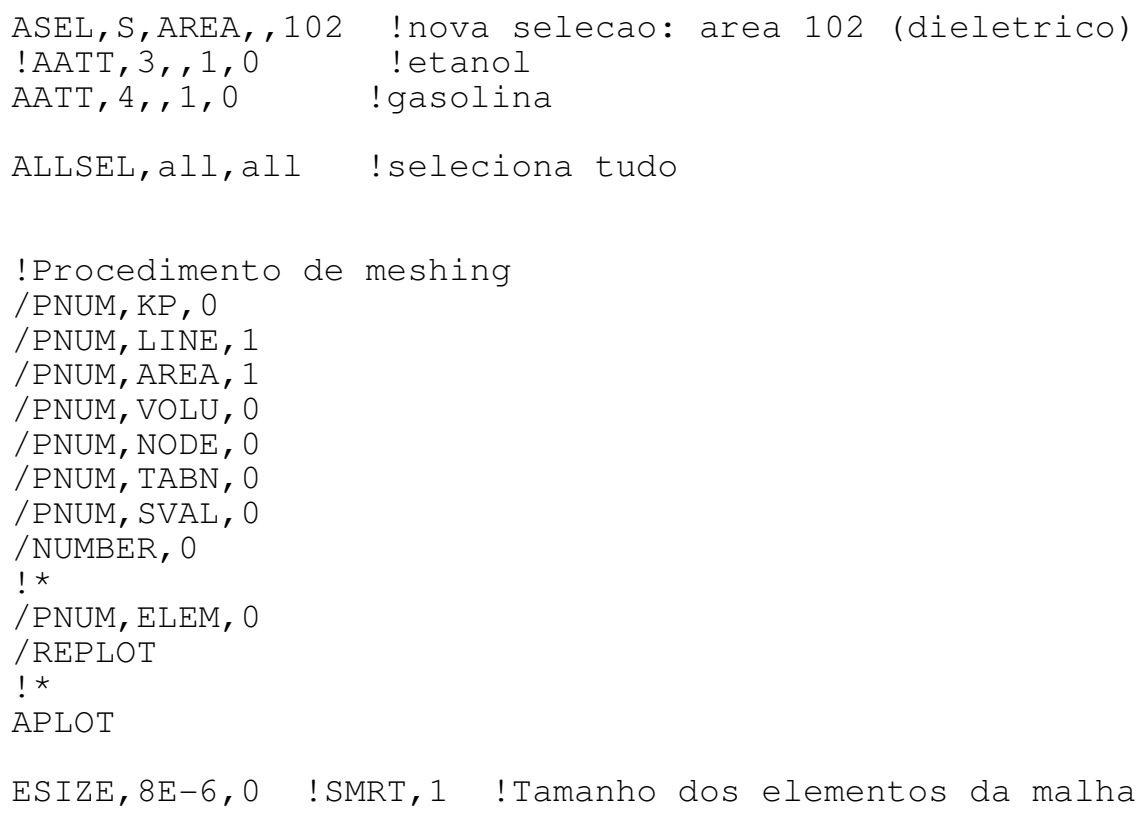


EPLOT

$/$ AUTO, 1

$/$ REP, FAST

ALLSEL, ALL

FINISH

/SOL

EQSLV, JCG, , 0

cmatrix, (CAPAC/ (NN-1))*LL, 'Cond', 2, 0, 'S1_Querosene_1' ! o valor 0.5 eh o fator de forma 


\section{APÊNDICE C: LISTA DE ARTIGOS PUBLICADOS DEVIDO A ESTE ESTUDO}

MENDONÇA, L. G. D., TORIKAI, D., IBRAHIM, R. C., SIMOES, E. W., MORIMOTO, N. I., Interdigitated Capacitive Sensor to Verify the Quality of Ethanol Automotive Fuel, Proceedings of COBEM 2007, CD-ROM, article 2101, Brasilia, Brazil, 2007.

MENDONÇA, L. G. D., IBRAHIM, R. C., Microsensor for the Measurement of Concentration of Liquid Solutions, ECS Transactions - Microelectronics Technology and Devices SBMICRO2006, v. 4, pp. 149-158, 2006.

MENDONÇA, L. G. D., IBRAHIM, R. C., Interdigitated-type Microsensor to Measure Solution Concentration, ABCM Symposium Series in Mechatronics, v. 2, pp. 465-468, 2006.

http://www.abcm.org.br/symposiumSeries/SSM_Vol2/ssMechatronicsSectionV I.shtml 


\section{ANEXO A- TABELA DE ESPECIFICAÇÕES DA GASOLINA ESTABELECIAS PELA ANP}

\begin{tabular}{|c|c|c|c|c|c|c|c|}
\hline \multirow{3}{*}{ CARACTERÍSTICA } & \multirow{3}{*}{ UNIDADE } & \multicolumn{4}{|c|}{ ESPECIFICAÇÃO } & \multirow{2}{*}{\multicolumn{2}{|c|}{ MÉTODO }} \\
\hline & & \multicolumn{2}{|c|}{ GasolinaComum } & \multicolumn{2}{|c|}{ Gasolina Premium } & & \\
\hline & & Tipo A & Tipo C & Tipo A & Tipo C & ABNT & ASTM \\
\hline cor & ---- & (1) & (2) & (1) & (2) & \multirow{2}{*}{\multicolumn{2}{|c|}{ Visual (3) }} \\
\hline Aspecto & ---- & (4) & (4) & (4) & (4) & & \\
\hline $\begin{array}{l}\text { Álcool Etílico Anidro } \\
\text { Combustível- AEAC }\end{array}$ & $\% \mathrm{vol}$ & 1 máx (5) & (6) & 1 máx (5) & (6) & \multicolumn{2}{|c|}{ NBR 13992} \\
\hline Massa específica a $20^{\circ} \mathrm{C}$ & $\mathrm{Kg} / \mathrm{m}^{3}$ & anotar & anotar & anotar & anotar & $\begin{array}{l}\text { NBR } 7148 \\
\text { NBR } 14065\end{array}$ & $\begin{array}{l}\text { D } 1298 \\
\text { D } 4052\end{array}$ \\
\hline Destilação & & & & & & NBR 9619 & D 86 \\
\hline 10\% evaporado, máx. & ${ }^{\circ} \mathrm{C}$ & 65,0 & 65,0 & 65,0 & 65,0 & & \\
\hline 50\% evaporado, máx. & ${ }^{\circ} \mathrm{C}$ & 120,0 & 80,0 & 120,0 & 80,0 & & \\
\hline $90 \%$ evaporado, máx. & ${ }^{\circ} \mathrm{C}$ & 190,0 & 190,0 & 190,0 & 190,0 & & \\
\hline PFE, máx. & ${ }^{\circ} \mathrm{C}$ & 220,0 & 220,0 & 220,0 & 220,0 & & \\
\hline Resíduo, max. & $\% \mathrm{vol}$ & 2,0 & 2,0 & 2,0 & 2,0 & & \\
\hline $\begin{array}{c}\mathrm{N}^{\circ} \text { de Octano Motor - MON, } \\
\text { min. }\end{array}$ & ---- & (8) (9) & $82,0(9)$ & ---- & --- & MB 457 & D 2700 \\
\hline $\begin{array}{l}\text { Índice Antidetonante - IAD, min. } \\
\text { (10) }\end{array}$ & --- & (8) & 87,0 & (8) & 91,0 & MB 457 & $\begin{array}{l}\text { D } 2699 \\
\text { D } 2700\end{array}$ \\
\hline Pressão de Vapor a $37,8^{\circ} \mathrm{C}(11)$ & $\mathrm{kPa}$ & 45,0 a 62,0 & 69,0 máx & 45,0 a 62,0 & 69,0 máx & $\begin{array}{l}\text { NBR } 4149 \\
\text { NBR } 14156\end{array}$ & $\begin{array}{l}\text { D } 4953 \\
\text { D } 5190 \\
\text { D } 5191 \\
\text { D } 5482 \\
\end{array}$ \\
\hline Goma Atual Lavada, máx. & $\mathrm{mg} / 100 \mathrm{ml}$ & 5 & 5 & 5 & 5 & NBR 1425 & D 381 \\
\hline Período de Indução a $100^{\circ} \mathrm{C}$, min. & $\min$ & (12) (13) & 360 & (12) (13) & 360 & NB 14478 & D 525 \\
\hline $\begin{array}{c}\text { Corrosividade ao Cobre a } 50^{\circ} \mathrm{C}, \\
3 \mathrm{~h}, \max .\end{array}$ & ---- & 1 & 1 & 1 & 1 & NBR 14359 & D 130 \\
\hline Enxofre, max. (14) & $\%$ massa & 0,12 & 0,10 & 0,12 & 0,10 & $\begin{array}{l}\text { NBR } 6563 \\
\text { NBR } 14533\end{array}$ & $\begin{array}{l}\text { D } 1266 \\
\text { D } 2622 \\
\text { D } 3120 \\
\text { D } 4294 \\
\text { D } 5453\end{array}$ \\
\hline Benzeno, max. (14) & $\%$ vol & 1,2 & 1 & 1,9 & 1,5 & ---- & $\begin{array}{l}\text { D } 3606 \\
\text { D } 5443 \\
\text { D } 6277 \\
\end{array}$ \\
\hline Chumbo, máx. (5) & $\mathrm{g} / \mathrm{L}$ & 0,005 & 0,005 & 0,005 & 0,005 & ---- & D 3237 \\
\hline Aditivos (15) & ---- & ---- & ---- & ---- & ---- & ---- & ---- \\
\hline Hidrocarbonetos: (14) (16) & $\% \mathrm{vol}$ & & & & & MB 424 & D 1319 \\
\hline Aromátios, máx. (17) & & 57 & 45 & 57 & 45 & & \\
\hline Olefinicos, máx. (17) & & 38 & 30 & 38 & 30 & & \\
\hline
\end{tabular}

(1) De incolor a amarelada, isenta de corante.

(2) De incolor a amarelada se isenta de corante cuja utilização é permitida no teor máximo de 50ppm com exceção da cor azul, restrita á gasolina de aviação.

(3) A visualização será realizada em proveta de vidro, conforme a utilizada n o Método NBR 7148 ou ASTM D1298.

(4) Límpido e isento de impurezas.

(5) Proibida a adição. Deve ser medido quando houver dúvida quanto à ocorrência de contaminação.

(6) O AEAC a ser misturado às gasolinas automotivas para produção de gasolina C deverá estar em conformidade com o teor e a especificação estabelecidos pela legislação em vigor.

(7) No intuito de coibir eventual presença de contaminantes o valor da temperatura para $90 \%$ de produto evaporado não poderá se inferior à $155^{\circ} \mathrm{C}$ para gasolina $\mathrm{A}$ e $145^{\circ} \mathrm{C}$ para gasolina $\mathrm{C}$.

(8) A Refinaria, a Central de Matérias-primas Petroquímicas, o Importador e o Formulador deverão reportar o valor das octanagem MON e do IAD da mistura de gasolina A, de sua produç ]ao ou importada, com AEAC no teor mínimo estabelecido pela legislação em vigor.

(9) Fica permitida a comercialização de gasolina automotiva com MON igual ou superior a 80 até 30/06/2002.

(10) Índice antidetonante é a média aritmética dos valores das octanagens determinadas pelos métodos MON e RON. 
(11) Para os Estados do Rio Grande do Sul, Santa Catarina, Paraná, São Paulo, Rio de Janeiro, Espírito Santo, Minas Gerais, Mato Grosso, Mato Grosso do Sul, Goiás e Tocantins, bem como para o Distrito Federal, admite-se, nos meses de abril a novembro, um acréscimo de $7,0 \mathrm{kPa}$ ao valor máximo especificado para a Pressão de Vapor.

(12) A Refinaria, a Central de Matérias-Primas Petroquímicas, o Importador e o Formulador deverão reportar o valor do Período de Indução da mistura de gasolina A, de sua produção ou importada, com AEAC no teor máximo estabelecido pela legislação em vigor.

(13) O ensaio do Período de Indução só deve interrompido após 720 minutos, quando aplicável, em pelo menos $20 \%$ das bateladas comercializadas. Neste caso, e se interrompido antes do final, deverá ser reportado o valor de 720 minutos.

(14) Os teores máximos de Enxofre, Benzeno, Hidrocarbonetos Aromáticos e Hidrocarbonetos Olefínicos permitidos para a gasolina $\mathrm{A}$ referem-se àquela que transformar-se-á em gasolina $\mathrm{C}$ através da adição de $22 \% \pm 1 \%$ de álcool. No caso de alteração legal do teor de álcool na gasolina os teores máximos permitidos para os componentes acima referidos serão automaticamente corrigidos proporcionalmente ao novo teor de álcool regulamentado.

(15) Utilização permitida conforme legislação em vigor, sendo proibidos os aditivos a base de metais pesados.

(16) Fica permitida alternativamente a determinação dos hidrocarbonetos aromáticos e olefínicos por cromatografia gasosa. Em caso de desacordo entre resultados prevalecerão os valores determinados pelos ensaios MB424 e D1319.

Até 30/06/2002 os teores de Hidrocarbonetos Aromáticos e Olefínicos podem ser apenas informados. 


\section{ANEXO B- TABELAS DE ESPECIFICAÇÕES DO AEAC E AEHC ESTABELECIAS PELA ANP}

Tabela I - Especificações do AEAC e do AEHC

\begin{tabular}{|c|c|c|c|c|c|}
\hline \multirow[t]{2}{*}{ CARACTERISTICA } & \multirow[t]{2}{*}{ UNIDADE } & \multicolumn{2}{|c|}{ ESPECIFICAÇÕES } & \multicolumn{2}{|c|}{ MÉTODO } \\
\hline & & AEAC & AEHC & ABNT/NBR & ASTM (1) \\
\hline Aspecto & - & $(2)$ & (2) & \multicolumn{2}{|c|}{ Visual } \\
\hline Cor & - & (3) & (4) & \multicolumn{2}{|c|}{ Visual } \\
\hline $\begin{array}{l}\text { Acidez total (como ácido } \\
\text { acético), máx. }\end{array}$ & $\mathrm{mg} / \mathrm{L}$ & 30 & 30 & 9866 & D 1613 \\
\hline Condutividade elétrica, máx & $\mu \mathrm{S} / \mathrm{m}$ & 500 & 500 & 10547 & D 1125 \\
\hline Massa especifica a $20^{\circ} \mathrm{C}$ & $\mathrm{kg} / \mathrm{m} 3$ & 791,5 máx. & $\begin{array}{l}807,6 \text { a } \\
811,0 \text { (5) }\end{array}$ & 5992 & D 4052 \\
\hline Teor alcoólico & 'INPM & 99,3 mín. & $\begin{array}{l}92,6 \text { a } 93,8 \\
(5)\end{array}$ & 5992 & - \\
\hline Potencial hidrogeniônico $(\mathrm{pH})$ & - & - & 6,0 a 8,0 & 10891 & - \\
\hline $\begin{array}{l}\text { Resíduo por evaporação, máx. } \\
\text { (6) }\end{array}$ & $\mathrm{mg} / 100 \mathrm{Ml}$ & - & 5 & 8644 & - \\
\hline $\begin{array}{l}\text { Teor de hidrocarbonetos, } \\
\text { máx.(6) }\end{array}$ & \%vol. & 3,0 & 3,0 & 13993 & - \\
\hline Íon Cloreto, máx. (6) & $\mathrm{mg} / \mathrm{kg}$ & - & 1 & $\begin{array}{l}10894 / \\
10895\end{array}$ & D 512(7) \\
\hline Teor de etanol, mín. (8) & \%vol. & 99,6 & 95,1 & - & D 5501 \\
\hline İon Sulfato, máx.(9) & $\mathrm{mg} / \mathrm{kg}$ & - & 4 & $10894 / 12120$ & - \\
\hline Ferro, máx. (9) & $\mathrm{mg} / \mathrm{kg}$ & - & 5 & 11331 & - \\
\hline Sódio, máx. (9) & $\mathrm{mg} / \mathrm{kg}$ & - & 2 & 10422 & - \\
\hline Cobre, máx. (9) (10) & $\mathrm{mg} / \mathrm{kg}$ & 0,07 & - & 10893 & - \\
\hline
\end{tabular}


(1) Poderão ser utilizados como métodos alternativos para avaliação das características nos casos de importação do álcool, com exceção do método ASTM D4052, que poderá ser sempre utilizado como método alternativo para a determinação da massa específica.

(2) Limpido e isento de impurezas.

(3) Incolor antes da adição de corante, segundo especificação constante da Tabela II deste Regulamento Técnico, que deverá ser adicionado no teor de $15 \mathrm{mg} / \mathrm{L}$ proporcionando ao produto a cor laranja.

(4) Incolor.

(5) Aplicam-se na Importação, Distribuição e Revenda os seguintes limites para massa específica e teor alcoólico do AEHC: 805,0 a 811,0 e 92,6 a 94,7 respectivamente.

(6) Limite requerido na Importação, Distribuição e Revenda, não sendo exigida esta análise para emissão do Certificado da Qualidade pelos Produtores.

(7) Procedimento C e modificação constante na ASTM D4806.

(8) Requerido quando o álcool não for produzido por via fermentativa a partir da cana-de-açúcar ou em caso de dúvida quando da possibilidade de contaminação por outros tipos de álcool.

(9) O produtor deverá transcrever no Certificado da Qualidade o resultado obtido na última determinação quinzenal, conforme previsto no $\S 1^{\circ}$ do Art. $5^{\circ}$ da presente Resolução.

(10) Deverá ser determinado no AEAC que tiver sido transportado ou produzido em local que possua equipamentos ou linhas de cobre, ou ligas que contenham este metal.

Tabela II - Especificação do corante a ser adicionado ao álcool etlilico anidro combustivel (AEAC)

\begin{tabular}{|c|c|c|}
\hline Caracte rística & Especificação & Método \\
\hline \multirow{2}{*}{$\begin{array}{l}\text { Aspecto liquido visual Família } \\
\text { química (\&quot;Color index\&quot;) }\end{array}$} & Solvent Red 19 ou Solvent Red 164 & - \\
\hline & Solvent Yellow 174 & - \\
\hline Cor & laranja & visual \\
\hline Absorvância a 420 nm & 0,150 a 0,190 & \multirow[t]{2}{*}{$\left({ }^{*}\right)$} \\
\hline Absorvância a $530 \mathrm{~nm}$ & 0,100 a 0,135 & \\
\hline Solubilidade & solúvel em AEAC e insolúvel em água & visual $\left({ }^{\star \star}\right)$ \\
\hline
\end{tabular}

$\left.{ }^{\star}{ }^{\star}\right)$ A absorbância deve ser determinada em amostra contendo $15 \mathrm{mg} / \mathrm{L}$ do corante em AEAC, medida em célula de caminho ótico de $1 \mathrm{~cm}$, no valor especificado para o comprimento de onda.

$\left.{ }^{(\star *}\right)$ A solubilidade deve ser avaliada em amostra contendo $15 \mathrm{mg} / \mathrm{L}$ do corante em AEAC. 